NBER WORKING PAPER SERIES

\title{
HAVE RECREATIONAL MARIJUANA LAWS UNDERMINED PUBLIC HEALTH PROGRESS ON ADULT TOBACCO USE?
}

\author{
Dhaval M. Dave \\ Yang Liang \\ Michael F. Pesko \\ Serena Phillips \\ Joseph J. Sabia \\ Working Paper 29706 \\ http://www.nber.org/papers/w29706 \\ NATIONAL BUREAU OF ECONOMIC RESEARCH \\ 1050 Massachusetts Avenue \\ Cambridge, MA 02138 \\ January 2022
}

Dr. Sabia acknowledges research support from the Center for Health Economics \& Policy Studies (CHEPS) at San Diego State University, which has received grant funding from the Charles Koch Foundation and the Troesh Family Foundation. The views expressed herein are those of the authors and do not necessarily reflect the views of the National Bureau of Economic Research.

NBER working papers are circulated for discussion and comment purposes. They have not been peer-reviewed or been subject to the review by the NBER Board of Directors that accompanies official NBER publications.

(C) 2022 by Dhaval M. Dave, Yang Liang, Michael F. Pesko, Serena Phillips, and Joseph J. Sabia. All rights reserved. Short sections of text, not to exceed two paragraphs, may be quoted without explicit permission provided that full credit, including $\odot$ notice, is given to the source. 
Have Recreational Marijuana Laws Undermined Public Health Progress on Adult Tobacco Use? Dhaval M. Dave, Yang Liang, Michael F. Pesko, Serena Phillips, and Joseph J. Sabia

NBER Working Paper No. 29706

January 2022

JEL No. I12,I18,K14

\section{ABSTRACT}

Public health experts caution that legalization of recreational marijuana may normalize smoking and undermine the decades-long achievements of tobacco control policy. However, very little is known about the impact of recreational marijuana laws (RMLs) on adult tobacco use. Using information from four national datasets (National Survey of Drug Use and Health, Behavioral Risk Factor Surveillance System, Current Population Survey-Tobacco Use Supplements, and Population Assessment of Tobacco and Health) and dynamic difference-in-differences and discrete-time hazard approaches, we find little support for the hypothesis that RML enactment leads to increases in adult tobacco use. In the short-run, RMLs have no effect on tobacco use and in the medium-run, we find some evidence of a lagged reduction in tobacco use on the order of approximately 0.5 to 2 percentage points. This finding generally persists across cigarettes and ecigarettes, is robust to event-study analyses generated from estimators designed to expunge bias due to heterogeneous dynamic treatment effects, and persists in panel data-based survival analyses that account for consumption dynamics. We conclude that fears of adult tobacco-related public health costs from RMLs are, at least in the short- and medium-run, unfounded; instead, there may be important public health benefits from reductions in adult tobacco use.

Dhaval M. Dave

Bentley University

Department of Economics

175 Forest Street, AAC 195

Waltham, MA 02452-4705

and IZA

and also NBER

ddave@bentley.edu

Yang Liang

San Diego State University

Department of Economics

Center for Health Economics

\& Policy Studies

5500 Campanile Drive

San Diego, CA 92182

yang.liang@sdsu.edu

Michael F. Pesko

Department of Economics

Andrew Young School of Policy Studies

Georgia State University

PO Box 3992

Atlanta, GA 30302-3992

and IZA

mpesko@gsu.edu
Serena Phillips

Georgia State University

Department of Economics

Andrew Young School of Policy Studies

Atlanta, GA 30302-3992

sphillips55@gsu.edu

Joseph J. Sabia

San Diego State University

Department of Economics

Center for Health Economics

\& Policy Studies

5500 Campanile Drive

San Diego, CA 92182

and IZA \& ESSPRI

jsabia@sdsu.edu 


\section{Introduction}

Public support for the legalization of recreational marijuana has increased substantially over the last decade and a half, rising from 25 percent in 1995 to 68 percent in 2020 (Gallup 2020). Since 2012, 18 states and the District of Columbia, have enacted recreational marijuana laws (RMLs), which legalize the possession, sale, and, in most cases, home cultivation of small quantities of marijuana for those ages 21 and older. While RMLs have garnered substantial support among policymakers and the public, the American Medical Association (AMA) and the American Public Health Association (APHA) have questioned their efficacy and withheld their support for recreational marijuana legalization (AMA 2021; APHA 2020).

Public health experts warn that the legalization of recreational marijuana could normalize smoking among adults, leading to an increase in tobacco use (Ong 2016). One piece of evidence used to support this hypothesis is that co-use of marijuana and tobacco, often as "blunts," has increased in recent years among U.S. adults (Goodwin et al. 2018; Schauer et al. 2015; Coley 2021).

Opponents of RMLs argue that frequent and heavy marijuana smoking has been linked to lung disease (American Lung Association 2021) and a host of respiratory problems, including chronic cough, bronchial episodes, and increased phlegm productivity (National Academies of Sciences, Engineering and Medicine 2017). ${ }^{1}$ Many of the adverse respiratory health effects of marijuana smoking are shared with tobacco smoking (Tashkin 2013). Nonsmokers' rights organizations argue that secondhand marijuana smoke is as important to curb as secondhand tobacco smoke (American Nonsmokers' Rights Foundation 2021).

However, adverse health effects of marijuana use are, in part, mitigated by smoke-avoidant methods of marijuana consumption (i.e., baked goods, edibles, beverages). Moreover, relative to tobacco use, far fewer studies have linked marijuana consumption to cancers, heart disease, or stroke (National Academies of Sciences, Engineering, and Medicine 2017). To the contrary, moderate marijuana use is associated with some important health benefits, including risks of mortality and mobility, and alleviating pain, anxiety, and many side effects of cancer and HIV treatments (Hall et al. 2005; Fiz et al. 2011; Ware et al. 2010; Choi et al. 2019; Anderson and Rees 2021).

In contrast, tobacco use is the leading cause of preventable death in the United States (U.S.) and has been linked to nearly one-half million deaths per year (Centers for Disease Control and

\footnotetext{
${ }^{1}$ Moreover, there is evidence that marijuana use may impair cognitive function (Volkow et al. 2014; Wang et al. 2013).
} 
Prevention 2021a). In addition, its consumption leads to increased risk of emphysema, cancers of the colon, liver, head, and lung, and stroke (U.S. Department of Health and Human Services 2020). If marijuana and tobacco are complements for adults, the direct medical costs — including “internality" costs resulting from non-rational addiction (Gruber and Köszegi 2001) — and healthrelated externality costs of RMLs could be substantial. ${ }^{2}$

Recent research shows that the legalization of marijuana for medicinal purposes is associated with a small reduction in tobacco cigarette use, suggesting that medical marijuana and tobacco are substitutes for adults (Choi, Dave, and Sabia 2019). However, the effects of RMLs could differ from MMLs for a number of reasons. First, to the extent that a non-trivial share of those who were induced to consume marijuana from MMLs were treating allowable medical conditions (i.e., pain, fibromyalgia, nausea, and side effects of cancers and HIV treatment), the marginal individual induced to consume marijuana from an RML may differ substantially on characteristics related to health production (i.e., age, health stock, depreciation rate). In this circumstance, the local average treatment effect (LATE) of RMLs on adult tobacco use may differ as well.

Second, the market for tobacco products changed dramatically from the mid-1990s, when the first MML was enacted (California in 1996). For instance, approximately one-quarter of the U.S. population lived in states with an MML before electronic cigarettes (e-cigarettes) were introduced to the U.S. market in 2006-2007 (Office of the Surgeon General 2016). While initial e-cigarette sales occurred largely via internet sales, it was during the 2009-2012 period that retail sales of e-cigarettes widely expanded (Huang et al. 2021). Moreover, the introduction of JUUL (Juice USB Lighting) in June 2015 - accompanied by a wide assortment of flavors - also greatly expanded the set of electronic nicotine delivery systems (ENDS) products (Truth Initiative 2019).

The wide availability of e-cigarette products at the time of RML-adoption may result in a very different tobacco use response. For example, vaping pens and JUUL devices used for ecigarette consumption may be adapted to permit marijuana smoking (Miech et al., 2020), which could result in a complementary relationship between e-cigarettes and marijuana. On the other hand, if e-cigarettes and marijuana both serve to produce euphoria ("high"), generate utility from a smoking experience, or serve the ends of quitting cigarette smoking, then marijuana and e-cigarettes may be substitutes.

\footnotetext{
${ }^{2}$ Estimates of the direct health care costs of tobacco use have been estimated to be $\$ 200$ billion per year and annual externality costs (i.e., secondhand and thirdhand tobacco smoke) to be approximately $\$ 7$ billion (U.S. Department of Health and Human Services 2014).
} 
Third, the tobacco policy environment continued to evolve during the period when RMLs were adopted. Between 2012 and mid-2019, state excise taxes on cigarettes increased 36 times with an average increase of $\$ 0.473$ per pack, with 37 states attaining excise taxes of over $\$ 1$ per pack (Orzechowski and Walker 2018). In addition, over this same period, 10 states and two large counties enacted taxes on ENDS (Abouk et al. 2021), clean indoor air laws were expanded in eight states (Centers for Disease Control and Prevention 2021b), and 16 states and the District of Columbia enacted a minimum legal purchasing age of 21 for all tobacco products (Hansen et al. 2021). ${ }^{3}$ These tobacco control policies increase the shadow price of tobacco at the same time RMLs were enacted, which could dampen a complementary relationship and potentially reinforce a substitutional relationship between recreational marijuana and tobacco. Alternatively, those who continue to consume tobacco following the enactment of a wide set of tobacco control policies (i.e., taxes, informational campaigns, clean indoor air laws, minimum legal purchasing ages) may have a relatively more inelastic demand for tobacco than prior smokers who were impacted by an MML. In this case, we might expect adult tobacco consumption to be relatively unaffected by the enactment of RMLs.

Finally, in part due to the success of past tobacco control efforts, a substantial share $(55.1$ percent) of current smokers expresses a desire to quit cigarette consumption (Centers for Disease Control and Prevention 2021c). This may reflect time-inconsistent preferences, social pressure to respond in this manner, or a desire for the costs of rational addiction to be lower. If the former reason dominates, the availability of a new consumer product, recreational marijuana, may aid these individuals in cessation efforts.

This study is the first to comprehensively examine the impact of the legalization of recreational marijuana on adult tobacco use. In so doing, we are also the first to explore dynamic consumption responses to RMLs, including through the use of (1) newly-developed difference-indifferences estimators that account for heterogeneous treatment effects over time, and (2) longitudinal data that permit the estimation of discrete-time hazard models that partial out individual (time-invariant) unmeasured heterogeneity and model dynamic transitions across consumption margins. Using four national datasets - the National Survey of Drug Use and Health (NSDUH), the Behavioral Risk Factor Surveillance System (BRFSS), the Current Population Survey-Tobacco Use Supplements (CPS-TUS), and the longitudinal Population Assessment of Tobacco and Health

\footnotetext{
${ }^{3}$ In December 2019, the Federal Tobacco to 21 Act was adopted by the U.S. Congress (https://www.congress.gov/bill/116th-congress/senate-bill/1258/text).
} 
(PATH) — over a two-decade period through 2019, and exploiting the staggered adoption of RMLs across states in a difference-in-differences framework, we document two findings. First, "firststage" results from the NSDUH and PATH show consistent evidence that RML adoption increases adult marijuana use by 2 - to 5 -percentage-points, including through vaping. Second, we find no evidence that legalization of recreational marijuana increases adult tobacco use. In fact, the preponderance of the evidence suggests that RML adoption is associated with a small, lagged decline in tobacco use. For instance, our NSDUH-based analysis suggests that two or more years after the adoption of an RML, legalization is associated with an approximately 0.5 to 2 percentage-point decline in tobacco use. Results from the CPS-TUS analyses largely corroborate these findings, showing evidence of an RML-induced decline in tobacco use within one to three years following enactment. This decline is largely driven by a decrease in everyday cigarette use. With respect to ecigarette use specifically, we also find some evidence of an RML-induced decline in use using data from the BRFSS. Event-study analyses using Callaway-Sant'Anna estimates, which expunge bias due to heterogeneous dynamic effects of RMLs, provide support for the common trends assumption and confirm a small, lagged decline in tobacco use across the NSDUH, BRFSS, and CPS-TUS data.

Finally, we turn to longitudinal analyses with the PATH data. Estimates from discrete time hazard models show that while RMLs increased initiation of marijuana, there is no evidence that RMLs increase tobacco use, with no statistically significant effect observed for initiation or cessation. Instead, individual fixed effects estimates show that RMLs are associated with a significant lagged decline in ENDS use on the order of 1 to 2 percentage points. While we find some evidence that RML enactment leads to an increase in dual consumption of marijuana and tobacco, this effect appears to be driven entirely by increases in marijuana initiation among baseline tobacco users.

Taken together, these results across multiple national datasets are consistent with the hypothesis that marijuana and tobacco are not complements for adults and may, in the medium-run, be substitutes. Moreover, these findings fail to support claims by some public health experts that liberalized marijuana availability for the adult population could be undermining the decades-long public health gains from reduced cigarette use.

\section{Background}

Much of the public health literature exploring the relationship between marijuana and tobacco use has been correlational in nature (Choi et al. 2019). In the main, these studies tend to 
find that tobacco use and marijuana use co-occur (McClure et al. 2018; Trivers et al. 2018; Goodwin et al. 2018; Ramo et al. 2013; Beenstock and Tahov 2002; Bentler et al. 2002; Agrawal et al. 2007; Leatherdale et al. 2007), or that higher marijuana use follows tobacco use (Driezen et al., 2022). While early marijuana users are more likely to initiate cigarette use (Agrawal et al. 2008; Behrendt et al. 2009) and are less likely to quit tobacco use (Richter et al. 2002) than their abstaining counterparts, this does not necessarily imply that the two substances are complements. ${ }^{4}$ Failing to econometrically account for factors that jointly determine use - through, for example, a policy shock that affects relative prices - could mean that consumption of both goods simply reflects difficult-to-measure personal characteristics such as one's discount rate, family support system, or peer quality.

More compelling evidence on the complementarity or substitutability of marijuana and tobacco tends to come from studies that have used state-specific policy shocks for identification (Anderson and Rees 2021; Farrelly et al. 2001; Anderson, Matsuzawa, and Sabia 2020). For instance, exploiting state changes in excise taxes on cigarettes, Farrelly et al. (2001) found that raising cigarette taxes reduced the intensity of marijuana use among individuals 12-20 years of age, suggesting that marijuana and tobacco may be complements for some youths. On the other hand, Anderson et al. (2020) found that increases in state cigarette taxes were essentially unrelated to youth marijuana use. Pesko, Hughes, and Faisal (2016) and Dave, Feng, and Pesko (2019) found that e-cigarette minimum legal purchase age law adoption did not affect youth marijuana use. Finally, a new working paper by Hansen et al. (2021) exploits within-state variation in a new tobacco control policy - Tobacco-21 (T21) laws (which raise the minimum legal purchasing age to 21 for tobacco products) — and find some evidence that restricting access to cigarettes reduces marijuana use among 18 -year-olds. ${ }^{5}$

Four studies of which we are aware have explored the relationship between the enactment of medical marijuana laws (MMLs) and tobacco consumption (Choi et al. 2019; Andreyeva and Ukert 2019; Veligati et al. 2020; Anderson et al. 2020), three of which focus on adults. ${ }^{6}$ Veligati et al. (2020) and Andreyeva and Ukert (2019) find that MMLs are unrelated to per capita cigarette sales

\footnotetext{
${ }^{4}$ In the reverse direction, public health literature has also found that 18-to-25-year-olds are almost an order of magnitude more likely to consume marijuana if they previously used tobacco products (Lai et al. 2000).

${ }^{5}$ Note that for outcomes at the extensive margin, symmetric cross-price effects are not a necessary property of demand functions without the imposition of requisite restrictions on parameters in the utility function. Thus, studies that have assessed the relationship between cigarette/tobacco use and marijuana use through variation in tobacco policy (i.e. variation in the full cost of tobacco use) may be of limited use in deciphering this relationship in the reverse direction, that is how tobacco use may respond if there are shifts in the full cost of marijuana use.

${ }^{6}$ Anderson et al. (2020) use data from the Youth Risk Behavior Surveys and find that MML adoption is associated with declines in marijuana use and cigarette use for U.S. high school students.
} 
and cigarette use, respectively. On the other hand, using data across three national datasets spanning two and a half decades, Choi et al. (2019) find consistent evidence that MMLs are associated with a 1 to 1.5 percentage-point decline in smoking participation, as well as a decline in cigarette use at the intensive margin (number of cigarettes consumed per day among smokers).

While results from the MML-tobacco literature are informative, particularly because we might expect that a non-trivial share of marijuana consumption that was induced by MMLs was for recreational purposes (Anderson, Hansen, and Rees 2013), it is not clear that the treatment effects will be similar for RMLs for a number of important reasons. The explosion of the electronic cigarette market, particularly since 2010, may result in different tobacco-related behavioral responses to increased access to marijuana. In addition, the regulatory environment for tobacco, including the adoption of T-21 laws, e-cigarette taxes, and tightening of clean indoor air laws, has changed in ways that may affect how a reduction in the shadow price of marijuana affects tobacco use. Relatedly, the marginal adult smoker may have changed vis-à-vis RML adoption as compared to MML adoption, perhaps with a relatively more inelastic demand for tobacco. Finally, the medical requirements to gain access to marijuana under an MML regime (i.e., permissible to purchase for "allowable medical conditions") may have resulted in more medicinal users to be affected by MMLs relative to RMLs. Such consumers may differ in their responses to changes in relative prices of marijuana to tobacco.

The literature on RMLs and adult tobacco use is quite nascent. Alley et al. (2020) use data from the National College Health Assessment (NCHA-II) from 2008-2018 in conjunction with a two-way fixed effects approach and find that RMLs are unrelated to tobacco use among college students. Two other studies use data on cigarette sales. Miller and Seo (2018) use Nielsen Retail Scanner data over the period 2013-2016 to explore the impact of marijuana prices on tobacco sales in Washington state. Using county-level variation in legal access to recreational marijuana across retailers as an instrumental variable (IV) for marijuana prices, they find that tobacco sales declined in response to legalization.

Veligati et al. (2020) use state-by-year data from the 1990-2016 Alcohol Epidemiologic Data System (AEDS) to explore the relationship between recreational legalization and tobacco sales. Using a two-way fixed effects model, they find that RML adoption is associated with a statistically insignificant 0.198 decline in per capita cigarette sales. While descriptively interesting, the study (i) solely examines tobacco cigarette sales without attention to electronic cigarettes, cigars, smokeless tobacco, or pipe tobacco, (ii) relies on only four (4) states (Washington, Colorado, Alaska, Oregon) and the District of Columbia for identification, only two (Colorado and Washington) of which 
include post-treatment data of three years (which may be inadequate to detect medium- to long-run tobacco effects), (iii) provides no descriptive tests of parallel pre-treatment trends in tobacco use or exploration of lagged effects of RMLs, and (iv) does not employ new difference-in-differences estimators designed to expunge bias due to heterogeneous and dynamic treatment effects. ${ }^{7}$

The current study contributes to this nascent literature by using four large national datasets to explore the medium- and longer-run effects of RMLs on both marijuana use (and its forms and delivery mechanisms), as well as a variety of tobacco products. We provide the first analysis of dynamic consumption responses to RMLs, including through the use of newly developed differencein-differences estimators that account for heterogeneous treatment effects over time. Moreover, our use of longitudinal data allows us to better explore the impacts of RMLs on changes in co-use of marijuana and tobacco as well as on heretofore unexplored behavioral margins, including the intensive and extensive margins of consumption as well as on the initiation and cessation margins, while accounting for person-specific heterogeneity.

\section{Data}

Our empirical analysis uses data from four national datasets. Each provides complementary strengths, which are highlighted below. Use of multiple national datasets further allows us to crossvalidate and produce textured findings, explore alternative and more detailed outcomes, and assess robustness and patterns across age-based sub-populations.

\subsection{National Survey of Drug Use and Health (NSDUH)}

We begin by using data on marijuana and tobacco use among those ages 18 and older from the 2002-2019 National Survey of Drug Use and Health (NSDUH), provided by the Substance Abuse and Mental Health Services Administration (SAMSHA). The NSDUH is a household survey representative of the U.S. non-institutionalized population. The survey is administered in individuals' homes, which may include private homes, public housing, and non-institutional group quarters (i.e., college dorms, rooming houses, shelters). However, neither residents of hospitals and jails nor homeless individuals (who do not reside in shelters) are included in the NSDUH sample. Information on health behaviors is collected via an individual audio computer-assisted self-

\footnotetext{
7 With respect to youths, Vuolo, Lindsay, and Kelley (2022) use data through 2015 from the National Longitudinal Survey of Youth 1997 and find no evidence that cannabis liberalization affects youth and young adult smoking. Here, short-run treatment effects are essentially identified from the two earliest-adopting RML states (Washington and Colorado).
} 
administered interview to increase privacy and the likelihood of a truthful response. While geocoded individual NSDUH data are not easily made available for scholars outside of the Centers for Disease Control and Prevention (CDC), two-year overlapping state-by-year averages are publicly available.

Our first empirical task will be to establish that that RMLs were binding on adults. Thus, we use state-by-year data on marijuana consumption prevalence rates among those ages 18 and older from the NSDUH for this purpose. Marijuana prevalence rates are compiled using a survey item that asks respondents to report the number of days in the last month on which s/he "use[d] marijuana or hashish." A calculation of weighted means shows that over the 2002-2019 period, 7.5 percent of respondents ages 18 and older reported marijuana use on a positive number of days during the past month. When we disaggregate adult marijuana consumption by age using publicly available NSDUH data ${ }^{8}$, we find that 18.8 percent of 18 -25-year-olds and 5.5 percent of those ages 26 and older used marijuana in the prior month. Panel (a) of Appendix Figure 1 shows trends in marijuana use for each of these age groups over the full sample period. We find that marijuana consumption rose rapidly from 6.0 percent in 2002 to a height of 11.1 percent in 2019.

Next, we turn to our key outcomes for this study. First, we measure tobacco product use. Over the period under study, this is defined as prior-month consumption of the following tobacco products: cigarettes, smokeless tobacco, cigars, and pipe tobacco. We find that over our analysis sample, 28.3 percent of adults - 37.8 percent of those ages $18-25$ and 26.6 percent of those ages 26 and older — used a tobacco product in the last month. Panel (b) of Appendix Figure 1 shows trends in adult tobacco product use over the period 2002-2019. We find that between 2002 and 2019, tobacco product use for all adults declined dramatically from 32.9 percent to 23.0 percent. Among younger adults ages 18-to-25, the decline in use was even more rapid, from 45.1 percent in 2002 to from 25.1 percent in 2019.

In addition, publicly available NSDUH data provide information on cigarette consumption among adults. We find that 23.6 percent of adults, including 31.8 percent of those ages $18-25$ and 22.2 percent of those ages 26 and older, used cigarettes in the past 30 days. Trends in cigarette use in Panel (c) of Appendix Figure 1 show similar movements as those in Panel (b), with 27.2 percent of cigarette smoking participation in 2002, falling to 18.4 percent in 2019. Moreover, at least descriptively, there does not appear to be a moderation in the downward trend in cigarette use over

${ }^{8}$ Information is made available for the following adult age groups: those ages 18-to-25 and those ages 26 and older. 
the past decade, when marijuana use experienced a resurgence after remaining largely stable since the late-1990s.

In summary, an important advantage of the NSDUH data is that they provide information on "first-stage" marijuana use as well as tobacco product use. This allows us to gauge, using the same dataset, whether the magnitudes of any spillover effects to tobacco are plausible given the magnitude of the first-stage effects on marijuana use. On the other hand, the publicly available NSDUH data do not include information on e-cigarette consumption, which may be affected by RML adoption. Moreover, the lack of individual data on tobacco use does not permit an exploration of heterogeneity in the policy impacts by individual characteristics such as race/ethnicity, gender, and household income. Finally, the age categories for which consumption data are available do not permit us to explore consumption decisions for adults who are strictly younger than the minimum legal purchasing age for marijuana under RMLs, which is age 21 . Analyses using the remaining datasets will, therefore, complement our NSDUH-based analyses and paint a more complete picture of the impact of RMLs on adult tobacco consumption.

\subsection{Behavioral Risk Factor Surveillance System (BRFSS)}

The second nationally representative dataset we utilize is the Behavioral Risk Factor Surveillance System (BRFSS) surveys. We focus on the period 2000 through 2019, which envelopes the adoption of RMLs, and our analysis sample consists of 7.4 million adults (those ages 18 and older) who were sampled over this period. The BRFSS is a telephone survey, which until 2011 was conducted exclusively with landlines. However, for the period 2011-2019, the survey began sampling individuals using cellular phones. When weighted, the sample represents noninstitutionalized adults in the U.S.

An important disadvantage of the BRFSS is that marijuana use is not asked in the main questionnaire, requiring us to rely on other data sources for the "first-stage" effects. ${ }^{9}$ We measure tobacco use in two ways. First, we measure cigarette use. Following CDC guidelines for measuring cigarette consumption, a respondent who reports smoking at least 100 cigarettes in their lifetime and reports current smoking on "some days" or "everyday" is coded as being a cigarette smoker. In our analysis sample, 21.7 percent of 18 -year-olds, 16.9 percent of those above the minimum legal

\footnotetext{
${ }^{9}$ While marijuana consumption data are available in limited modules of the BRFSS between 2016 and 2019 (Geissler et al. (2020), only one RML-enacting state (California) would contribute to identification of the effects of the RML on marijuana use in this dataset.
} 
purchasing age of marijuana (MLPA) (18-to-20-year-olds), and 22 percent of those above the MLPA for marijuana (ages 21 and older) were current cigarette users. ${ }^{10}$ Trends in adult cigarette use shown in Panel (a) of Appendix Figure 2 show a similar pattern to that observed in the NSDUH (Panel (c) of Appendix Figure 1).

In addition to any current cigarette use, we also measure current everyday cigarette use, in part to focus on smoking behavior at the intensive margin of use. We find that 16.2 percent of 18year-olds were everyday smokers, with trends in use (Panel (b) of Appendix Figure 2) largely following trends in any current use.

Third, while the BRFSS data are not longitudinal in nature, the nature of the retrospective questions allows us to measure current smoking (or non-smoking) behavior or former smokers, thus capturing a margin of quit behavior. We condition the sample on ever smokers (those who reported smoking 100 cigarettes in their lifetime) and then generate an indicator for whether the person is currently a non-smoker. We find that 52 percent of ever smokers were currently former smokers. Panel (c) of Appendix Figure 2 shows the emerging trend in smoking cessation among US adults. In 2000, nearly 52.3 percent of ever adult smokers quit smoking, and this ratio rose to around 61.4 percent by the end of 2019. This quitting pattern was more salient among younger smokers (those ages 18-to-20), rising from 20.1 percent in 2000 to 33.1 percent in 2019.

Our final BRFSS measure captures whether the respondent has consumed electronic cigarettes (e-cigarettes). Because of the relatively recent arrival of e-cigarettes in the U.S. market and the lag in collection of information on use, data on e-cigarette consumption is available only for the years 2016 through 2018. BRFSS respondents are asked whether they "use e-cigarettes or other electronic vaping products" on "some days" "every day" or "not at all." Over the three years over which we have data available, 3.4 percent of adults ages 18 and older reported current consumption of e-cigarettes, with an expectedly higher prevalence (13.3 percent) among younger adults ages 1820.

\subsection{Current Population Survey Tobacco Use Supplements (CPS-TUS)}

To supplement the above datasets, we next turn to the Current Population Survey Tobacco Use Supplements (CPS-TUS). The CPS-TUS data are repeated cross sectional data, sponsored by the National Cancer Institute and periodically administered by the Census Bureau as part of the

\footnotetext{
10 In robustness checks shown in the appendix tables, we also report results from the BRFSS for those ages 18-to-25 and ages 26 and older.
} 
CPS's monthly surveys. We focus on a sample of adults ages 18 and older over the period from 2000 through 2019. ${ }^{11}$ Our analysis sample is comprised of over 1.13 million adults ages 18 and older that, when weighted, are designed to be representative of all U.S. adults.

The CPS-TUS data do not contain information on marijuana use, but have detailed information on tobacco use, including use of vaping products (since 2014) and more detailed measures of consumption at the intensive margin. Our measure of current smoking mirrors the measure described above using the BRFSS. Current cigarette use is defined as smoking at least 100 cigarettes in one's lifetime as well as currently smoking cigarettes "every day" or "some days." In our weighted analysis sample, 16.9 percent of adult respondents ages 18 and older, 15.3 percent of those ages 18-to-20, and 17.0 percent of those ages 21 and older were current cigarette smokers. In addition, 13.3 percent of those ages 18 and older were current everyday smokers and 54.0 percent of ever smokers were former smokers (consuming 100 cigarettes in their lifetime, but not smoking at all currently). Appendix Figure 3 shows trends in these measures of cigarette use for adults. The pattern generally confirms those seen in Appendix Figures 1 (NSDUH) and 2 (BRFSS). In addition to the above measures, the CPS-TUS also permits us to measure the number of cigarettes consumed daily on average among current everyday smokers, a measure of the intensive margin of smoking behavior.

Beginning in 2014, the CPS-TUS also started collecting information on e-cigarette use. We measure whether respondents ever consumed e-cigarettes and currently consume e-cigarettes. Among adults ages 18 and older, 8.5 percent report having tried e-cigarettes at some point in their lifetime, and 2.3 percent are current users. These rates are substantially higher for younger adults ages 18-to-20, with 14.8 percent reporting ever-use and 4.8 percent reporting current use over the sample period spanning 2014-2019. There is a marked increase in e-cigarette use among young adults, rising from 3.6 percent to 6.4 percent over this period.

We also define a more comprehensive measure of any tobacco use, which includes current use of cigarettes, pipes, cigars, or e-cigarettes. Over our sample period, about 19 percent of adults (ages $18+$ ) are current tobacco users, with the vast majority of these (89 percent) consuming cigarettes.

\footnotetext{
11 We use data from all available TUS waves since 2000: January and May 2000; June and November 2001/February 2002; February, June and November 2003; May and August 2006/January 2007; May and August 2010/January 2011; July 2014/January and May 2015; July 2018/January and May 2019.
} 
While the CPS-TUS is useful because of its more detailed measures of cigarette use on the intensive margin, other tobacco use, and the longer window of e-cigarette information than is available in the BRFSS (2016-2018), there are important disadvantages. The cross-sectional data are more staggered than in the NSDUH and BRFSS, which in the latter are available in every calendar year. This makes it more difficult to identify year-specific lagged effects for many RML-adopting states. Moreover, like the other national datasets described above, the data are repeated crosssections rather than longitudinal in nature. Thus, the data do not allow us to detect the precise timing of tobacco cessation and initiation decisions. For this purpose, as well as several others, we turn to our final dataset.

\subsection{Population Assessment of Tobacco and Health (PATH)}

The Population Assessment of Tobacco and Health (PATH) study is a nationally representative longitudinal cohort study jointly conducted by the National Institutes of Health $(\mathrm{NIH})$ and the Food and Drug Administration (FDA) that ascertains patterns of tobacco product use and health among youth and adults (Hyland et al., 2017). To further supplement estimates from other datasets, we utilized all five available waves of restricted use adult survey data from the PATH study, spanning 2013 to 2019 (United States Department of Health and Human Services, 2021). A cohort of 32,320 adults was established in the first wave of the study using a four-stage stratified area probability sample design and followed at each subsequent wave. At wave 4, additional adults were sampled to replenish the cohort. Respondents from the PATH youth sample who "age up" when they reach 18 years of age also entered the adult sample at each wave. Altogether, our analytic sample consisted of 156,945 observations across all five waves of data collection for adults. ${ }^{12}$ Weighted estimates are reflective of the U.S. adult civilian non-institutionalized population.

The PATH dataset offers several key advantages that complement other analyses. Firstly, the longitudinal nature of the data allows us to assess initiation and cessation of tobacco and marijuana products from wave to wave to conduct survival analysis. Secondly, some details of marijuana use are made available. We are able to assess the number of days that participants used blunts containing marijuana in the last 30 days, as well as specific routes of consumption (e.g., vaped, smoked as a blunt). Thirdly, PATH provides extremely detailed measures of tobacco use, covering the timing and amount of use for many combustible tobacco products and ENDS. The inclusion of these survey

\footnotetext{
${ }^{12}$ We drop 11 observations due to unclear state of residence and 5 observations due to unknown age.
} 
items allows us to create measures of dual use of marijuana and other tobacco products. Lastly, the individual panel data allows us to include individual fixed effects in our models and capture unmeasured person-specific heterogeneity.

We created various measures of marijuana and tobacco use to capture different aspects of consumption. Marijuana measures include use of "marijuana, hash, THC, grass, pot or weed;" use of any cigar product as blunts; or use of "marijuana, marijuana concentrates, marijuana waxes, THC, or hash oils" in e-products. Prior-month use measures are mostly based on items asking respondents whether they used a product "in the past 30 days." For our prior-month cigar use measure, we combined any affirmative response from questions about traditional cigars, filtered cigars, and cigarillos. Daily use was defined as using a product "30" of the past 30 days, or "every day" if number of days was missing. "Combustible tobacco" measures include: cigarettes, traditional cigars, cigarillos, filtered cigars, pipes, and hookah. "Tobacco" measures include all combustible tobacco products plus snus, smokeless tobacco, dissolvables, and ENDS. For all items, PATH-provided derived variables were included in the creation of our measures whenever available. Some measures, such as vaped marijuana measures and number of days of blunt use, were not available across all waves. There was also variation in survey skip logic and wording for some items across waves.

Survival analysis examining cessation and initiation of substances was conducted for the following age groups: ages 18-and-older and ages 21 -and-older for our main analysis, and we include additional subgroups of individuals ages 18-to-20, 21-to-25, and 26-and-older in the Appendix. ${ }^{13}$

Table 1 shows descriptive statistics for our main dependent variables across the four datasets, NSDUH (Panel I), BRFSS (Panel II), CPS-TUS (Panel III), and PATH (Panel IV). The means for cigarette use are comparable across the NSDUH, BRFSS, and PATH (22-24 percent for adults ages 18+) datasets and somewhat lower for the CPS-TUS (17 percent); this latter difference may be due to the staggered non-continuous nature of the CPS-TUS. Reassuringly, trends in any tobacco use and in cigarette use, track quite similarly across each of the four datasets over the common sample periods.

\section{Methods}

We capitalize on the considerable variation in the adoption of RMLs across states and over time to identify their short and longer-term effects on tobacco use behaviors. We begin by using

\footnotetext{
${ }^{13}$ For these age-specific analysis samples, participants were included in analyses when they contributed at least 2 waves
} of data. 
state-by-year data from the NSDUH and estimate a two-way fixed effects (TWFE) difference-indifferences model using the following specification:

$$
Y_{s t}=\gamma_{0}+\gamma_{1} R M L_{s t}+\gamma_{2} M M L_{s t}+\boldsymbol{X}_{s t} \boldsymbol{\beta}+\alpha_{s}+\theta_{t}+\varepsilon_{s t},
$$

where $Y_{s t}$ denotes the prevalence rate of the outcome of interest (marijuana use, tobacco use, or cigarette use) for adults in state $s$ in survey wave $t .^{14}$ The primary independent variable of interest, $R M L_{s t}$, measures the share of the period $t$ for which state $s$ has an RML in effect. For instance, if a state enacted an RML on July 1, 2015, the value of $\mathrm{RML}_{\mathrm{st}}$ for the 2013-2014 wave would be 0; for 2014-2015,0.25, for 2015-2016, 0.75, and for 2016-2017 and later 1. In alternate specifications, we explore heterogeneity in the effects of recreational marijuana laws by whether recreational sales are permissible. ${ }^{15}$ We control for whether state $s$ had enacted a medical marijuana law (MML) at wave $t$. Every state that adopted an RML had previously enacted an MML. Therefore, the LATE we identify is the marginal effect of an RML over and above an MML.

The vector $\mathbf{X}_{\mathrm{st}}$ includes a set of state-specific, time-varying controls for demographic characteristics of the state population (the share of the state population that was female, Black, Hispanic, and college educated, as well as the average age of the population), macroeconomic controls (unemployment rate, poverty rate, and the log of average pre-tax personal income), tobacco control policies (index of indoor vaping restrictions, the presence of an electronic cigarette minimum legal sales age, per pack excise tax on cigarettes, an index of indoor smoking restrictions, and the minimum age for cigarette sales), other social welfare policy controls (Earned Income Tax Credit refundable credit rate, the per hour minimum wage, whether the governor was a Democrat, whether the state had enacted a Medicaid expansion as part of the Affordable Care Act, the presence of a Prescription Drug Monitoring Program - PDMP, and the beer tax per gallon). ${ }^{16}$

In addition, $\alpha_{s}$ is a time-invariant state effect, and $\theta_{t}$ is a state-invariant wave (year pair) effect. All regressions are weighted using the relevant population of adults (ages 18 and older, ages

\footnotetext{
14 SAMHSA provides publicly available state-specific estimates for two-year averages (i.e., 2002-2003, 2003-2004...20182019). As in Sabia et al. (2021), we use overlapping state panels in the analyses, and match information on RMLs based on the month and year of enactment. The values for the controls in the vector $\mathrm{X}$ are also calculated as the weighted average of these measures over the two-year window that comprises each data wave. ${ }^{15}$ Note that nearly all RML states permit home cultivation of small quantities of marijuana, which is likely to result in some immediate effects on marijuana consumption (see Sabia et al. 2021), but lags in the opening of dispensaries for recreational sales following the adoption of RMLs may also result in delayed consumption responses and potential spillovers into other behaviors such as tobacco use.

16 Means of state-level control variables are shown in Panel V of Table 1.
} 
18-to-25, or ages 26 and older) and standard errors are clustered at the state level (Bertrand et al. 2004).

Our key parameter of interest, $\gamma_{1}$, is the reduced-form relationship between RML enactment and adult tobacco (or marijuana use). Identifying variation comes from within-state enactment of RMLs. Appendix Table 1 lists the effective dates of RMLs for the period 2000-2019 along with the dates that recreational sales of marijuana were permitted (Anderson and Rees 2021). A total of 11 states contribute to identifying the parameter $\gamma_{1}$.

The estimated policy impact will be unbiased if the control states capture how RML states' tobacco use would have evolved in the absence of RML enactment. While testing this assumption is not possible given the unobservability of the counterfactual, we take a number of tacks to descriptively provide evidence in support of the identifying assumption. First, we estimate eventstudy analyses, where we decompose the estimated treatment effect over time:

$$
Y_{s t}=\gamma_{0}+\sum_{j=\underline{J}}^{\bar{J}} \pi^{j} D_{s t}^{j}+\gamma_{2} M M L_{s t}+\boldsymbol{X}_{s t} \boldsymbol{\beta}+\alpha_{s}+\theta_{t}+\varepsilon_{s t}
$$

where $\mathrm{D}_{\text {st }}^{\mathrm{i}}$ it is a treatment indicator for an event (RML enactment) happening $j$ periods away from $t$, where treatment indicators are binned at the "endpoints" (the last open-ended lead and lag variables). The vector $\pi$ denotes the coefficients on the treatment effect, with the reference period being $j-1$, the year prior to RML enactment. If the estimates of $\pi$ for the period $[\underline{J}, j-2]$ are equal to 0 , this would provide evidence in support of the parallel trends assumption.

Second, we examine the robustness of our estimates to the inclusion of state-specific linear time trends:

$$
Y_{s t}=\gamma_{0}+\gamma_{1} R M L_{s t}+\gamma_{2} M M L_{s t}+\boldsymbol{X}_{s t} \boldsymbol{\beta}+\alpha_{s}+\theta_{t}+\alpha_{s} * \text { time }+\varepsilon_{s t},
$$

where $\alpha_{s} *$ time is a state-specific linear time trend. This control may aid in reducing omitted variables bias by controlling for unobserved state trends unfolding linearly that are incidentally correlated with the enactment of an RML and with tobacco use. However, this additional control may come at a cost. If there are dynamic treatment effects of RMLs on tobacco use, then the inclusion of such time trends may obscure important treatment effects (Wolfers 2006). Moreover, it is not always the case that the policy variation that remains following the inclusion of such controls 
is necessarily more orthogonal to $\varepsilon_{s t}$ than the policy variation exploited when such time trends are omitted (Neumark, Salas and Wascher 2014). Thus, we are careful in interpreting estimates that include these trends.

Third, recent advancements in the difference-in-differences literature caution that in the presence of heterogeneous dynamic treatment effects, estimates of $\gamma_{1}$ from equation (1) and $\pi_{\mathrm{j}}$ from equation (2) may be biased (Goodman-Bacon 2021; Sun and Abraham 2021). To explore this possibility, we take two tacks. We estimate a Goodman-Bacon (GB) decomposition of $\gamma_{1}$ into the possible two-by-two comparisons that generate this estimate: (i) early RML adopters versus later RML adopters, (ii) later RML adopters versus early RML adopters, and (iii) ever adopters versus never adopters. If, as we might expect given that there are 40 never-adopters in our sample, the vast majority of the "weight" in the GB decomposition is given to the two-by-two comparisons described in (i) and (iii), it is less likely that our estimated treatment effects are biased due to heterogeneous treatment effects over time. In the presence of dynamic treatment effects, it is the use of early RML adopters as a counterfactual for identifying effects for later RML adopters that presents the problematic comparison.

In addition, we employ a new estimator proposed by Callaway and Sant'Anna (2021) to expunge potential biases arising in the standard TWFE estimator with staggered treatment adoption in the presence of dynamic heterogeneity in the treatment effects. Here, we explicitly select never adopters as the counterfactuals for each RML-adopting state to estimate our treatment effect and event study coefficients. A comparison of Callaway-Sant'Anna estimates to those generated via TWFE models will allow us to further assess the degree to which heterogeneous dynamic treatment effects are an important source of bias.

Finally, to more fully explore heterogeneity in the effects of RMLs across treatment states, as well as allow for longer lagged effects of RMLs on tobacco use, we turn to a synthetic control approach (Abadie et al. 2010). Specifically, we examine effects for the six earliest adopting RML states (Alaska, California, Colorado, Massachusetts, Oregon, and Washington), for which we have at least 3 years of post-treatment data. Following Sabia et al. (2021), we select a donor pool comprised of states that never enacted an RML over our sample window. In addition, to ensure that our donor pool is not contaminated from the effects of post-RML MML adoption by donors, we select the donor pool from within the non-RML states that also did not enact any MML in the post-RML period. We then generate a synthetic control state for each RML state that closely approximates adult tobacco use prevalence rates in each wave (year pair) of the pre-treatment period. 
We generate the counterfactual tobacco prevalence rate in pre-treatment wave $t$ by $\sum_{n} w_{n} *$ Tobacco Use Rate ${ }_{n t}$, where $w_{n}$ is the weight assigned to donor state $n$ and choose $w_{n}{ }^{*}$

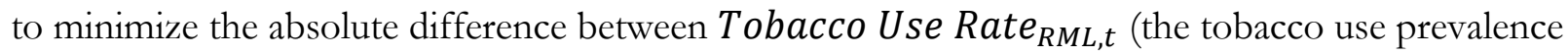

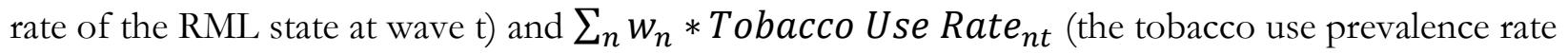
for the synthetic control) and for all pretreatment waves. The ATT is then the average difference in the tobacco use prevalence rate for the RML (treatment) state and its synthetic control in the posttreatment period. Permutation-based p-values from placebo tests (randomly assigning treatment to each donor state) are generated in order to conduct statistical inference.

Following the above comprehensive analyses of state-level tobacco use in the NSDUH, we extend the analyses to individual-level data from the BRFSS and CPS-TUS and estimate a variant of the above-described specification:

$$
Y_{i s t}=\delta_{0}+\delta_{1} R M L_{s t}+\delta_{2} M M L_{s t}+\boldsymbol{X}_{i s t} \boldsymbol{\kappa}+\alpha_{s}+\theta_{t}+\varepsilon_{i s t},
$$

where $i$ indexes the individual survey respondent and $\theta_{t}$ is a year-by-month fixed effect. In this specification, some of the controls in the vector $\mathbf{X}$ are now measured at the individual level, including gender, race/ethnicity, and educational attainment. As noted above, one of the advantages of using the individual-level data will be our ability to explore heterogeneous treatment effects by these individual characteristics. The remaining state-specific, time-varying controls in the vector $\mathbf{X}$ are identical to those described above. Regressions are weighted using the sample weights provided with each survey and standard errors are corrected for clustering at the state level.

Here, $\delta_{1}$ is the estimated effect of RML enactment on smoking behavior. Again, we explore the sensitivity of our estimated treatment effect to the inclusion of controls for state-specific linear time trends, to an event study analysis, and to the use of the Callaway-Sant'Anna estimator.

Finally, our analysis turns to the PATH data. The longitudinal nature of these data allows us to estimate several different specifications that capture dynamic behavioral responses to the enactment of RMLs, as well as additionally control for person-specific heterogeneity.

Specifically, we extend equation (4) to further control for all observed and unobserved timeinvariant person-specific characteristics, such as stable risk- and time-preference and lifetime exposure to tobacco control prior to the respondents' first observation in the PATH.

$$
Y_{i s t}=\delta_{0}+\delta_{1} R M L_{s t}+\delta_{2} M M L_{s t}+\boldsymbol{X}_{i s t} \boldsymbol{\kappa}+\alpha_{s}+\theta_{t}+\mu_{i}+\varepsilon_{i s t},
$$


Equation (5) incorporates individual-level fixed effects $\left(\mu_{i}\right)$ to account for stable person-specific heterogeneity, and is estimated for current use of any tobacco, and specific tobacco products (cigarettes, cigars, e-cigarettes), as well as dual use of marijuana and tobacco products.

Finally, to assess the dynamics of how exposure to RMLs specifically affects the probability of initiating cigarette use or use of other tobacco products among tobacco abstainers (a margin that may be salient for younger adults) and affects the probability of quitting cigarette use or use of other tobacco products (a margin that may be more salient for older adults), we exploit the longitudinal structure of the PATH and estimate discrete-time hazard models.

$$
\begin{aligned}
\operatorname{Prob}\left(S_{i s t}=1 \mid t-1<T<t\right) & = \\
& \delta_{0}+\delta_{1} R M L_{s t}+\delta_{2} M M L_{s t}+\boldsymbol{X}_{i s t} \boldsymbol{\kappa}+\alpha_{s}+\theta_{t}+\mu_{i}+\varepsilon_{i s t}
\end{aligned}
$$

The discrete time hazard specification in equation (6) models the conditional probability of switching across margins of tobacco use $(S)$ between periods $t-1$ and $t$. When studying initiation, the sample is restricted to adults who had not used tobacco at baseline, and an indicator is defined for transitioning to tobacco use in period $t$, conditional on being an abstainer in period $t-1$. Similarly, when studying cessation, the sample is restricted to tobacco users at baseline, and an indicator is defined for transitioning to no reported use in period $t$, conditional on being a user in period $t-1$. The parameter of interest, $\delta_{2}$, above can be interpreted as changes in the transition probability between states of consumption as affected by the RMLs. We also estimate similar models, with the PATH, for transitioning into marijuana initiation and marijuana cessation. Additionally, we also explore transition into marijuana use among baseline tobacco users, and transition into dual use (of both marijuana and tobacco) among baseline abstainers.

\section{Results}

Our main findings appear in Tables 2 through 15 and Figures 1 through 10. Supplemental analyses are presented in the appendix.

\subsection{NSDUH Results}

First-Stage Marijuana Use. In Panel I of Table 2, we provide "first-stage" estimates of the effect of RMLs on marijuana consumption among those ages 18 and older. After controlling for state fixed effects, wave fixed effects, and whether the state had adopted an MML, TWFE estimates show that RML adoption is associated with a 3.7 percentage-point increase in marijuana consumption (column 1, Panel I), representing a relatively large change (49.4 percent) compared to 
the pre-treatment mean in RML states. The addition of controls for demographic and socioeconomic characteristics (column 2), tobacco control policies (column 3), and other social welfare policy controls (column 4) has relatively little effect on the estimated treatment effect. Controlling for all observable state characteristics (column 4), we find that RMLs are associated with a 4.1 percentage-point increase in marijuana consumption. The inclusion of controls for statespecific linear time trends (column 5) reduces the magnitude of the estimated treatment effect to 2.1 percentage-points, but it remains statistically distinguishable at the 5 percent level.

Finally, in column (6), we use the estimator proposed by Callaway and Sant'Anna (2021) to expunge any bias due to heterogeneous dynamic treatment effects. We use never adopters as the pool of counterfactuals, though using not-yet-adopters yields a qualitatively similar pattern of results. The average RML effect on marijuana use in treated states (ATT) is estimated to be 3.1 percentagepoints, consistent with our TWFE estimator. This result is not surprising given that a GoodmanBacon decomposition places 92.9 percent of the weight of the TWFE estimator on "ever vs. never" adopters and 5.5 percent of the weight was placed on "early vs. later" adopters. Just 1.6 percent of the weight of the TWFE estimator was comprised of the potentially problematic comparison of "later vs. earlier" adopters.

In Panel II, we explore whether there are important dynamic effects on marijuana use using both TWFE (columns 1 through 5) and Callaway-Sant'Anna (column 6) estimators. ${ }^{17}$ In the main, the findings suggest that the effects of RMLs on marijuana use increases over time, with the smallest impacts in the year of enactment (1.0 to 1.6 percentage-points) and the largest effects three or more years following RML enactment (1.9 to 3.9 percentage-points). This dynamic pattern of effects is consistent with dispensary openings and full retail access lagging the enactment of marijuana liberalization policies. Appendix Figure 4 shows event study analyses using TWFE estimators and Callaway-Sant'Anna estimators. The pattern of findings is consistent with parallel pre-treatment trends, and with marijuana use increasing in the years following RML enactment. Finally, when we explore heterogeneity in the effects of RMLs on marijuana use for those ages 18-to-25 and 26 and older (Table 3), we find that both older and younger adults are impacted by RMLs, with estimated marginal effects of roughly comparable magnitudes ( 2 to 4 percentage-points). Together, these firststage findings are consistent with those reported in Sabia et al. (2021).

\footnotetext{
${ }^{17}$ Note that the TWFE specifications depicted in the table do not include lead effects, which are also included in eventstudy analyses discussed below.
} 
Tobacco Use. Establishing the first-stage effect of how RMLs have impacted marijuana consumption is important for framing what the maximal effect would potentially be if there are spillover responses into smoking and other tobacco use given that these individuals (those who shift their marijuana consumption in response to the policies) represent the affected group. Effects on tobacco use that we estimate are an intention-to-treat (ITT) effect. Most adults in the population would not be affected by RMLs, and thus the estimated reduced-form tobacco use response is an average across two groups - those who are potentially affected by RMLs and those who are not. It is unlikely that RMLs would have a direct effect on tobacco use behaviors, independent of their effect on marijuana use.

In the remaining NSDUH tables, we turn to our main outcome of interest, adult tobacco use. Our findings in Panel I of Table 4 show that RML adoption is associated with a (largely) statistically insignificant 0.3 to 1.3 percentage-point decline in tobacco use, a measure that encompasses cigarettes, pipe tobacco, smokeless tobacco, and cigars. However, this null effect masks small, lagged tobacco effects of RMLs. Two or more years following the enactment of an RML, we find that adult tobacco use falls by approximately 0.6 to 1.6 percentage points. The lagged effect three or more years after RML enactment is uniformly statistically different from zero at conventional levels. Importantly, the absolute magnitudes of these tobacco effects are one-fourth to one-third the size of the first-stage marijuana results in standard TWFE models, which suggests the effect sizes are plausible. Together, these results suggest that recreational marijuana and tobacco are substitutes for the average marginally affected individual.

Turning to age-specific estimates in Table 5, we find that RML enactment is associated with small, lagged tobacco use declines for both 18-to-25-year-olds (Panel II) and those ages 26 and older (Panel IV). However, the effects are stronger and more consistently significant for younger adults.

Event-study analyses using TWFE (Figure 1) and Callaway-Sant'Anna (Figure 2) estimators show consistent evidence of parallel pre-treatment trends, followed by declines in tobacco use with about a 2- to 3-year lag, consistent with the regression results shown in Tables 4 and 5.

Tables 6 and 7 repeat the above exercise for cigarette consumption. Again, while the overall treatment effect is relatively small ( 0.2 to 0.8 percentage points in Panel I of Table 6$)$, three or more years following RML enactment, we find evidence of a statistically significant 0.9 to 1.9 percentagepoint decline in cigarette use among adults (Table 6, Panel II). These patterns for cigarette use largely and expectedly mirror the results for tobacco use, and suggest that cigarettes and recreational marijuana are substitutes. 
Interestingly, age-specific estimates in Table 7 suggest that for younger adults (ages 18-to25), the negative relationship between marijuana and tobacco is driven more by non-cigarette tobacco products. With the remaining datasets, where we can disaggregate tobacco products more fully, we probe this issue further. For those ages 26 and older, lagged cigarette use declines more consistently in the years following RML enactment.

Event-study analyses using TWFE (Figure 3) and Callaway-Sant'Anna (Figure 4) estimators continue to show that cigarette use was trending similarly in RML and non-RML states prior to RML adoption. However, cigarette use declines — with about a 2- to 3-year lag — in RML as compared to non-RML states.

As an additional robustness exercise that allows us to capture longer-run tobacco effects of RML enactment, we explore synthetic control estimates of the effect of RML enactment on tobacco use for the six earliest adopting states. The results, shown in Appendix Figures 5 through 10, provide some support for the hypothesis that tobacco use declined in several of the earliest adopting states, most notably in Colorado and Washington, which are also those states that saw the largest increases in marijuana use following RML enactment. This pattern of results is consistent with the hypothesis that RML-induced increases in recreational marijuana partly substitute for tobacco use for the average marginally affected adult.

Finally, we explore heterogeneity in the effects of RMLs on marijuana and tobacco use by whether the state permits retail sale of recreational marijuana (see dates listed in Appendix Table 1, following Anderson and Rees 2021). We note that there are important reasons to expect that even in the absence of retail sales being permissible, with the repeal of legal penalties for possession of small quantities of marijuana - as well as allowances for home cultivation of marijuana (permissible in all but two RML states that contribute to identification) - RMLs could increase marijuana use and affect tobacco use. However, retail sales may accelerate market availability of marijuana.

Appendix Table 2 presents estimates from specifications that replace our RML indicator with two mutually exclusive indicators for RMLs that permit recreational sales and those without such allowances. Our results provide some support for the hypothesis that the effects of RMLs on marijuana use and tobacco use are each larger (in absolute magnitude) when the RML is accompanied by legal sales of recreational marijuana. 


\subsection{BRFSS Results}

We next turn to individual data from the 2000-2019 BRFSS data in Tables 8 through 10. In the first three columns of Table 8, we present estimates of the effect of RMLs on current cigarette smoking. Consistent with our NSDUH-based results, TWFE estimates provide little support for the hypothesis that liberalizing recreational access to marijuana leads to complementary spillovers into cigarette consumption. The precision of the estimated treatment effect in Panel I of column (1) is such that we can rule out, with 95 percent confidence, RML-induced increases in adult cigarette use of greater than 0.8 percentage points, or about 4.1 percent relative to the pre-treatment mean.

When state-specific linear time trends are included on the right hand side of the estimating equation (column 2), the estimated treatment effect is nearly an order of magnitude smaller (Panel I, column 2) and the lagged effect three or more years after enactment is slightly negative (Panel II, column 2) The use of the Callaway-Sant'Anna (2021) estimator in column (3) provides evidence of a small, negative, and statistically insignificant relationship between RML enactment and cigarette use. Moreover, using this estimator, there is stronger evidence of a negative lagged effect of RMLs on cigarette use, with a (statistically insignificant) one percentage-point long-run decline in adult cigarette use.

Turning to everyday smoking in columns (4) through (6), the pattern of results is quite similar, with specifications that include state-specific linear time trends (column 5) or use the Callaway-Sant'Anna estimation strategy (column 6) returning stronger evidence of small reductions in everyday smoking following RML enactment.

Event-study analyses based on the Callaway-Sant'Anna estimates, shown in panels (a) and (b) of Figure 5, suggest relatively flat pre-treatment trends in cigarette use and a small decline in consumption approximately three or more years following RML enactment in treatment relative to control states.

In columns (7) through (9), we turn to quit behavior to explore whether RMLs affect cessation behavior among "ever smokers," those who have smoked at least 100 cigarettes in their lifetime. We find that recreational marijuana legalization is associated with a small and statistically insignificant change in the probability of successful quitting (columns 7 through 9), with more positive coefficients in columns (8) and (9). Event-study analyses, shown in panel (c) of Figure 5 show small, positive effects, with quit behavior diverging between treated and control groups three years after RML enactment. However, we are cautious in interpreting these estimates given that 
RMLs may affect the sample of ever smokers such that the estimates reflect changes in the distribution of characteristics of ever smokers. ${ }^{18}$

Table 9 shows estimates for younger and older adults, dividing the sample across the age threshold of the minimum legal purchasing age for recreational marijuana (age 21). ${ }^{19}$ The findings continue to provide little evidence that recreational marijuana and cigarettes are complements. While there is somewhat stronger evidence from the signs of the coefficients that the substances are substitutes for 18-to-20-year-olds than for those ages 21 and older, event-study analyses in Figure 6 point to a suggestive pattern of longer-run declines in cigarette use for those ages 21 and older.

As noted above, one of the important advantages of individual-level data from the BRFSS is the ability to explore heterogeneous treatment effects by demographic characteristics of individuals and their families. In Figure 7, we show estimated effects of RMLs on our three BRFSS outcomes by gender (male, female), race/ethnicity (non-Hispanic white, Black, Hispanic), and education (high school degree or less, some college or more). While we do not find estimated treatment effects that are statistically distinguishable between male and female adults, the substitution away from tobacco appears slightly larger for less educated and whites, relative to more highly educated and Black individuals.

Finally, in Table 10, we use data from the 2016-2018 BRFSS to examine the effect of RML enactment on e-cigarette use. Here, the estimated treatment effect is identified from five states that enacted RMLs with a very short post-treatment window, so the results should be thought of as descriptive rather than dispositive. The results provide no evidence that recreational marijuana and e-cigarettes are complements and some evidence that they are substitutes. For all adults (columns 1 and 2), we find that RML enactment is associated with a 2.7 to 6.5 percentage-point decline in current e-cigarette use (Panel I). These effects are observed for both 18-to-20-year-olds (columns 3 and 4) as well as those ages 21-and-older, though the estimated marginal effects are much larger (on the order of 3 to 6 times) for those under the MLPA for marijuana.

\footnotetext{
18 When we explore heterogeneity in the tobacco effects of RML enactment by whether retail sales are permissible, the effects are not statistically significant and the magnitudes for both RML indicators (with/without recreational sales allowance) are small, close-to-zero, and similar to those reported in Table 8.

${ }_{19}$ Appendix Table 3 repeats this table for those ages 18-to-25 and 26-and-older to provide comparable comparison to the NSDUH and uncovers a similar pattern of results.
} 


\subsection{CPS-TUS Results}

Turning to the CPS-TUS, our main estimates for all adults ages 18-and-older, presented in Table 11 (Panel I), continue to show very little evidence of any significant complementary uptake in overall tobacco use or cigarette use in response to the RML enactment. Event studies (Figure 8, Panels a through c) corroborate: (1) tobacco use behaviors between RML and non-RML states trended very similarly prior to policy adoption, and; (2) in conjunction with the lagged policy effects (see Figure 8), there is suggestive evidence of RML-induced substitution away from cigarette use over time, particularly two or more years post-policy enactment. ${ }^{20}$

Moreover, we find that the average policy response appears to mask heterogeneity across age groups. Age-specific differential estimates (Panels II and III of Table 11) provide more robust evidence that RML-induced increases in marijuana use and tobacco use are substitutes for younger adults (ages 18-20) below the age threshold for legally purchasing marijuana for recreational use in RML states. The coefficients point to a significant three percentage points decline in smoking and everyday smoking. Supplementary analyses confirm that these effects largely materialize over the longer-term, two or more years post-treatment. To place the effect magnitude into context, note that the NSDUH analyses indicated a significant 4.5 to 4.8 percentage points increase in marijuana use among young adults ages 18-25. Though the age groups do not perfectly overlap (due to data constraints in the public use NSDUH), these estimates broadly indicate that substitution away from cigarette use may be especially sizeable, at the margin, among underage young adults who are driven by the RMLs to increase their marijuana use. Among those ages 21-and-older, a group that would be legally able to purchase marijuana for recreational purposes in the RML states, there is no indication of any significant or substantial spillovers from marijuana to tobacco use. ${ }^{21}$

In supplementary analyses (Appendix Table 4), we capitalize on information available in the CPS-TUS since 2014 on e-cigarette use, to assess if RMLs had any spillover effects on these newer and increasingly more popular tobacco product entry. These estimates are identified off nine treatment states that adopted RMLs between 2014-2019 (Appendix Table 1). The event study in Figure 8 (Panel C) shows no evidence of differential pre-policy trends, and essentially little-to-no effects post-policy. However, there is some indication in the results of heterogeneity in the policy

\footnotetext{
${ }^{20}$ Figure 9 presents event studies generated based on the Callaway-Sant'Anna estimator, and continues to show little evidence of differential pre-policy trends.

${ }^{21}$ We also analyzed young adults ages 21-25 as a separate group and found similar longer-term substitution patterns between tobacco and marijuana. Point estimates for this age group indicated about a one to three percentage points decrease in tobacco use, cigarette use, and everyday cigarette use two or more years following the period when RMLs became effective in the state. Only the estimate for everyday cigarette use achieved statistical significance.
} 
response by age. Among younger adults, the overall treatment effect is indicative of a complementary increase in e-cigarette use, on the order of about one to two percentage points. Disentangling the timing and dynamics of these effects for this age group is, however, a noisy endeavor due to the very limited sample size. Among older adults, the estimates point to little-to-no spillover effects on e-cigarette use, and if anything. ${ }^{22}$ Taken at face value, CPS-TUS estimates for adults under the legal purchase age for marijuana suggest that these adults are increasing their consumption of marijuana possible of e-cigarettes as well, and that these increases are substituting away from combustible tobacco use.

\subsection{PATH Results}

Finally, we turn to longitudinal evidence from the 2013-2019 PATH data. In Table 12, we capitalize on rich information on marijuana use and modes of use to estimate first-order RML effects on these behaviors. In addition to state, year-month, and survey wave fixed-effects, as well as controls that vary over time at the individual or state-level, all models further control for individual-specific heterogeneity through person fixed effects. ${ }^{23}$

Among all adults ages 18-and-older (Panel I), RML enactment is associated with a 2.0 percentage-point increase in past 12-month marijuana use and a 1.9-percentage-point increase in past 30-day use (columns 1 and 2); the latter effect represents a change of approximately 10 percent relative to the pre-treatment mean in RML states and is comparable to what we find in the NSDUH. No statistically significant relationships were seen for blunt use (columns 3 and 4). In addition, RMLs appear to increase both past 2-day and ever-vaped marijuana use (columns 5 and 6) by 0.8percentage-points (22 percent) and 1.9-percentage-points (11.5 percent), respectively. Estimates were similar for those ages 21 and older (Panel II).

Turning to tobacco-related outcomes in Table 13A, we find that RML enactment is not statistically significantly associated with increases in any tobacco use or any specific forms of tobacco use for either those ages 18-and-older or ages 21 -and-older, largely mirroring previously discussed findings. With regard to e-cigarette use, there is some evidence of a statistically insignificant negative relationship between RML-adoption and tobacco use, on the order of 0.1- to 0.6-percentage-points.

\footnotetext{
${ }^{22}$ Due to the limited sample sizes, particularly for the younger adult age group, and the reduction in the number of identifying states (skewed toward later adopters), we view the estimates in Appendix Table 4 as suggestive.

23 State and person fixed effects are not perfectly collinear due to some individuals who migrate cross-state over time.
} 
Dynamics in these policy responses are presented in Table 13B. Here, we find that in the periods lagging RML adoption, ENDS use significantly decreases, on the order of one to two percentage points. These results are consistent with evidence from the BRFSS and suggest that marijuana and e-cigarettes are medium-to-long-run economic substitutes. However, we find little evidence of effects of RMLs on combustible tobacco products.

Finally, in Tables 14 and 15, we more fully exploit the longitudinal nature of the PATH data to estimate the effects of RML enactment on initiation and cessation of tobacco and marijuana based on a discrete-time hazard model (i.e., survival analysis). Findings shown in the odd-numbered columns of Table 14 provide no evidence that the enactment of state RMLs impacted the probability of initiating use of cigarettes (column 1), cigars (column 3), or e-cigarettes (and other ENDS products) (column 5) among those who were current non-users at baseline. ${ }^{24}$ The estimated effects are economically small, often negative, and never statistically distinguishable from zero at conventional levels. However, we find strong evidence that RML enactment increased initiation of marijuana use on prior non-users (column 7); the transition probability is estimated to increase by 1.3 percentage points (27-30 percent relative to the baseline mean). This result suggests that the initiation margin of marijuana use is one on which RMLs have substantial bite.

Turning to cessation in the even-numbered columns of Table 14, we continue to find no evidence that RML enactment significantly affected the probability of cessation of tobacco products among those who were previous users (columns 2, 4, and 6), though the estimated effect for cigar cessation (4.0 to 5.7 percentage points) is non-trivial. While the estimated effect of RMLs on cessation of marijuana among prior users was negative, as theoretically expected, and the estimated effect is economically meaningful (1.9 to 2.5 percentage points decline in the probability of transitioning to marijuana cessation; 12-17 percent relative to the mean), the effects are never statistically distinguishable from zero at conventional levels. This is, in part, due to the effect being imprecisely estimated due to a relatively small sample of prior marijuana users (relative to non-users).

Finally, through results reported in Table 15, we explore how RML enactment may have impacted dual use of tobacco and marijuana products. Column (1) provides prima facie indication that RML enactment is significantly associated with a 1.2 to 1.3 percentage-point increase in joint use of tobacco and marijuana. Conceptually, this increase in dual use could be driven by an: i)

\footnotetext{
${ }^{24}$ Initiation was defined as the first instance of past 30-day use among baseline non-users, while cessation was defined as the first instance of past 30-day non-use among baseline users. For initiation models, only baseline non-users are included, and the individual remains in the sample until use occurs (if ever), and opposite for cessation models.
} 
increase in marijuana use among baseline current tobacco users; and/or ii) increase in both marijuana and tobacco use among baseline abstainers of both substances. ${ }^{25}$ The longitudinal nature of the PATH data allows us to distinguish between these hypotheses in a dynamic consumption framework.

In columns (3) and (4), we present estimates from discrete-time hazard models to parse out which of these margins may be driving the observed increase in dual use. These analyses show a substantial and significant increase in the probability of transitioning from marijuana abstention to marijuana initiation ( 3.0 to 3.2 percentage points; or nearly 50 percent relative to the baseline mean) among baseline tobacco users (column 2). On the other hand, there is no statistically or economically significant impact on the probability of transitioning to both tobacco and marijuana use among prior abstainers of both substances (column 3). Together, these findings indicate that the RML-induced increase in dual use we observe in column (1) is driven by an increase in marijuana initiation among the sub-population of individuals who were already using tobacco prior to the policy shift. And as such, these results are consistent with the previously discussed findings on the impacts of RMLs on net marijuana use (positive) and tobacco use (null or negative). Lastly, results in column (4) show that RML adoption had no effect on dual use of marijuana and ENDS products. Thus, there is little evidence to suggest that vaping products and marijuana are complements and, given findings in Table 13B (and Table 10), stronger evidence to suggest that they may be substitutes. $^{26,27}$

\section{Conclusions}

While public support for recreational marijuana has skyrocketed in recent decades, public health experts have taken a more cautious approach, urging more research to assess the health benefits and costs of marijuana use, as well as to understand potentially unintended consequences on other health behaviors (American Medical Association 2021). One important unintended consequence could be the renormalization of smoking, which could undermine the achievements of tobacco control policies over the last two decades.

\footnotetext{
${ }^{25}$ Note that the latter transition does not preclude a sequencing of use from abstention to marijuana (tobacco) use to subsequent tobacco (marijuana) use over the longitudinal window. Also, note that (i) is consistent with no net increase in tobacco use, whereas (ii) would imply net increases in both marijuana and tobacco use.

${ }^{26}$ In Figure 10, we explore heterogeneity in the estimated treatment effect by gender, race/ethnicity, and education for marijuana and tobacco use. In no case do we find estimated RML effects that differ across key demographic groups.

${ }_{27}$ Appendix Tables 5 through 7 present age-specific (younger adults vs. older adults) estimates from the PATH, with a pattern of findings generally similar to those presented for those ages 18 and older and 21 and older.
} 
Indeed, since 1964 when the first Surgeon General report was released, cigarette smoking rates among male adults have declined from 55 percent to 16 percent and female smoking rates have declined from 35 percent to 12 percent (Centers for Disease Control and Prevention 2021c; Holford et al. 2014). While the causes of these declines are the subject of much debate, most public health experts seek to preserve the health gains related to anti-smoking efforts of the previous half-decade.

This study is the first to comprehensively examine the impact of legalizing recreational marijuana on tobacco use, and in doing so, use novel econometric tools that permit us to estimate dynamic consumption effects of RMLs. Using data from four, large, nationally representative datasets (National Survey of Drug Use and Health, Behavioral Risk Factor Surveillance Survey, Current Population Survey Tobacco Use Supplements, and Population Assessment of Tobacco and Health) and a generalized difference-in-differences approach, we find very little evidence that recreational marijuana and tobacco are complements among adults. Our findings provide little support for the hypothesis that RMLs increase the overall consumption of cigarettes, e-cigarettes, cigars, or smokeless tobacco, either at the extensive or intensive margins. Rather, the preponderance of the evidence points to small, occasionally significant longer-run declines in adult tobacco use, more consistent with the hypothesis that recreational marijuana and tobacco may be substitutes. Effects are particularly pronounced from younger adults ages 18-20, who are under the legal marijuana purchase age for recreational use; these adults appear to significantly increase their marijuana use, and substitute away from cigarette use - including more frequent, everyday cigarette use - in response to more liberalized recreational access to marijuana.

The findings from this study complement the results from Sabia et al. (2021), which found that RML-induced increases in marijuana use also did not encourage harder drug use, which is associated with larger adverse public health consequences relative to marijuana use. The potential health care cost savings from substitution away from cigarette consumption, which our study points to, could be substantial. Scaling our estimates to the national level, our estimates indicate a reduction in smoking prevalence by as many as 5.1 million, translating into tobacco-related healthcare cost savings of about $\$ 10.2$ billion per year. ${ }^{28}$ These cost-savings, of course, need to be balanced against the public health costs and benefits associated with increased marijuana use, and against effects on marijuana use and tobacco use realized for youth (Anderson et al. 2021). Our

\footnotetext{
${ }_{28}$ These estimates are based on the approximate two percentage points longer-term decline in smoking prevalence, based on the NSDUH results. Xu et al. (2015) estimated annual health care costs related to cigarette smoking of $\$ 170$ billion, which imply $\$ 1995$ (deflated to 2019 dollars) in added health care costs per year per smoker.
} 
study underscores the importance of quantifying and incorporating policy-driven spillovers when attempting to evaluate the benefits and costs of liberalized access to recreational marijuana. 


\section{References}

Abadie, A., Diamond, A., \& Hainmueller, J. 2010. "Synthetic Control Methods for Comparative Case Studies: Estimating the Effect of California's Tobacco Control Program." Journal of the American statistical Association, 105(490), 493-505.

Abouk, Rahi, Charles J. Courtemanche, Dhaval M. Dave, Bo Feng, Abigail S. Friedman, Johanna Catherine Maclean, Michael F. Pesko, Joseph J. Sabia, and Samuel Safford. 2021. "Intended and Unintended Effects of E-cigarette Taxes on Youth Tobacco Use." National Bureau of Economic Research (NBER) Working Paper No. 29216. Available at: https://www.nber.org/papers/w29216

Agrawal, A., Lynskey, M., Bucholz, K., Madden, P., \& Heath, A. 2007. “Correlates of Cannabis Initiation in a Longitudinal Sample of Young Women: The Importance of Peer Influences.” Preventive Medicine 45: 31-34.

Agrawal, A., Madden, P., Bucholz, K., Heath, A., \& Lynskey, M. 2008. "Transitions to Regular Smoking and to Nicotine Dependence in Women Using Cannabis.” Drug and Alcohol Dependence 95: $107-114$.

Alley, Zoe, David Kerr, and Harold Bae. 2020. "Trends in College Students' Alcohol, Nicotine, Prescription Opioid and Other Drug Use After Recreational Marijuana Legalization: 2008-2018.” Addictive Behaviors, 102: 106212.

American Lung Association. 2021. "Marijuana and Lung Health.” Available at: https://www.lung.org/quit-smoking/smoking-facts/health-effects/marijuana-and-lung-health

American Medical Association. 2021. "Questions Still Surround Cannabis Use and Public Health." Available at: https://www.ama-assn.org/about/leadership/questions-still-surround-cannabis-useand-public-health

American Nonsmokers Rights Foundation. 2021. "Secondhand Marijuana Smoke." Available at: https://no-smoke.org/secondhand-marijuana-smoke-fact-sheet/

American Public Health Association. 2020. "A Public Health Approach to Regulating Commercially Legalized Cannabis." Available at: https://www.apha.org/policies-and-advocacy/public-healthpolicy-statements / policy-database/2021/01/13/a-public-health-approach-to-regulatingcommercially-legalized-cannabis

Anderson, D. Mark, Benjamin Hansen, and Daniel I. Rees. 2013. "Medical Marijuana Laws, Traffic Fatalities, and Alcohol Consumption.” Journal of Law and Economics 56(2): 333-69.

Anderson, D. Mark, Kyutaro Matsuzawa, and Joseph J. Sabia. 2020. "Cigarette Taxes and Teen Marijuana Use." National Tax Journal 73, no. 2: 475-510.

Anderson, D. Mark, Daniel I. Rees, Joseph J. Sabia, and Samuel Safford. "Association of Marijuana Legalization With Marijuana Use Among US High School Students, 1993-2019." JAMA Network. Open 4, no. 9 (2021): e2124638-e2124638. 
Anderson, D. Mark, and Daniel I. Rees. 2021. "The Public Health Effects of Legalizing Marijuana." National Bureau of Economic Research (NBER) Working Paper No. w28647. Available at: https://www.nber.org/papers/w28647

Andreyeva, Elena and Benjamin Ukert. 2019. “The Impact of Medical Marijuana Laws and Dispensaries on Self-Reported Health.” Forum for Health Economics and Policy, 22(2): 1-20.

Beenstock, Michael, and Giora Rahav. 2002. "Testing Gateway Theory: Do Cigarette Prices Affect Illicit Drug Use?” Journal of Health Economics 21(4): 679-98.

Behrendt, S., Wittchen, H., Höfler, M., Lieb, R., \& Beesdo, K. 2009. “Transitions From First Substance Use to Substance Use Disorders in Adolescence: Is Early Onset Associated With a Rapid Escalation?" Drug and Alcohol Dependence 99: 68-78.

Bentler, P., Newcomb, M., \& Zimmerman, M. 2002. "Cigarette Use and Drug Use Progression: Growth Trajectory and Lagged Effect Hypotheses." In: Kandel D B, editor. Stages and pathways of drug involvement. Cambridge, England: Cambridge University Press, 223-253.

Bertrand, Marianne, Esther Duflo, and Sendhil Mullainathan. 2004. "How Much Should We Trust Differences-In-Differences Estimates?” Quarterly Journal of Economics 119(1): 249-275.

Callaway, Brantly, and Pedro HC Sant'Anna. 2021. "Difference-In-Differences with Multiple Time Periods." Forthcoming, Journal of Econometrics.

Centers for Disease Control and Prevention. 2021a "Smoking Diseases and Death: Fast Facts." Available at: https://www.cdc.gov/tobacco/data statistics/fact sheets/fast facts/index.htm\#diseases

Centers for Disease Control and Prevention. 2021b. "STATE system Smokefree Indoor Air Fact Sheet." Available at: https://www.cdc.gov/statesystem/factsheets/sfia/SmokeFreeIndoorAir.html

Centers for Disease Control and Prevention. 2021c "Smoking Cessation: Fast Facts." Available at: https://www.cdc.gov/tobacco/data statistics/fact sheets/cessation/smoking-cessation-fastfacts/index.html

Choi, Anna, Dhaval Dave, and Joseph J. Sabia. 2019. "Smoke Gets in Your Eyes: Medical Marijuana Laws and Tobacco Cigarette Use." American Journal of Health Economics 5(3): 303-333.

Coley, Rebekah Levine, Claudia Kruzik, Marco Ghiani, Naoka Carey, Summer Sherburne Hawkins, and Christopher F. Baum. 2021. "Recreational Marijuana Legalization and Adolescent Use of Marijuana, Tobacco, and Alcohol." Journal of Adolescent Health 69(1): 41-49.

Dave, Dhaval, Bo Feng, and Michael Pesko. 2019. “The Effects of E-cigarette Minimum Legal Sale Age Laws on Youth Substance Use.” Health Economics 28(3): 419-436.

Driezen, P., Gravely, S., Wadsworth, E., Smith, D.M., Loewen, R., Hammond, D., Li, L., Abramovici, H., McNeill, A., Borland, R. and Cummings, K.M., 2022. "Increasing Cannabis Use Is 
Associated With Poorer Cigarette Smoking Cessation Outcomes: Findings From the ITC Four Country Smoking and Vaping Surveys, 2016-2018." Nicotine and Tobacco Research 24(1):53-59.

Farrelly, M. C., Bray, J. W., Zarkin, G. A., \& Wendling, B. W. 2001. “The Joint Demand for Cigarettes and Marijuana: Evidence from the National Household Surveys on Drug Abuse." Journal of Health Economics 20(1): 51-68

Fiz, Jimena, Marta Durán, Dolors Capellà, Jordi Carbonell, and Magí Farré. 2011. "Cannabis Use in Patients With Fibromyalgia: Effect on Symptoms Relief and Health-Related Quality of Life." PloS One 6, no. 4: e18440.

Gallup. 2020. “Support for Legal Marijuana Inches Up to New High of 68\%.” Available at: https://news.gallup.com/poll/323582/support-legal-marijuana-inches-new-high.aspx

Geissler, K. H., Kaizer, K., Johnson, J. K., Doonan, S. M., \& Whitehill, J. M. (2020). Evaluation of availability of survey data about cannabis use. JAMA network open, 3(6), e206039-e206039.

Goodman-Bacon, Andrew. 2021. "Difference-In-Differences With Variation in Treatment Timing." Forthcoming, Journal of Econometrics.

Goodwin, R.D., Pacek, L.R., Copeland, J., Moeller, S.J., Dierker, L., Weinberger, A., Gbedemah, M., Zvolensky, M.J., Wall, M.M. and Hasin, D.S., 2018. "Trends in Daily Cannabis Use Among Cigarette Smokers: United States, 2002-2014.” American Journal of Public Health, 108(1): 137-142.

Gruber, Jonathan, and Botond Köszegi. 2001. "Is Addiction "Rational”? Theory and Evidence." The Quarterly Journal of Economics, 116(4), pp.1261-1303.

Hall, Wayne, MacDonald Christie, and David Currow. 2005. "Cannabinoids and Cancer: Causation, Remediation, and Palliation." The Lancet Oncology 6(1): 35-42.

Hansen, Benjamin, Drew McNichols, and Joseph J. Sabia, Bryan, Calvin. 2020. "Do State Tobacco 21 Laws Work?" (No. w28173). National Bureau of Economic Research. Available at: https://www.nber.org/papers/w28173

Holford, T. R., Levy, D. T., McKay, L. A., Clarke, L., Racine, B., Meza, R., ... \& Feuer, E. J. (2014). Patterns of birth cohort-specific smoking histories, 1965-2009. American journal of preventive medicine, 46(2), e31-e37.

Huang, J., Wang, Y., Duan, Z., Kim, Y., Emery, S.L. and Chaloupka, F.J., 2021. "Do E-cigarette Sales Reduce the Demand for Nicotine Replacement Therapy (NRT) Products in the US? Evidence from the Retail Sales Data." Preventive Medicine, 145, p.106376.

Hyland, A., Ambrose, B.K., Conway, K.P., Borek, N., Lambert, E., Carusi, C., Taylor, K., Crosse, S., Fong, G.T., Cummings, K.M. and Abrams, D., 2017. "Design and Methods of the Population Assessment of Tobacco and Health (PATH) Study." Tobacco Control 26(4): 371-378.

Lai, S., Lai, H., Page, J. B., \& McCoy, C. B., 2000. The association between cigarette smoking and drug abuse in the United States. Journal of addictive diseases, 19(4): 11-24. 
Leatherdale, S.T., Hammond, D.G., Kaiserman, M. and Ahmed, R., 2007. "Marijuana and Tobacco Use Among Young Adults in Canada: Are They Smoking What We Think They Are Smoking?” Cancer Causes \& Control 18(4): 391-397.

McClure, Erin A., Nathaniel L. Baker, Susan C. Sonne, Udi E. Ghitza, Rachel L. Tomko, LaTrice Montgomery, Shanna Babalonis, Garth E. Terry, and Kevin M. Gray. 2018. “'Tobacco Use During Cannabis Cessation: Use Patterns and Impact on Abstinence in a National Drug Abuse Treatment Clinical Trials Network Study." Drug and Alcohol Dependence 192: 59-66.

Miech, Richard A., Megan E. Patrick, Patrick M. O’Malley, Lloyd D. Johnston, and Jerald G. Bachman. 2020. “Trends in Reported Marijuana Vaping Among Us Adolescents, 2017-2019." Journal of the American Medical Association 323 (5): 475-476.

Miller, K. and B. Seo. 2018. "Tax Revenues When Substances Substitute: Marijuana, Alcohol, and Tobacco." Kelley School of Business Research Paper,(18-27).

National Academies of Sciences, Engineering, and Medicine. 2017. "The Health Effects of Cannabis and Cannabinoids: The Current State of Evidence and Recommendations for Research." Washington, D.C.: National Academies Press.

Neumark, David, JM Ian Salas, and William Wascher. 2014. "Revisiting the Minimum WageEmployment Debate: Throwing Out the Baby with the Bathwater?" Industrial and Labor Relations Review 67(3); 608-648.

Office of Disease Prevention and Health Promotion. 2020. "Behavioral Risk Factor Surveillance System.” U.S. Department of Health and Human Services. Available at: https://www.healthypeople.gov/2020/data-source/behavioral-risk-factor-surveillance-system.

Office of the Surgeon General. 2016. "Surgeon General's Report." Available at: https://addiction.surgeongeneral.gov/

Ong. 2016. "Will Legal Marijuana Lead To More People Smoking Tobacco?” Available at: https://www.npr.org/sections/health-shots/2016/11/18/502567273/will-legal-marijuana-lead-tomore-people-smoking-tobacco

Orzechowski, William and Robert Walker. 2021. "The Tax Burden on Tobacco, 1970-2019." Available at: https://chronicdata.cdc.gov/Policy/The-Tax-Burden-on-Tobacco-1970-2019/7nwe$\underline{3 a j} 9$

Pesko, M.F., Hughes, J.M. and Faisal, F.S., 2016. "The influence of electronic cigarette age purchasing restrictions on adolescent tobacco and marijuana use." Preventive medicine, 87; 207-212.

Ramo, Danielle, Kevin Delucchi, Sharon Hall, Howard Liu, and Judith Prochaska. 2013. "Marijuana and Tobacco Co-use in Young Adults: Patterns and Thoughts about Use." Journal of Studies on Alcohol and Drugs 74 (2): 301-10. 
Richter, K.P., Ahluwalia, H.K., Mosier, M.C., Nazir, N. and Ahluwalia, J.S., 2002. "A Population Based Study of Cigarette Smoking Among Illicit Drug Users in the United States." Addiction 97(7): 861-869.

Sabia, Joseph J., Dhaval Dave, Fawaz Alotaibi, and Daniel Rees. 2021. "Is Recreational Marijuana a Gateway to Harder Drug Use and Crime?” National Bureau of Economic Research (NBER) Working Paper No. 29038. Available at: https://www.nber.org/papers/w29038

Schauer, G.L., Berg, C.J., Kegler, M.C., Donovan, D.M. and Windle, M. 2015. “Assessing the Overlap Between Tobacco and Marijuana: Trends in Patterns of Co-use of Tobacco and Marijuana in Adults From 2003-2012." Addictive Behaviors (49): 26-32.

Substance Abuse and Mental Health Data Archive (SAMHDA). 2015. "National Survey on Drug Use and Health (NSDUH-2002-2014).” Available at: https://www.datafiles.samhsa.gov/study/nationalsurvey-drug-use-and-health-nsduh-2002-2014nid16959.

Sun, L. and Abraham, S., 2021. "Estimating Dynamic Treatment Effects in Event Studies With Heterogeneous Treatment Effects.” Journal of Econometrics 225(2): 175-199.

Tashkin, Donald P. 2013 "Effects of Marijuana Smoking on the Lung." Annals of the American Thoracic Society 10.3: 239-247.

Trivers, K.F., Phillips, E., Gentzke, A.S., Tynan, M.A. and Neff, L.J., 2018. "Prevalence of cannabis use in electronic cigarettes among US youth.” JAMA: Pediatrics 172(11): 1097-1099.

Truth Initiative. 2019. “How Much Nicotine Is in JUUL?” Truth Initiative. February 2019. Available at: https://truthinitiative.org/research-resources/emerging-tobacco-products/how-muchnicotinejuul

United States Department of Health and Human Services. National Institutes of Health. National Institute on Drug Abuse, and United States Department of Health and Human Services. Food and Drug Administration. Center for Tobacco Products. Population Assessment of Tobacco and Health (PATH) Study [United States] Restricted-Use Files. Inter-university Consortium for Political and Social Research [distributor], 2021-12-16. https://doi.org/10.3886/ICPSR36231.v29

U.S. Department of Health and Human Services. (2014). The Health Consequences of Smoking: 50 Years of Progress. A Report of the Surgeon General. Atlanta, GA: U.S. Department of Health and Human Services, Centers for Disease Control and Prevention, National Center for Chronic Disease Prevention and Health Promotion, Office on Smoking and Health. Printed with corrections, January 2014.

U.S. Department of Health and Human Services. 2020. "Tobacco Use." Available at: https://health.gov/healthypeople/objectives-and-data/browse-objectives/tobacco-use

Veligati, S., Howdeshell, S., Beeler-Stinn, S., Lingam, D., Allen, P.C., Chen, L.S. and Grucza, R.A., 2020. "Changes in Alcohol and Cigarette Consumption in Response to Medical and Recreational 
Cannabis Legalization: Evidence From Us State Tax Receipt Data." International Journal of Drug Policy, 75, p.102585.

Volkow, N.D., Baler, R.D., Compton, W.M. and Weiss, S.R. 2014. “Adverse Health Effects of Marijuana Use.” New England Journal of Medicine 370(23): 2219-2227.

Vuolo, M., Lindsay, S. L., \& Kelly, B. C, 2022. "Further Consideration of the Impact of Tobacco Control Policies on Young Adult Smoking in Light of the Liberalization of Cannabis Policies." Nicotine and Tobacco Research 24(1): 60-68.

Wang, G.S., Roosevelt, G. and Heard, K., 2013. "Pediatric Marijuana Exposures in a Medical Marijuana State.” JAMA: Pediatrics 167(7): 630-633.

Ware, M.A., Wang, T., Shapiro, S., Robinson, A., Ducruet, T., Huynh, T., Gamsa, A., Bennett, G.J. and Collet, J.P., 2010. "Smoked Cannabis for Chronic Neuropathic Pain: A Randomized Controlled Trial.” Cmaj, 182(14), pp.E694-E701.

Wolfers, J., 2006. "Did Unilateral Divorce Laws Raise Divorce Rates? A Reconciliation and New Results." American Economic Review 96(5): 1802-1820.

Xu, X., Bishop, E. E., Kennedy, S. M., Simpson, S. A., \& Pechacek, T. F., 2015. "Annual healthcare spending attributable to cigarette smoking: an update." American journal of preventive medicine, 48(3), 326-333. 
Figure 1. Event-Study Analyses of RMLs and Tobacco Use, Using Two-Way Fixed Effects (TWFE) Estimates, NSDUH, 2002-2019

Panel (a): Ages 18 and Older

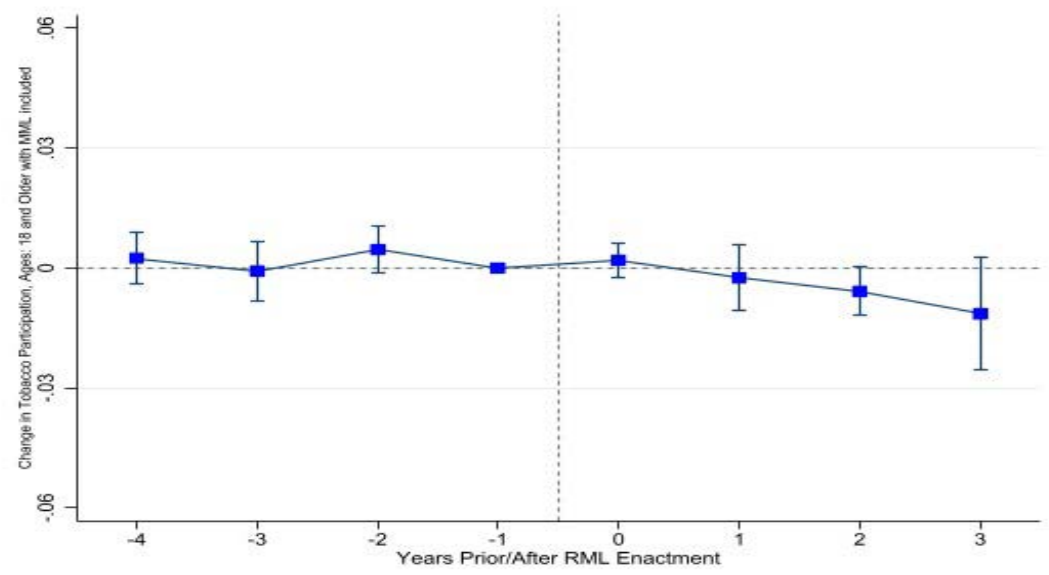

Panel (b): Ages 18-25

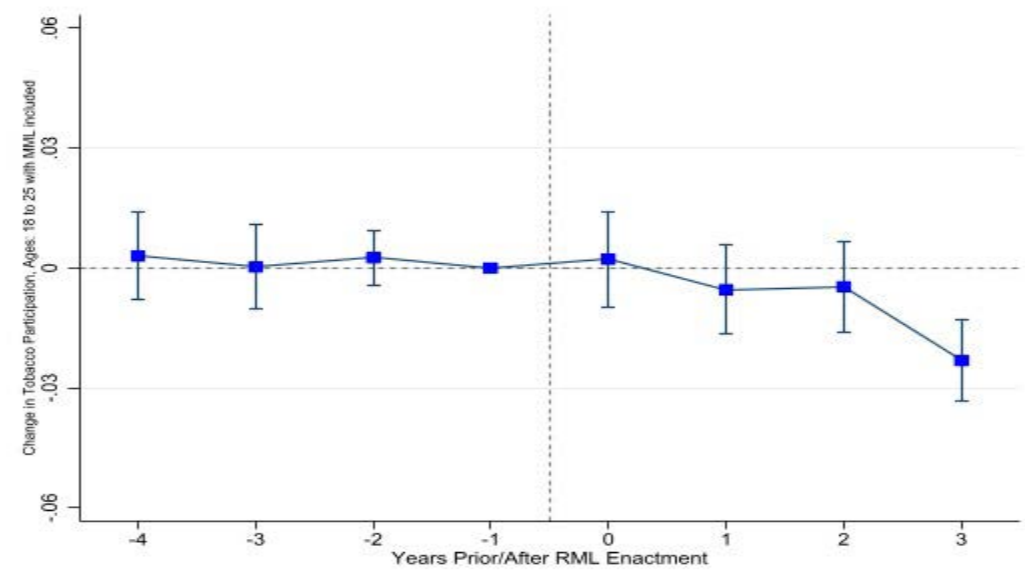

Panel (c): Ages 26 and Older

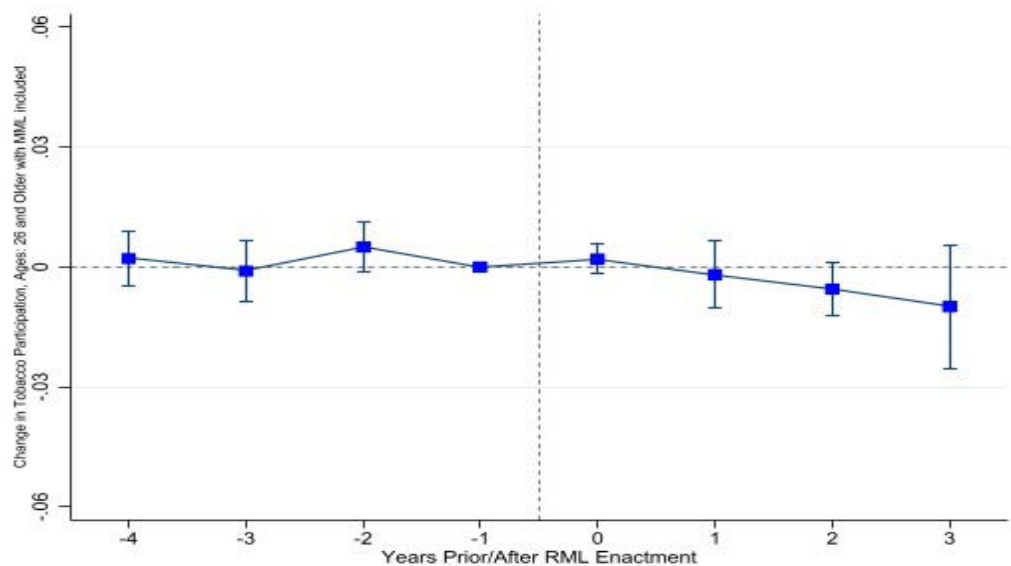

Notes: Population weighted OLS estimates (and their 95\% CIs) from a regression model are shown. Regressions used to generate the OLS estimates include state fixed effects, year fixed effects, and medical marijuana laws. 
Figure 2. Event-Study Analyses of RMLs and Tobacco Use, Using Callaway-Sant'Anna (CS) Estimates, NSDUH, 2002-2019

Panel (a): Ages 18 and Older

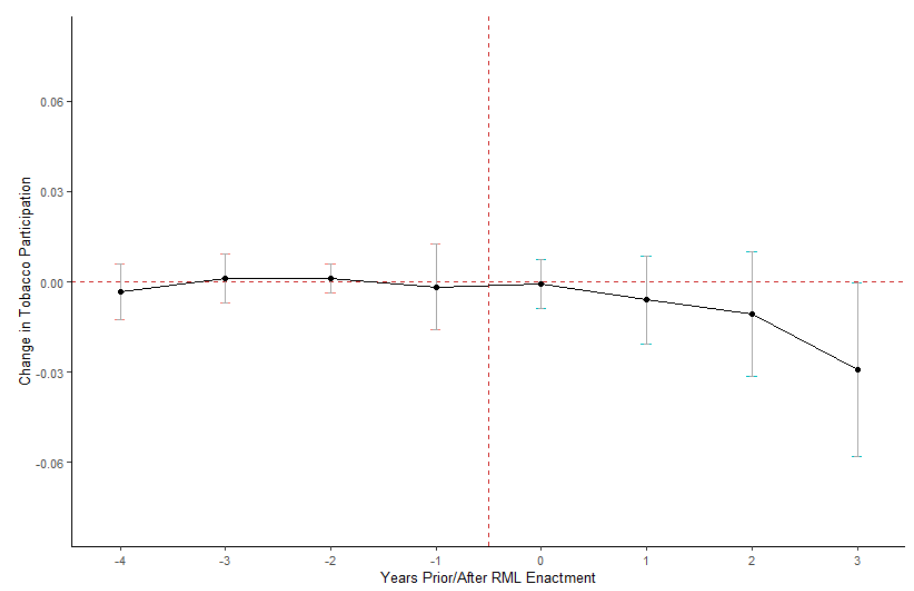

Panel (b): Ages 18-25

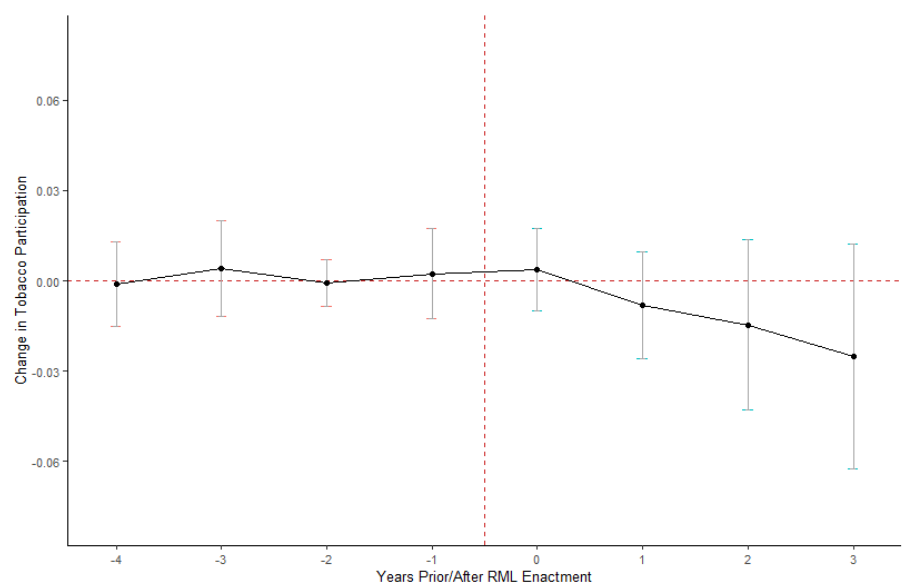

Panel (c): Ages 26 and Older

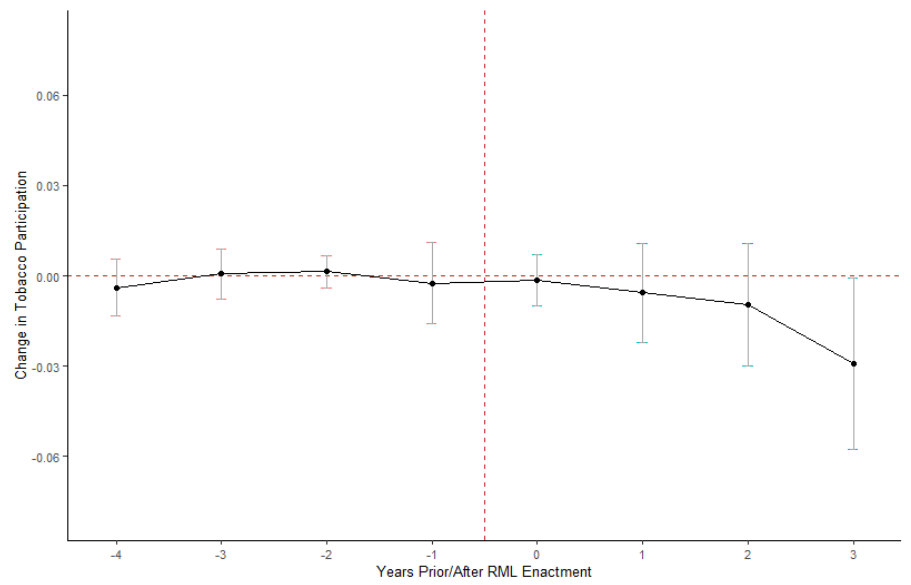

Note: Callaway-Sant'Anna (2021) estimates (and their 95\% CIs) are shown above. 
Figure 3. Event-Study Analyses of RMLs and Cigarette Use, Using Two-Way Fixed Effects (TWFE) Estimates, NSDUH, 2002-2019

Panel (a): Ages 18 and Older

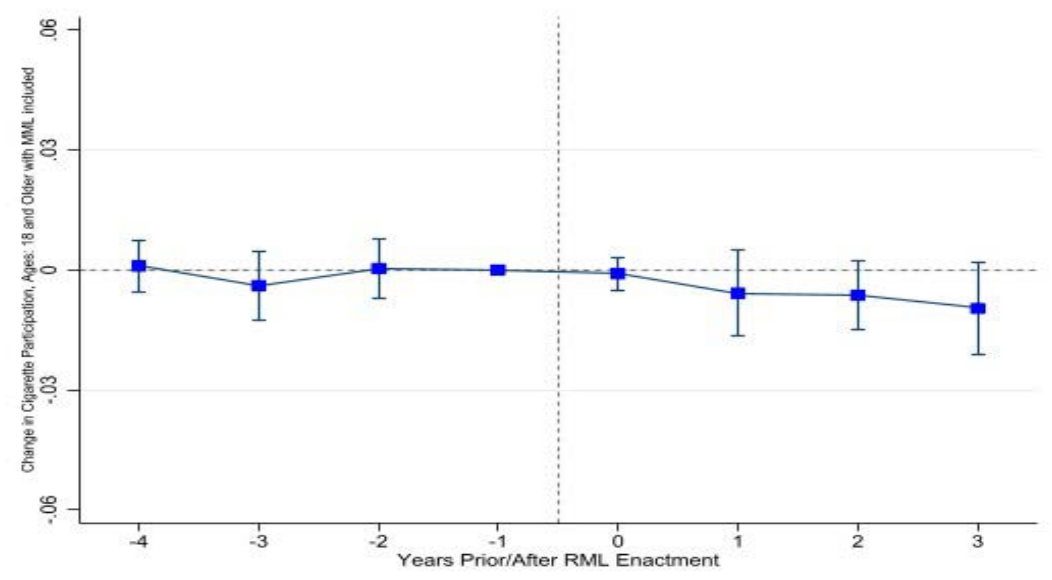

Panel (b): Ages 18-25

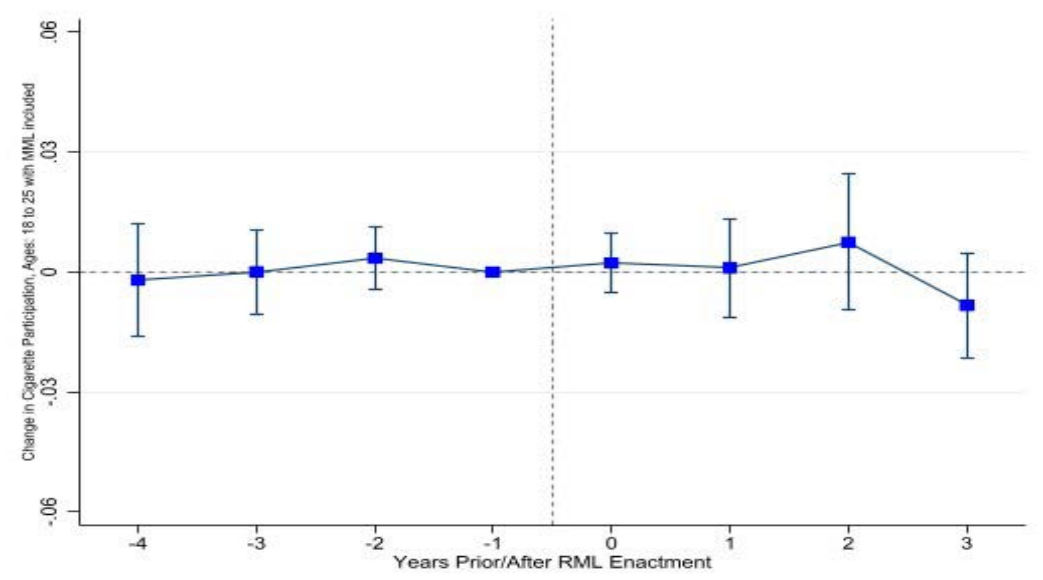

Panel (c): Ages 26 and Older

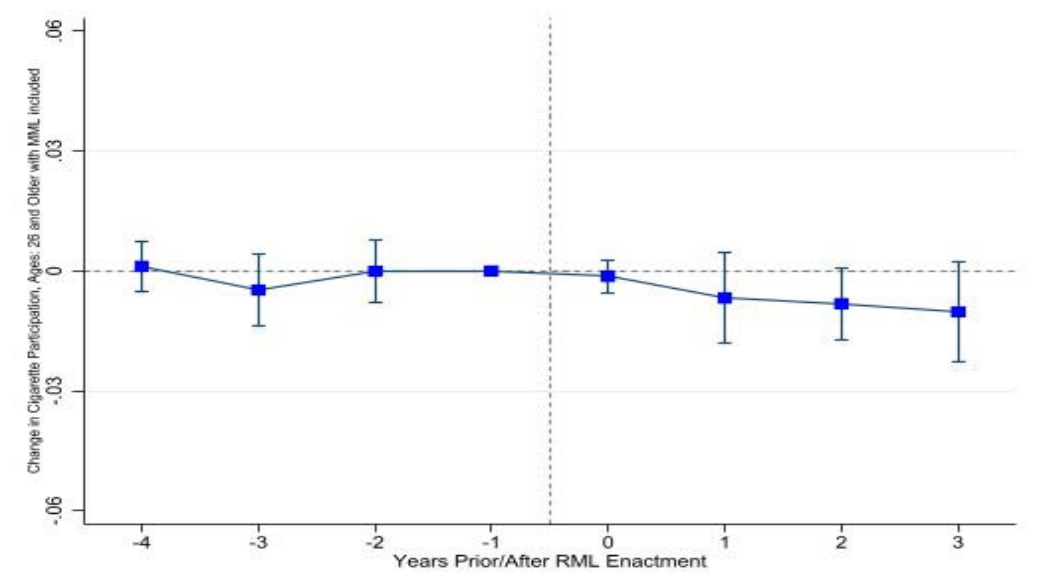

Notes: Population weighted OLS estimates (and their 95\% CIs) from a regression model are shown. Regressions used to generate the OLS estimates include state fixed effects, year fixed effects, and medical marijuana laws. 
Figure 4. Event-Study Analyses of RMLs and Cigarette Use, Using Callaway-Sant'Anna (CS) Estimates, NSDUH, 2002-2019

Panel (a): Ages 18 and Older
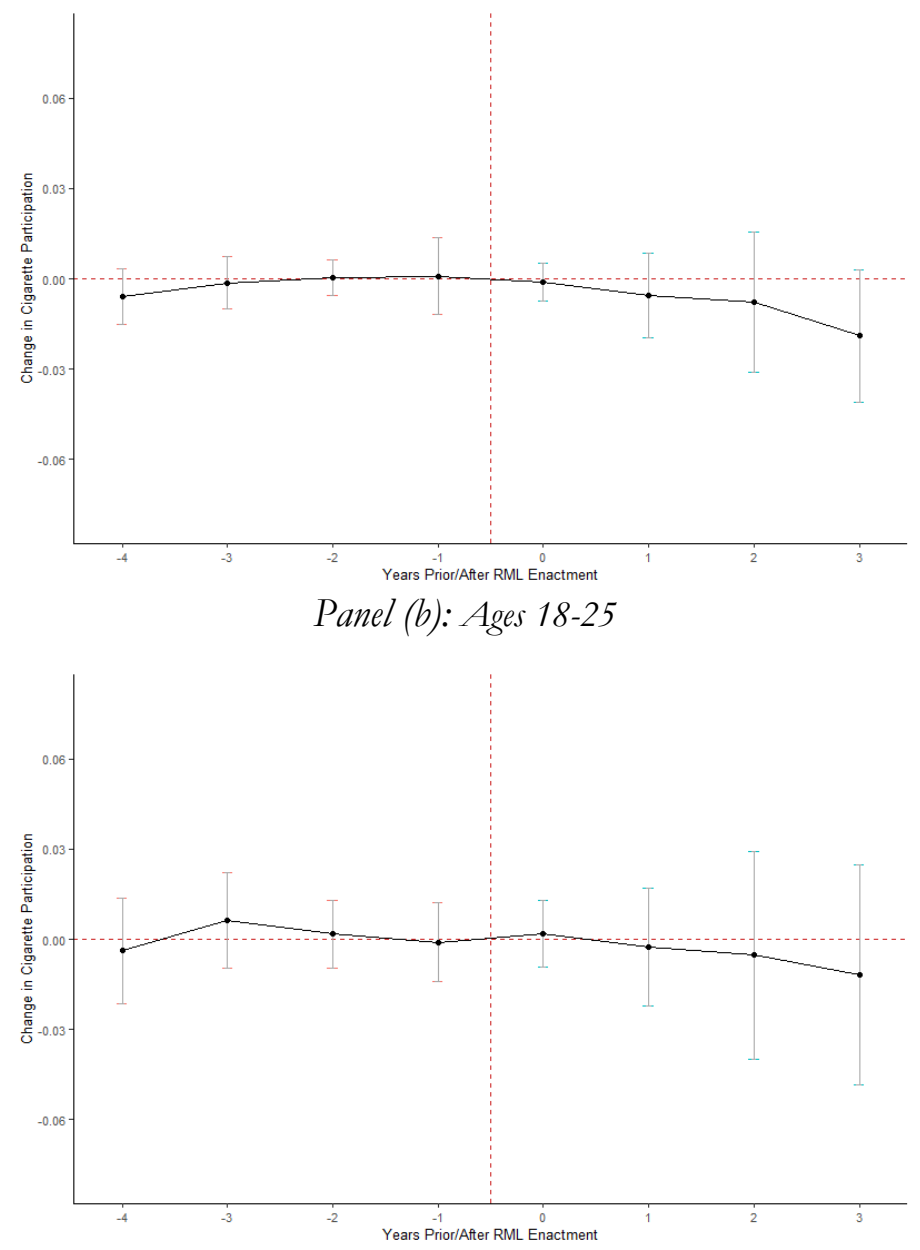

Panel (c): Ages 26 and Older

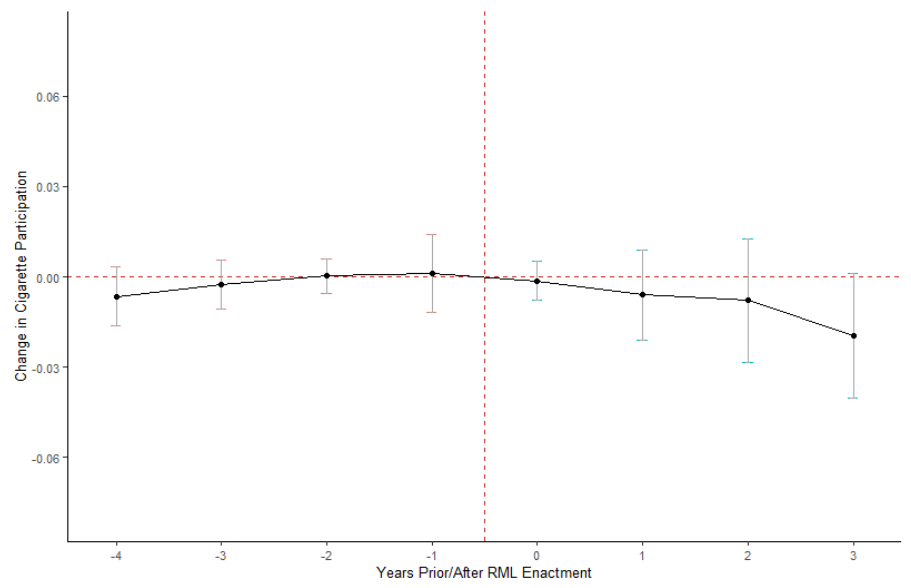

Notes: Callaway-Sant'Anna (2021) estimates (and their 95\% CIs) are shown above. 
Figure 5. Event-Study Analyses of RMLs and Tobacco Use Among Ages 18 and Older, Using Callaway-Sant'Anna (CS) Estimates, BRFSS, 2000-2019

Panel (a): Any Cigarette Use

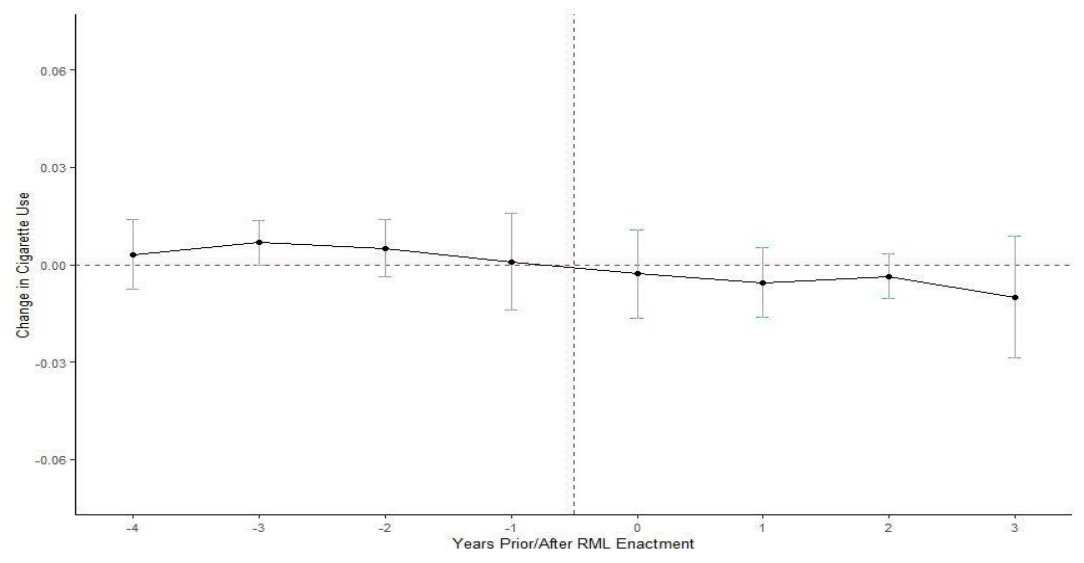

Panel (b): Everyday Smoking

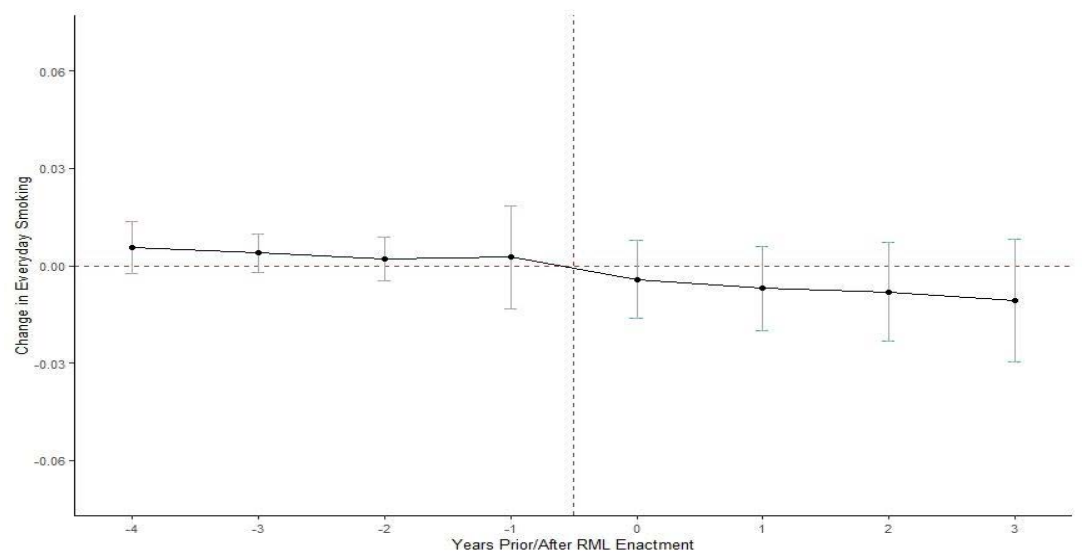

Panel (c): Quit

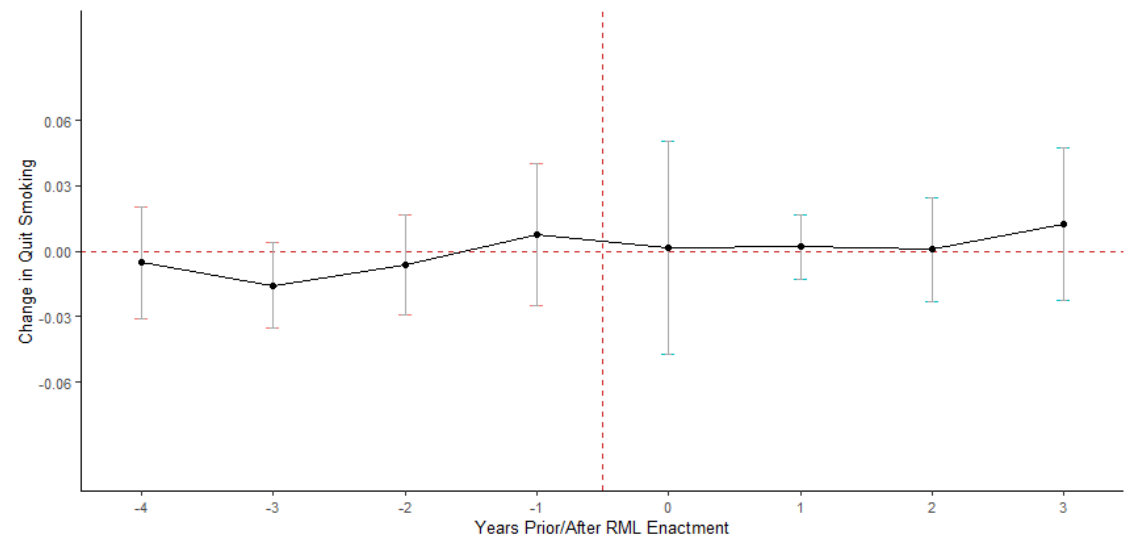

Notes: Callaway-Sant'Anna (2021) estimates (and their 95\% CIs) are shown above. 
Figure 6. Event-Study Analyses of RMLs and Cigarette Use, by Age, Using Callaway-Sant'Anna (CS) Estimates, BRFSS, 2000-2019

Panel (a): Any Cigarette Use, Ages 18-to-20

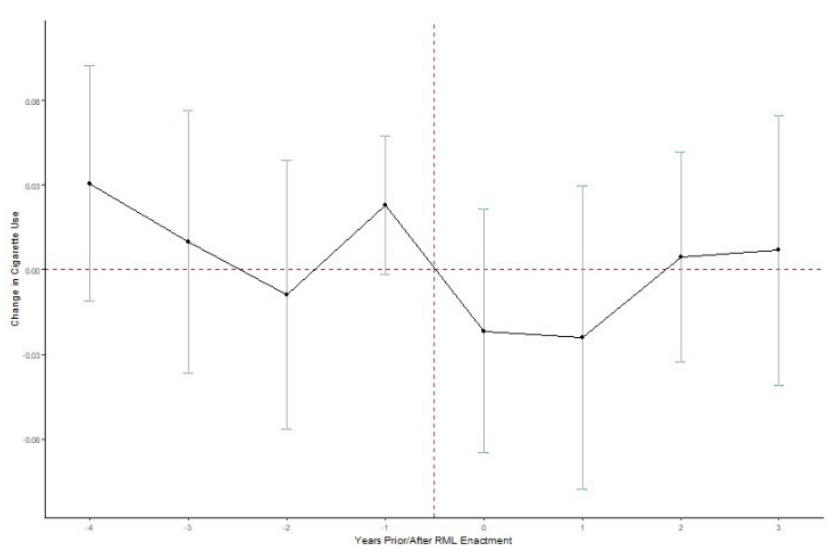

Panel (c): Any Cigarette Use, Ages 21 and Older

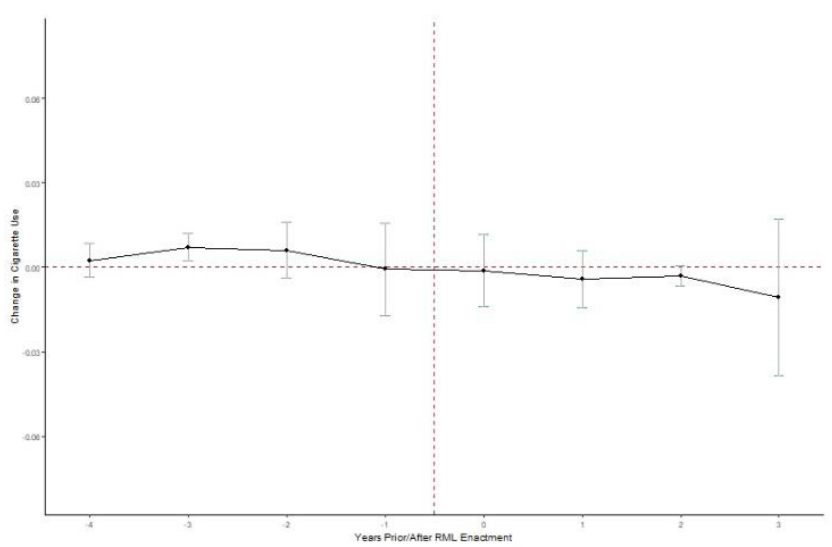

Panel (b): Everyday Smoking, Ages 18-to-20

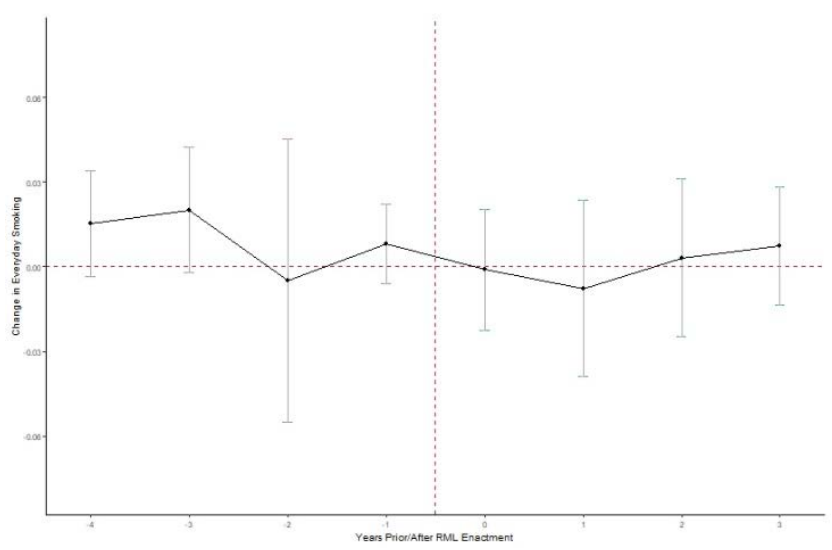

Panel (d): Everyday Smoking, Ages 21 and Older

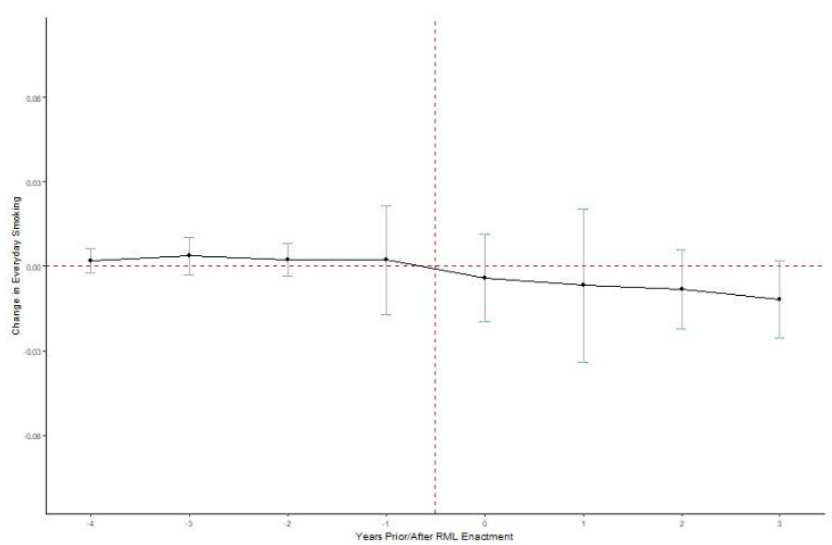

Notes: Callaway-Sant'Anna (2021) estimates (and their 95\% CIs) are shown above. 
Figure 7. Heterogeneity in RML Effects by Gender, Race, and Education, Ages 18 and Older, BRFSS, 2000-2019

Panel (a): Cigarette Use

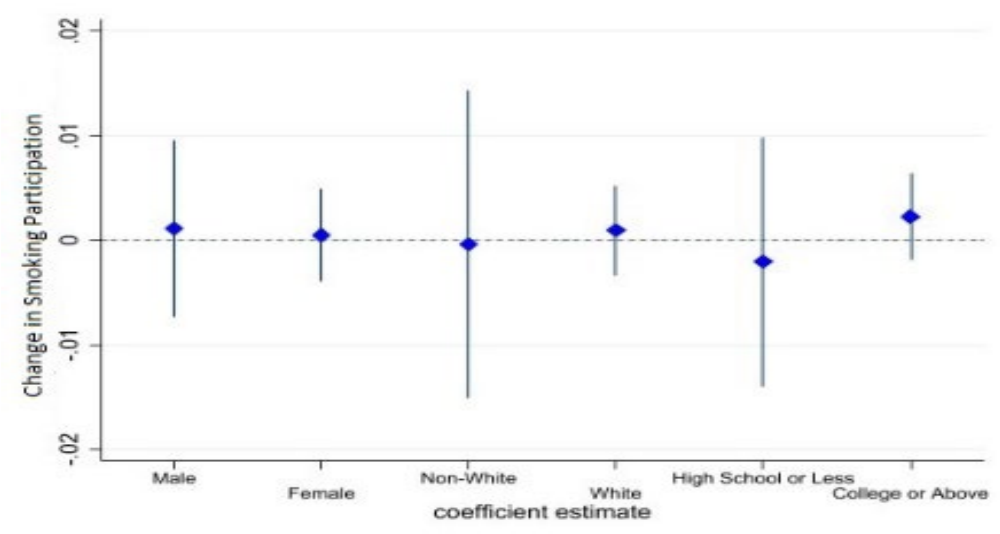

Panel (b): Everyday Smoking

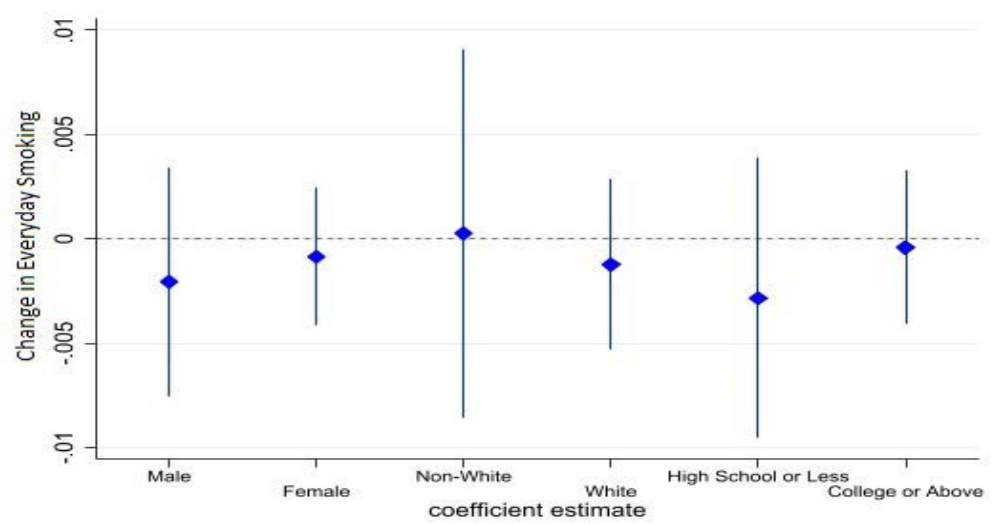

Panel (c): E-Cigarette Use

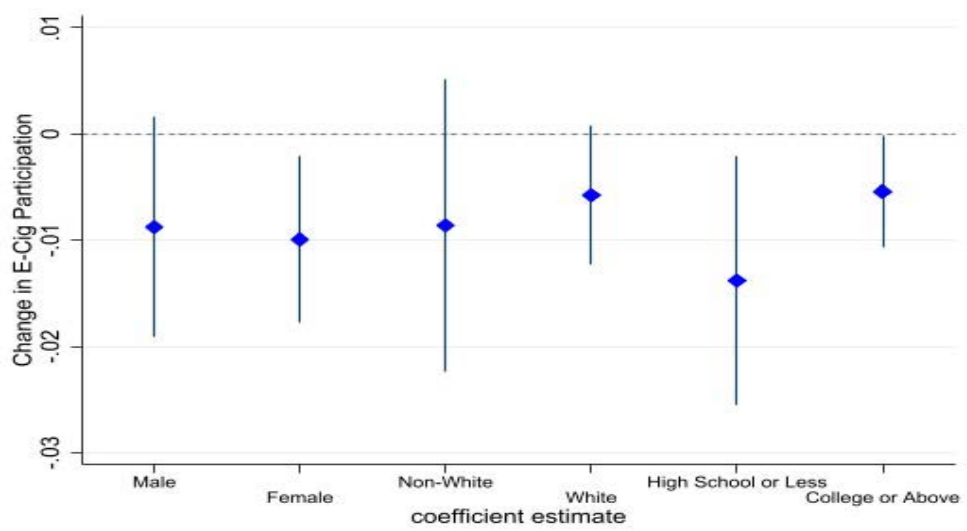

Notes: This figure presents the coefficient comparison for RML using different BRFSS subgroups. Population weighted OLS estimates (and their 95\% CIs) from a regression model are shown. Regressions used to generate the OLS estimates include state, year fixed effects, and state specific linear time trends. 
Figure 8. Event-Study Analyses of RMLs and Tobacco Use Among Ages 18 and Older, Using Two-Way Fixed Effects (TWFE) Estimates, CPS-TUS, 2000-2019

Panel (a): Current Tobacco Use

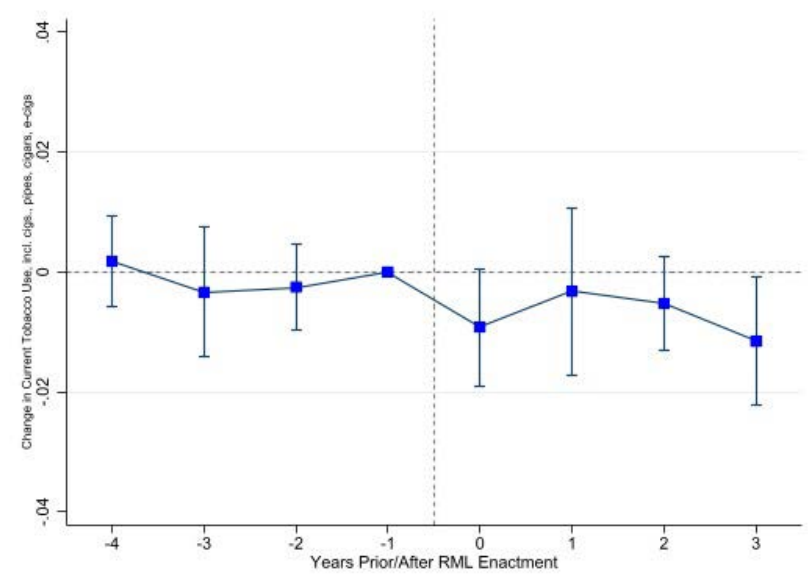

Panel (c): Everyday Cigarette Use

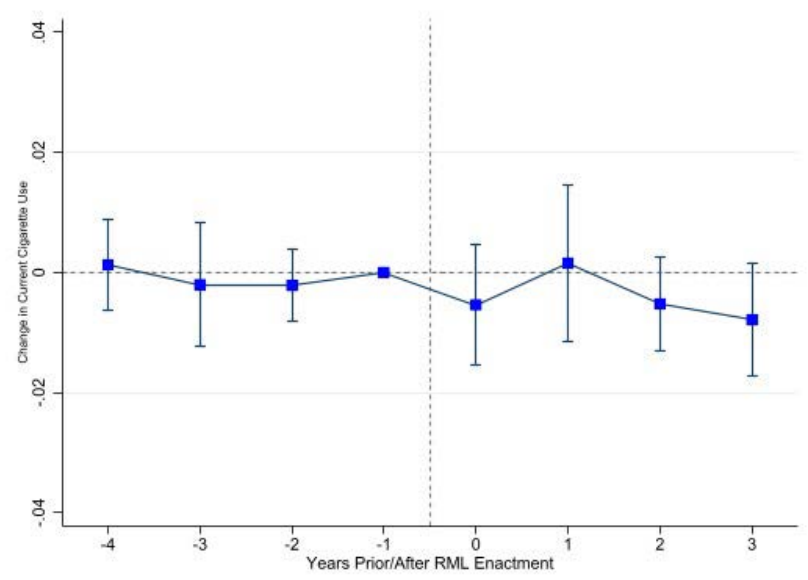

Panel (b): Current Cigarette Use

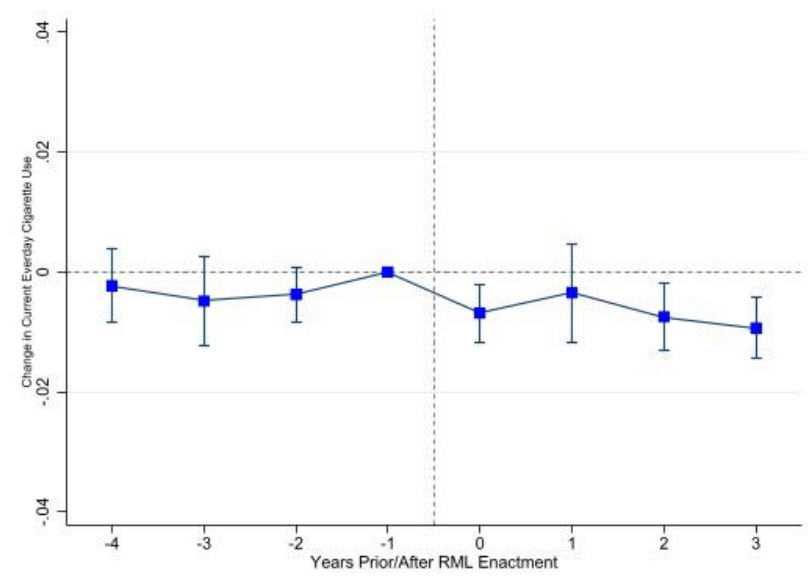

Panel (d): Current E-cigarette Use

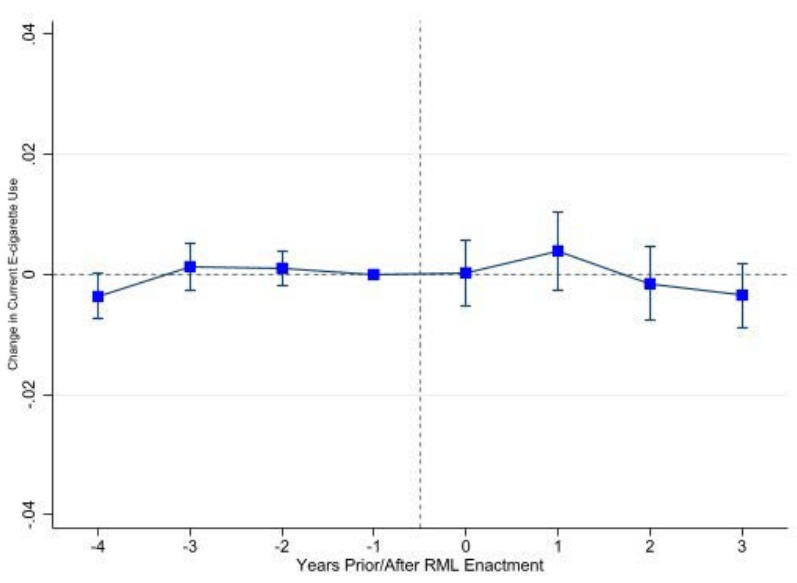


Figure 9. Event-Study Analyses of RMLs and Tobacco Use Among Ages 18 and Older, Using Callaway-Sant'Anna (CS) Estimates, CPS-TUS, 2000-2019

Panel (a): Current Tobacco Use
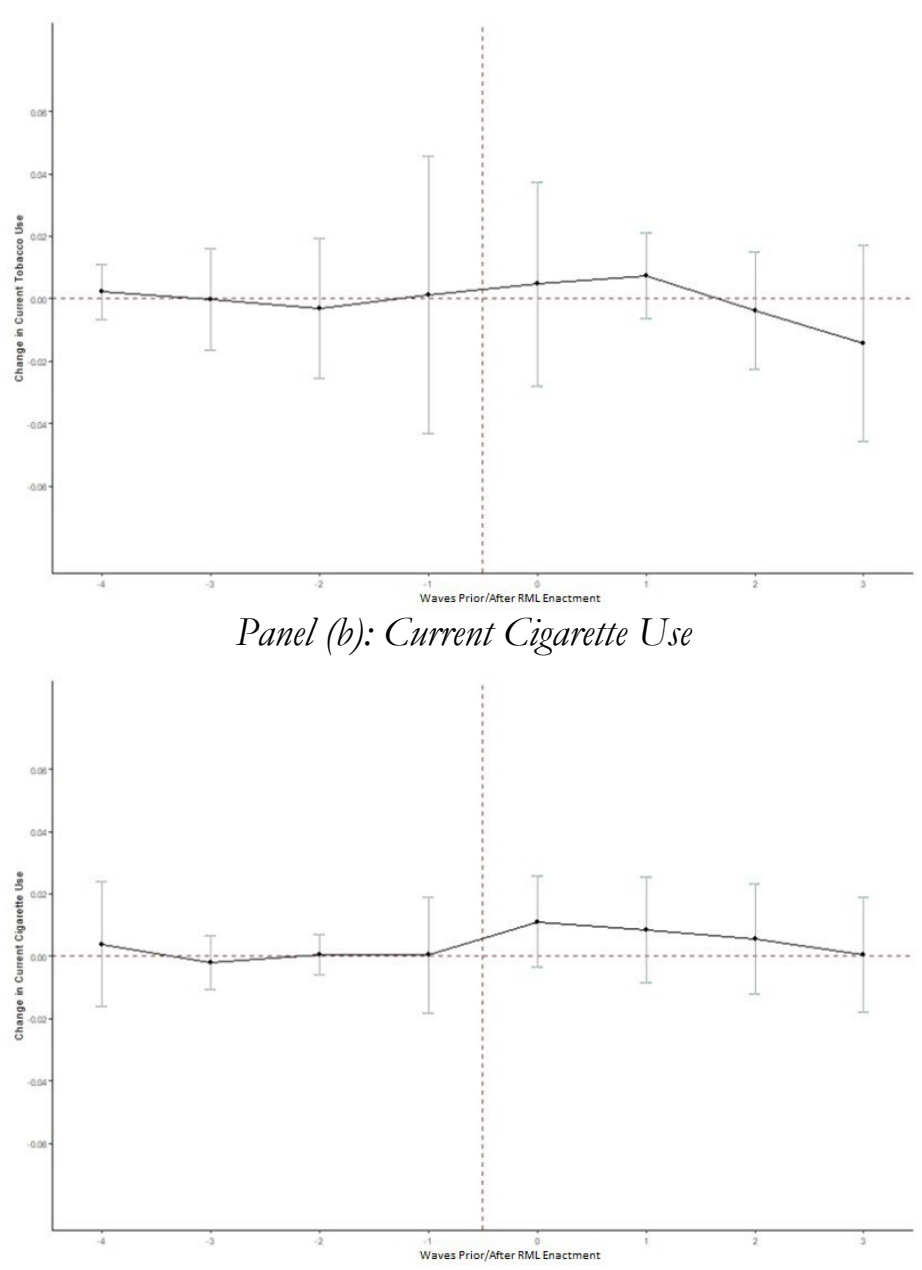

Panel (c): Everyday Cigarette Use

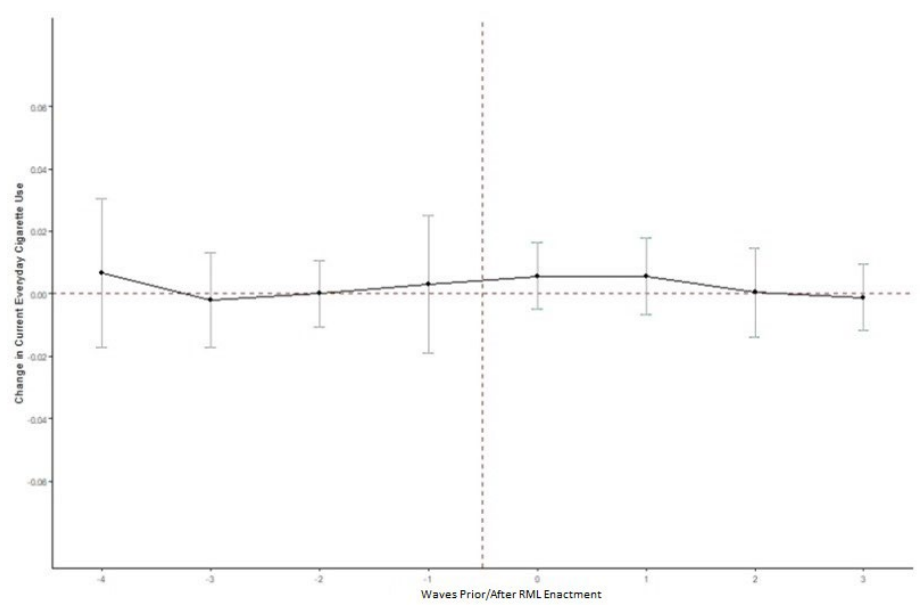

Notes: Callaway-Sant'Anna (2021) estimates (and their 95\% CIs) are shown above. 


\section{Figure 10. Heterogeneity in RML Effects by Gender, Race, and Education,}

PATH, 2013-2019

\section{Panel (a): Marijuana Use}

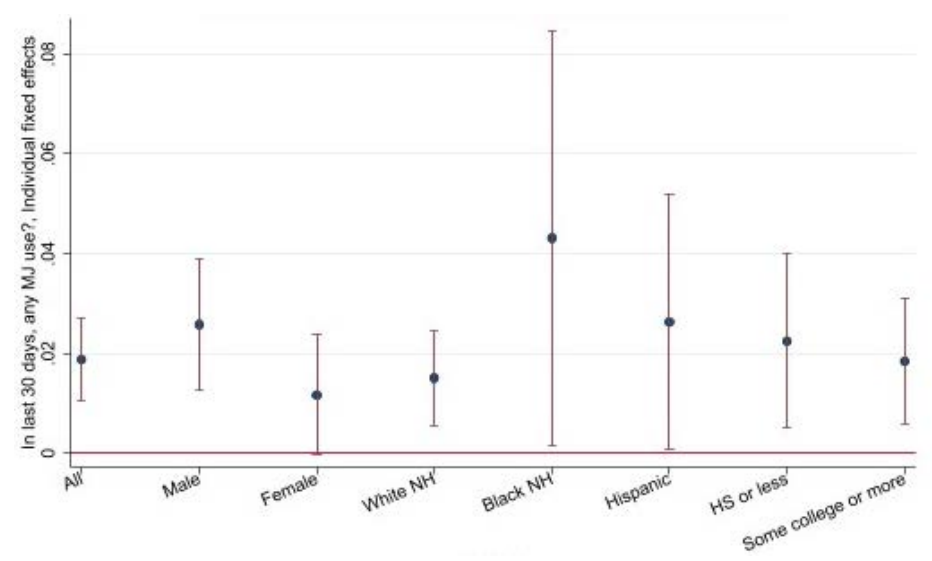

Panel (b): Tobacco Use

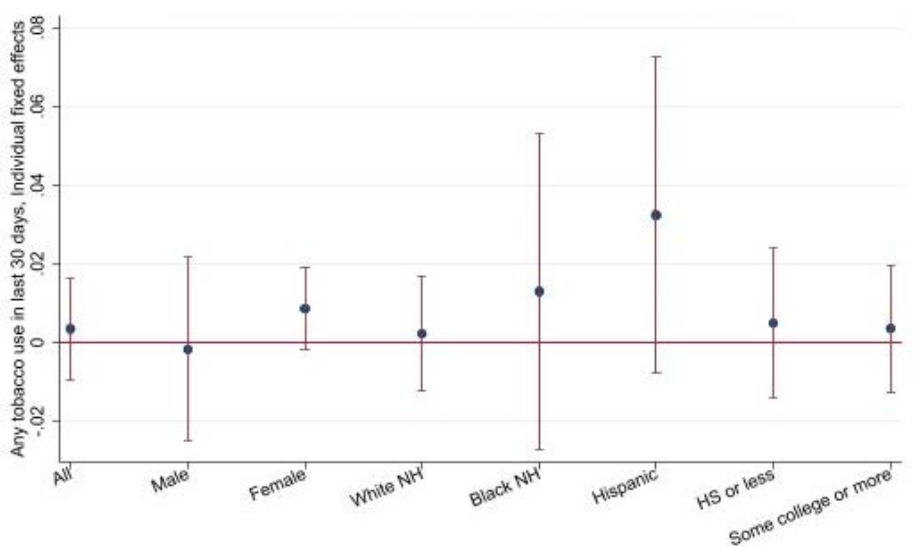

Notes: This figure presents the coefficient comparison for RML using different PATH subgroups. Population weighted OLS estimates (and their 95\% CIs) from a regression model are shown. Regressions used to generate the OLS estimates include state, yearmonth, wave, and individual fixed-effects. 
Table 1. Summary Statistics

\begin{tabular}{|c|c|c|c|}
\hline & $\begin{array}{c}\text { Ages } 18 \text { and } \\
\text { Older }\end{array}$ & $\begin{array}{c}\text { Ages } \\
18 \text { to } 25\end{array}$ & $\begin{array}{c}\text { Ages } 26 \text { and } \\
\text { Older }\end{array}$ \\
\hline \multicolumn{4}{|l|}{ Panel I: NSDUH ${ }^{a}$} \\
\hline \multirow[t]{2}{*}{ Marijuana Use } & 0.075 & 0.188 & 0.055 \\
\hline & $(0.025)$ & $(0.042)$ & $(0.024)$ \\
\hline \multirow[t]{2}{*}{ Tobacco Use } & 0.283 & 0.378 & 0.266 \\
\hline & $(0.052)$ & $(0.082)$ & $(0.049)$ \\
\hline \multirow[t]{2}{*}{ Cigarette Use } & 0.236 & 0.318 & 0.222 \\
\hline & $(0.045)$ & $(0.080)$ & $(0.041)$ \\
\hline \multirow[t]{2}{*}{ Panel II: BRFSS ${ }^{\mathrm{b}}$} & Ages 18 and & Ages & Ages 21 and \\
\hline & Older & 18 to 20 & Older \\
\hline \multirow[t]{2}{*}{ Cigarette Use } & 0.185 & 0.166 & 0.186 \\
\hline & $(0.388)$ & $(0.372)$ & $(0.389)$ \\
\hline \multirow{2}{*}{ Everyday Smoking } & 0.133 & 0.107 & 0.134 \\
\hline & $(0.339)$ & $(0.309)$ & $(0.341)$ \\
\hline \multirow[t]{2}{*}{ Quit } & 0.564 & 0.215 & 0.574 \\
\hline & $(0.496)$ & $(0.411)$ & $(0.494)$ \\
\hline \multirow[t]{2}{*}{ E-Cigarette Use } & 0.034 & 0.133 & 0.031 \\
\hline & $(0.181)$ & $(0.340)$ & $(0.175)$ \\
\hline \multirow[t]{2}{*}{ Panel III: CPS-TUS } & Ages 18 and & Ages & Ages 21 and \\
\hline & Older & 18 to 20 & Older \\
\hline \multirow[t]{2}{*}{ Tobacco Use } & 0.190 & 0.177 & 0.191 \\
\hline & $(0.392)$ & $(0.381)$ & $(0.393)$ \\
\hline \multirow[t]{2}{*}{ Cigarette Use } & 0.169 & 0.153 & 0.170 \\
\hline & $(0.374)$ & $(0.360)$ & $(0.375)$ \\
\hline \multirow[t]{2}{*}{ Daily Cigarette Use } & 0.133 & 0.116 & 0.134 \\
\hline & $(0.340)$ & $(0.320)$ & $(0.341)$ \\
\hline \multirow[t]{2}{*}{ E-cigarette Use } & 0.023 & 0.048 & 0.022 \\
\hline & $(0.151)$ & $(0.214)$ & $(0.147)$ \\
\hline \multirow[t]{2}{*}{ Panel IV: PATH ${ }^{\mathrm{c}}$} & Ages 18 and & Ages & Ages 21 and \\
\hline & Older & 18 to 20 & Older \\
\hline \multirow[t]{2}{*}{ Marijuana Use } & 0.103 & 0.228 & 0.096 \\
\hline & $(0.303)$ & $(0.419)$ & $(0.294)$ \\
\hline \multirow[t]{2}{*}{ Tobacco Use } & 0.286 & 0.374 & 0.281 \\
\hline & $(0.452)$ & $(0.484)$ & $(0.449)$ \\
\hline \multirow[t]{2}{*}{ Cigarette Use } & 0.216 & 0.208 & 0.216 \\
\hline & $(0.411)$ & $(0.406)$ & $(0.412)$ \\
\hline \multirow[t]{2}{*}{ Daily Cigarette Use } & 0.144 & 0.078 & 0.148 \\
\hline & $(0.352)$ & $(0.268)$ & $(0.355)$ \\
\hline \multirow[t]{2}{*}{ E-cigarette Use } & 0.069 & 0.178 & 0.062 \\
\hline & $(0.253)$ & $(0.383)$ & $(0.242)$ \\
\hline
\end{tabular}

aMeans are weighted using the relevant adult state population.

bMean coefficients; SD in parentheses. Means are weighted using sample weights in BRFSS.

c Means are weighted using PATH survey weights. 
Table 1, Continued

\begin{tabular}{lcc}
\hline & Mean & SD \\
\hline Panel V: State-Level Control Variables & & 0.006 \\
\hline Share of Female & 0.508 & 0.129 \\
Share of Hispanic & 0.162 & 0.081 \\
Share of Black & 0.122 & 0.025 \\
Share of College & 0.170 & 1.772 \\
Mean Age & 37.494 & 2.051 \\
Unemployment Rate & 6.207 & 2.746 \\
Poverty Rate & 14.072 & 5637.465 \\
Average State Income & 34342.154 & 1.200 \\
Cigarette Excise Tax & 2.194 & 0.284 \\
Index of Indoor Smoking Restrictions & 0.683 & 0.523 \\
Minimum Age for Cigarette Sales & 18.148 & 0.289 \\
E-cigarette Tax & 0.059 & 0.230 \\
Index of Indoor Vaping Restrictions & 0.095 & 0.459 \\
E-cigarette Minimum Sales Age & 0.361 & 0.157 \\
EITC Refundable Credit Rate & 0.078 & 1.386 \\
Minimum Wage & 7.200 & 0.474 \\
Governor is Democrat & 0.447 & 0.388 \\
ACA Medicaid Expansion & 0.201 & 0.242 \\
Beer Tax per Gallon & 0.271 & 0.372 \\
Prescription Drug Monitoring Program & 0.817 & \\
\hline
\end{tabular}


Table 2. Recreational Marijuana Laws and Marijuana Use, Ages 18 and Older, NSDUH, 2002-2019

\begin{tabular}{|c|c|c|c|c|c|c|}
\hline & \multicolumn{5}{|c|}{$\begin{array}{l}\text { Two-Way Fixed Effects } \\
\text { (TWFE) }\end{array}$} & \multirow{2}{*}{$\begin{array}{c}\text { Callaway- } \\
\text { Sant'Anna (CS) } \\
(6)\end{array}$} \\
\hline & $(1)$ & $(2)$ & (3) & (4) & (5) & \\
\hline & \multicolumn{6}{|c|}{ Panel I: Overall RML Effect } \\
\hline \multirow[t]{2}{*}{ RML } & $0.0368^{* * *}$ & $0.0346^{* * *}$ & $0.0429^{* * *}$ & $0.0414^{* * *}$ & $0.0205^{* * *}$ & $0.0310^{* *}$ \\
\hline & $(0.00719)$ & $(0.00765)$ & $(0.00498)$ & $(0.00462)$ & $(0.00705)$ & $(0.0040)$ \\
\hline \multirow[t]{2}{*}{ Pre-Treatment Mean DV } & 0.0745 & 0.0745 & 0.0745 & 0.0745 & 0.0745 & 0.0745 \\
\hline & \multicolumn{6}{|c|}{ Panel II: Lagged RML Effects } \\
\hline \multirow[t]{2}{*}{ Year of RML Enactment } & $0.0104^{* * *}$ & $0.0102^{* * *}$ & $0.0146^{* * *}$ & $0.0159^{* * *}$ & $0.0113^{* * *}$ & $0.0140^{* * *}$ \\
\hline & $(0.00331)$ & $(0.00329)$ & $(0.00277)$ & $(0.00309)$ & $(0.00334)$ & $(0.0033)$ \\
\hline \multirow[t]{2}{*}{1 Year After RML } & $0.0151^{* *}$ & $0.0149^{* *}$ & $0.0227^{* * *}$ & $0.0245^{* * *}$ & $0.0159^{* *}$ & $0.0245^{* *}$ \\
\hline & $(0.00618)$ & $(0.00637)$ & $(0.00576)$ & $(0.00562)$ & $(0.00599)$ & $(0.0072)$ \\
\hline \multirow[t]{2}{*}{2 Year After RML } & $0.0161^{* *}$ & $0.0161^{* *}$ & $0.0253^{* * *}$ & $0.0278^{* * *}$ & $0.0168^{* *}$ & $0.0244^{* *}$ \\
\hline & $(0.00607)$ & $(0.00654)$ & $(0.00796)$ & $(0.00824)$ & $(0.00812)$ & $(0.0083)$ \\
\hline \multirow[t]{2}{*}{3 Years + After RML } & $0.0377^{* * *}$ & $0.0393^{* * *}$ & $0.0383^{* * *}$ & $0.0376^{* * *}$ & $0.0185^{* * *}$ & $0.0259^{* *}$ \\
\hline & $(0.00244)$ & $(0.00234)$ & $(0.00323)$ & $(0.00279)$ & $(0.00364)$ & $(0.0087)$ \\
\hline State FE, Year FE \& MML? & Yes & Yes & Yes & Yes & Yes & Yes \\
\hline Socioeconomic controls? & No & Yes & Yes & Yes & Yes & No \\
\hline Tobacco control policies? & $\mathrm{No}$ & No & Yes & Yes & Yes & No \\
\hline Social welfare policies? & No & No & No & Yes & Yes & No \\
\hline State Linear Time Trends? & No & No & No & No & Yes & No \\
\hline$N$ & 867 & 867 & 867 & 867 & 867 & 867 \\
\hline
\end{tabular}

*** Significant at $1 \%$ level **Significant at $5 \%$ level *Significant at $10 \%$ level.

Columns (1) to (5) are based on the TWFE estimation and column (6) provides Callaway-Sant'Anna estimates. All estimates are weighted. Demographic controls include gender, age, educational attainment, race/ethnicity; economic controls include unemployment rate, state poverty rate, and log of ACS mean total pre-tax personal income; smoking policy controls include index of indoor vaping restrictions, any e-cig MLSA, total cig taxes, index of indoor smoking restrictions, minimum age for cig sales; other policy controls include: state EITC refundable credit rate, log of minimum wage, whether the governor is a Democrat, presence of an ACA Medicaid expansion, presence of a must access prescription drug monitoring program, and beer tax per gallon. Standard errors corrected for clustering at the state level are in parentheses. All regressions include state fixed effects and year fixed effects. 
Table 3. Heterogeneity in Effect of RMLs on Marijuana Use by Age, NSDUH, 2002-2019

\begin{tabular}{lcccccc}
\hline \multicolumn{7}{c}{ Two-Way Fixed Effects } \\
(TWFE)
\end{tabular}

Panel III: Overall RML Effect, Ages 26 and Older

\begin{tabular}{lcccccc}
\hline RML & $0.0365^{* * *}$ & $0.0343^{* * *}$ & $0.0421^{* * *}$ & $0.0408^{* * *}$ & $0.0188^{* * *}$ & $0.0321^{* * *}$ \\
& $(0.00716)$ & $(0.00751)$ & $(0.00484)$ & $(0.00431)$ & $(0.00639)$ & $(0.0037)$ \\
\hline Pre-Treatment Mean DV & 0.0554 & 0.0554 & 0.0554 & 0.0554 & 0.0554 & 0.0554 \\
\hline
\end{tabular}

Panel IV: Lagged RML Effects, Ages 26 and Older

\begin{tabular}{lcccccc}
\hline Year of RML Enactment & $0.0103^{* * *}$ & $0.0100^{* * *}$ & $0.0140^{* * *}$ & $0.0153^{* * *}$ & $0.0101^{* * *}$ & $0.0125^{* * *}$ \\
& $(0.00287)$ & $(0.00284)$ & $(0.00283)$ & $(0.00318)$ & $(0.00318)$ & $(0.0030)$ \\
1 Year After RML & $0.0157^{* *}$ & $0.0154^{* *}$ & $0.0225^{* * *}$ & $0.0241^{* * *}$ & $0.0151^{* *}$ & $0.0245^{* *}$ \\
& $(0.00610)$ & $(0.00625)$ & $(0.00582)$ & $(0.00564)$ & $(0.00594)$ & $(0.0071)$ \\
2 Year After RML & $0.0173^{* * *}$ & $0.0170^{* *}$ & $0.0254^{* * *}$ & $0.0277^{* * *}$ & $0.0165^{* *}$ & $0.0262^{* *}$ \\
& $(0.00613)$ & $(0.00658)$ & $(0.00768)$ & $(0.00777)$ & $(0.00782)$ & $(0.0077)$ \\
3 Years+ After RML & $0.0394^{* * *}$ & $0.0406^{* * *}$ & $0.0396^{* * *}$ & $0.0388^{* * *}$ & $0.0190^{* * *}$ & $0.0272^{* *}$ \\
& $(0.00206)$ & $(0.00200)$ & $(0.00279)$ & $(0.00246)$ & $(0.00355)$ & $(0.0087)$ \\
\hline State FE, Year FE \& MML? & Yes & Yes & Yes & Yes & Yes & Yes \\
Socioeconomic controls? & No & Yes & Yes & Yes & Yes & No \\
Tobacco control policies? & No & No & Yes & Yes & Yes & No \\
Social welfare policies? & No & No & No & Yes & Yes & No \\
State Linear Time Trends? & No & No & No & No & Yes & 867 \\
\hline$N$ & 867 & 867 & 867 & 867 & 867 & 867 \\
\hline
\end{tabular}

$* * *$ Significant at $1 \%$ level $* *$ Significant at $5 \%$ level $*$ Significant at $10 \%$ level.

Columns (1) to (5) are based on the TWFE estimation and column (6) provides Callaway-Sant'Anna estimates. All estimates are weighted. Demographic controls include gender, age, educational attainment, race/ethnicity; economic controls include unemployment rate, state poverty rate, and log of ACS mean total pre-tax personal income; smoking policy controls include index of indoor vaping restrictions, any e-cig MLSA, total cig taxes, index of indoor smoking restrictions, minimum age for cig sales; other policy controls include: state EITC refundable credit rate, log of minimum wage, whether the governor is a Democrat, presence of an ACA Medicaid expansion, presence of a must access prescription drug monitoring program, and beer tax per gallon. Standard errors corrected for clustering at the state level are in parentheses. All regressions include state fixed effects and year fixed effects. 


\section{Table 4. Recreational Marijuana Laws and Tobacco Use, Ages 18 and Older,}

NSDUH, 2002-2019

\begin{tabular}{|c|c|c|c|c|c|c|}
\hline & \multicolumn{5}{|c|}{$\begin{array}{l}\text { Two-Way Fixed Effects } \\
\text { (TWFE) }\end{array}$} & \multirow{2}{*}{$\begin{array}{c}\text { Callaway- } \\
\text { Sant'Anna (CS) } \\
(6)\end{array}$} \\
\hline & $(1)$ & $(2)$ & (3) & $(4)$ & (5) & \\
\hline & \multicolumn{6}{|c|}{ Panel I: Overall RML Effect } \\
\hline \multirow[t]{2}{*}{ RML } & $-0.00674 * *$ & -0.00343 & -0.00340 & -0.00484 & -0.0100 & -0.0131 \\
\hline & $(0.00263)$ & $(0.00361)$ & $(0.00414)$ & $(0.00462)$ & $(0.00843)$ & $(0.0089)$ \\
\hline \multirow[t]{2}{*}{ Pre-Treatment Mean DV } & 0.2826 & 0.2826 & 0.2826 & 0.2826 & 0.2826 & 0.2826 \\
\hline & \multicolumn{6}{|c|}{ Panel II: Lagged RML Effects } \\
\hline \multirow[t]{2}{*}{ Year of RML Enactment } & 0.00145 & 0.00162 & 0.00243 & 0.00217 & 0.000318 & -0.0008 \\
\hline & $(0.00190)$ & $(0.00202)$ & $(0.00158)$ & $(0.00196)$ & $(0.00376)$ & $(0.0034)$ \\
\hline \multirow[t]{2}{*}{1 Year After RML } & -0.00120 & -0.000157 & 0.00278 & 0.00341 & -0.00591 & -0.0061 \\
\hline & $(0.00321)$ & $(0.00379)$ & $(0.00327)$ & $(0.00381)$ & $(0.00610)$ & $(0.0064)$ \\
\hline \multirow[t]{2}{*}{2 Year After RML } & $-0.00719^{* * *}$ & $-0.00640^{*}$ & -0.00292 & -0.00179 & $-0.0162^{* *}$ & -0.0107 \\
\hline & $(0.00265)$ & $(0.00373)$ & $(0.00347)$ & $(0.00464)$ & $(0.00751)$ & $(0.0102)$ \\
\hline \multirow{2}{*}{3 Years+ After RML } & $-0.0118^{*}$ & $-0.0145^{* *}$ & $-0.0141^{* *}$ & $-0.0138^{*}$ & $-0.0353^{* * *}$ & $-0.0291^{*}$ \\
\hline & $(0.00665)$ & $(0.00702)$ & $(0.00685)$ & $(0.00804)$ & $(0.00974)$ & $(0.0118)$ \\
\hline State FE, Year FE \& MML? & Yes & Yes & Yes & Yes & Yes & Yes \\
\hline Socioeconomic controls? & No & Yes & Yes & Yes & Yes & No \\
\hline Tobacco control policies? & No & No & Yes & Yes & Yes & No \\
\hline Social welfare policies? & $\mathrm{No}$ & $\mathrm{No}$ & No & Yes & Yes & $\mathrm{No}$ \\
\hline State Linear Time Trends? & No & No & No & No & Yes & No \\
\hline$N$ & 867 & 867 & 867 & 867 & 867 & 867 \\
\hline
\end{tabular}

$* * *$ Significant at $1 \%$ level **Significant at $5 \%$ level $*$ Significant at $10 \%$ level.

Columns (1) to (5) are based on the TWFE estimation and column (6) provides Callaway-Sant'Anna estimates. All estimates are weighted. Demographic controls include gender, age, educational attainment, race/ethnicity; economic controls include unemployment rate, state poverty rate, and log of ACS mean total pre-tax personal income; smoking policy controls include index of indoor vaping restrictions, any e-cig MLSA, total cig taxes, index of indoor smoking restrictions, minimum age for cig sales; other policy controls include: state EITC refundable credit rate, log of minimum wage, whether the governor is a Democrat, presence of an ACA Medicaid expansion, presence of a must access prescription drug monitoring program, and beer tax per gallon. Standard errors corrected for clustering at the state level are in parentheses. All regressions include state fixed effects and year fixed effects. 
Table 5. Heterogeneity in Effect of RMLs on Tobacco Use, by Age, NSDUH, 2002-2019

\begin{tabular}{|c|c|c|c|c|c|c|}
\hline & \multicolumn{5}{|c|}{$\begin{array}{l}\text { Two-Way Fixed Effects } \\
\text { (TWFE) }\end{array}$} & \multirow{2}{*}{$\begin{array}{c}\text { Callaway- } \\
\text { Sant'Anna (CS) } \\
(6)\end{array}$} \\
\hline & $(1)$ & $(2)$ & (3) & (4) & $(5)$ & \\
\hline & \multicolumn{6}{|c|}{ Panel I: Overall RML Effect, Ages 18-25 } \\
\hline RML & $\begin{array}{l}-0.00900 \\
(0.00537) \\
\end{array}$ & $\begin{array}{l}-0.00784 \\
(0.00694) \\
\end{array}$ & $\begin{array}{l}-0.00879 \\
(0.00831) \\
\end{array}$ & $\begin{array}{l}-0.00758 \\
(0.00819)\end{array}$ & $\begin{array}{l}-0.00900 \\
(0.00537) \\
\end{array}$ & $\begin{array}{c}-0.0192^{* *} \\
(0.0062) \\
\end{array}$ \\
\hline Pre-Treatment Mean DV & 0.3783 & 0.3783 & 0.3783 & 0.3783 & 0.3783 & 0.3783 \\
\hline & \multicolumn{6}{|c|}{ Panel II: Lagged RML Effects, Ages 18-25 } \\
\hline Year of RML Enactment & $\begin{array}{c}0.00203 \\
(0.00597)\end{array}$ & $\begin{array}{c}0.00218 \\
(0.00615)\end{array}$ & $\begin{array}{c}0.00348 \\
(0.00517)\end{array}$ & $\begin{array}{c}0.00350 \\
(0.00497)\end{array}$ & $\begin{array}{c}0.00203 \\
(0.00597)\end{array}$ & $\begin{array}{c}0.0037 \\
(0.0059)\end{array}$ \\
\hline 1 Year After RML & $\begin{array}{l}-0.00413 \\
(0.00568)\end{array}$ & $\begin{array}{l}-0.00424 \\
(0.00583)\end{array}$ & $\begin{array}{c}0.00204 \\
(0.00708)\end{array}$ & $\begin{array}{c}0.00318 \\
(0.00714)\end{array}$ & $\begin{array}{l}-0.00413 \\
(0.00568)\end{array}$ & $\begin{array}{l}-0.0082 \\
(0.0082)\end{array}$ \\
\hline 2 Year After RML & $\begin{array}{l}-0.00443 \\
(0.00727)\end{array}$ & $\begin{array}{l}-0.00522 \\
(0.00743)\end{array}$ & $\begin{array}{l}0.00247 \\
(0.0118)\end{array}$ & $\begin{array}{l}0.00459 \\
(0.0117)\end{array}$ & $\begin{array}{l}-0.00443 \\
(0.00727)\end{array}$ & $\begin{array}{l}-0.0147 \\
(0.0127)\end{array}$ \\
\hline 3 Years+ After RML & $\begin{array}{l}-0.0226^{* * *} \\
(0.00610)\end{array}$ & $\begin{array}{l}-0.0256^{* * *} \\
(0.00656)\end{array}$ & $\begin{array}{l}-0.0253^{* * *} \\
(0.00648)\end{array}$ & $\begin{array}{l}-0.0233^{* * *} \\
(0.00623)\end{array}$ & $\begin{array}{l}-0.0226^{* * *} \\
(0.00610)\end{array}$ & $\begin{array}{l}-0.0252 \\
(0.0163) \\
\end{array}$ \\
\hline & \multicolumn{6}{|c|}{ Panel III: Overall RML Effect, Ages 26 and Older } \\
\hline RML & $\begin{array}{c}-0.00617^{* *} \\
(0.00293) \\
\end{array}$ & $\begin{array}{l}-0.00282 \\
(0.00366)\end{array}$ & $\begin{array}{l}-0.00293 \\
(0.00413) \\
\end{array}$ & $\begin{array}{l}-0.00493 \\
(0.00463)\end{array}$ & $\begin{array}{c}-0.0125 \\
(0.00909) \\
\end{array}$ & $\begin{array}{l}-0.0121 \\
(0.0100) \\
\end{array}$ \\
\hline Pre-Treatment Mean DV & 0.2662 & 0.2662 & 0.2662 & 0.2662 & 0.2662 & 0.2662 \\
\hline & \multicolumn{6}{|c|}{ Panel IV: Lagged RML Effects, Ages 26 and Older } \\
\hline Year of RML Enactment & $\begin{array}{c}0.00143 \\
(0.00169)\end{array}$ & $\begin{array}{c}0.00157 \\
(0.00189)\end{array}$ & $\begin{array}{c}0.00222 \\
(0.00176)\end{array}$ & $\begin{array}{c}0.00179 \\
(0.00216)\end{array}$ & $\begin{array}{l}-0.000886 \\
(0.00396)\end{array}$ & $\begin{array}{l}-0.0014 \\
(0.0035)\end{array}$ \\
\hline 1 Year After RML & $\begin{array}{r}-0.000671 \\
(0.00356)\end{array}$ & $\begin{array}{l}0.000442 \\
(0.00408)\end{array}$ & $\begin{array}{c}0.00251 \\
(0.00358)\end{array}$ & $\begin{array}{c}0.00295 \\
(0.00413)\end{array}$ & $\begin{array}{l}-0.00727 \\
(0.00694)\end{array}$ & $\begin{array}{l}-0.0056 \\
(0.0070)\end{array}$ \\
\hline 2 Year After RML & $\begin{array}{c}-0.00737^{* *} \\
(0.00288)\end{array}$ & $\begin{array}{l}-0.00649 \\
(0.00392)\end{array}$ & $\begin{array}{l}-0.00411 \\
(0.00335)\end{array}$ & $\begin{array}{l}-0.00327 \\
(0.00462)\end{array}$ & $\begin{array}{l}-0.0190^{* *} \\
(0.00811)\end{array}$ & $\begin{array}{l}-0.0096 \\
(0.0087)\end{array}$ \\
\hline 3 Years+ After RML & $\begin{array}{c}-0.0106 \\
(0.00746) \\
\end{array}$ & $\begin{array}{c}-0.0135^{*} \\
(0.00787) \\
\end{array}$ & $\begin{array}{c}-0.0132^{*} \\
(0.00771) \\
\end{array}$ & $\begin{array}{c}-0.0131 \\
(0.00876) \\
\end{array}$ & $\begin{array}{c}-0.0391^{* * *} \\
(0.0110) \\
\end{array}$ & $\begin{array}{l}-0.0294 \\
(0.0123) \\
\end{array}$ \\
\hline State FE, Year FE \& MML? & Yes & Yes & Yes & Yes & Yes & Yes \\
\hline Socioeconomic controls? & No & Yes & Yes & Yes & Yes & No \\
\hline Tobacco control policies? & No & No & Yes & Yes & Yes & No \\
\hline Social welfare policies? & No & No & No & Yes & Yes & No \\
\hline State Linear Time Trends? & No & No & No & No & Yes & No \\
\hline$N$ & 867 & 867 & 867 & 867 & 867 & 867 \\
\hline
\end{tabular}

*** Significant at $1 \%$ level $* *$ Significant at $5 \%$ level $*$ Significant at $10 \%$ level.

Columns (1) to (5) are based on the TWFE estimation and column (6) provides Callaway-Sant'Anna estimates. All estimates are weighted. Demographic controls include gender, age, educational attainment, race/ethnicity; economic controls include unemployment rate, state poverty rate, and log of ACS mean total pre-tax personal income; smoking policy controls include index of indoor vaping restrictions, any e-cig MLSA, total cig taxes, index of indoor smoking restrictions, minimum age for cig sales; other policy controls include: state EITC refundable credit rate, $\log$ of minimum wage, whether the governor is a Democrat, presence of an ACA Medicaid expansion, presence of a must access prescription drug monitoring program, and beer tax per gallon. Standard errors corrected for clustering at the state level are in parentheses. All regressions include state fixed effects and year fixed effects. 
Table 6. Recreational Marijuana Laws and Cigarette Use, Ages 18 and Older, NSDUH, 2002-2019

Two-Way Fixed Effects

(TWFE)
Callaway-

Sant'Anna (CS)

\section{(1)}

(2)

(3)

(4)

(5)

(6)

Panel I: Overall RML Effect

\begin{tabular}{lcccccc}
\hline RML & $-0.00494^{*}$ & -0.00234 & -0.00279 & -0.00453 & -0.00770 & -0.0074 \\
& $(0.00258)$ & $(0.00339)$ & $(0.00407)$ & $(0.00434)$ & $(0.00717)$ & $(0.0068)$ \\
\hline Pre-Treatment Mean DV & 0.2358 & 0.2358 & 0.2358 & 0.2358 & 0.2358 & 0.2358 \\
\hline
\end{tabular}

\section{Panel II: Lagged RML Effects}

\begin{tabular}{lcccccc}
\hline Year of RML Enactment & -0.00123 & -0.00104 & -0.000490 & -0.00155 & -0.00293 & -0.0010 \\
& $(0.00196)$ & $(0.00209)$ & $(0.00208)$ & $(0.00238)$ & $(0.00360)$ & $(0.0027)$ \\
1 Year After RML & -0.00354 & -0.00279 & -0.000137 & -0.000362 & -0.00544 & -0.0056 \\
& $(0.00410)$ & $(0.00445)$ & $(0.00414)$ & $(0.00428)$ & $(0.00590)$ & $(0.0066)$ \\
2 Year After RML & $-0.00604^{*}$ & -0.00542 & -0.00231 & -0.00232 & -0.0102 & -0.0078 \\
& $(0.00339)$ & $(0.00407)$ & $(0.00400)$ & $(0.00491)$ & $(0.00707)$ & $(0.0097)$ \\
3 Years+ After RML & $-0.00862^{*}$ & $-0.0108^{*}$ & $-0.0106^{* *}$ & -0.00989 & $-0.0187^{* *}$ & $-0.0189^{*}$ \\
& $(0.00495)$ & $(0.00542)$ & $(0.00517)$ & $(0.00599)$ & $(0.00819)$ & $(0.0094)$ \\
\hline State FE, Year FE \& MML? & Yes & Yes & Yes & Yes & Yes & Yes \\
Socioeconomic controls? & No & Yes & Yes & Yes & Yes & No \\
Tobacco control policies? & No & No & Yes & Yes & Yes & No \\
Social welfare policies? & No & No & No & Yes & Yes & No \\
State Linear Time Trends? & No & No & No & No & Yes & 867 \\
\hline$N$ & 867 & 867 & 867 & 867 & 867 \\
\hline
\end{tabular}

$* * *$ Significant at $1 \%$ level **Significant at $5 \%$ level $*$ Significant at $10 \%$ level.

Columns (1) to (5) are based on the TWFE estimation and column (6) provides Callaway-Sant'Anna estimates. All estimates are weighted. Demographic controls include gender, age, educational attainment, race/ethnicity; economic controls include unemployment rate, state poverty rate, and log of ACS mean total pre-tax personal income; smoking policy controls include index of indoor vaping restrictions, any e-cig MLSA, total cig taxes, index of indoor smoking restrictions, minimum age for cig sales; other policy controls include: state EITC refundable credit rate, log of minimum wage, whether the governor is a Democrat, presence of an ACA Medicaid expansion, presence of a must access prescription drug monitoring program, and beer tax per gallon. Standard errors corrected for clustering at the state level are in parentheses. All regressions include state fixed effects and year fixed effects. 
Table 7. Heterogeneity in Effect of RMLs on Cigarette Use, by Age, NSDUH, 2002-2019

\begin{tabular}{|c|c|c|c|c|c|c|}
\hline & \multicolumn{5}{|c|}{$\begin{array}{l}\text { Two-Way Fixed Effects } \\
\text { (TWFE) }\end{array}$} & \multirow{2}{*}{$\begin{array}{c}\text { Callaway- } \\
\text { Sant'Anna (CS) } \\
(6)\end{array}$} \\
\hline & $(1)$ & $(2)$ & (3) & (4) & $(5)$ & \\
\hline & \multicolumn{6}{|c|}{ Panel I: Overall RML Effect, Ages 18-25 } \\
\hline \multirow[t]{2}{*}{ RML } & 0.000510 & 0.000533 & -0.00235 & -0.00160 & 0.00384 & -0.0061 \\
\hline & $(0.00617)$ & $(0.00706)$ & $(0.00805)$ & $(0.00805)$ & $(0.0105)$ & $(0.0075)$ \\
\hline \multirow[t]{2}{*}{ Pre-Treatment Mean DV } & 0.3184 & 0.3184 & 0.3184 & 0.3184 & 0.3184 & 0.3184 \\
\hline & \multicolumn{6}{|c|}{ Panel II: Lagged RML Effects, Ages 18-25 } \\
\hline \multirow[t]{2}{*}{ Year of RML Enactment } & 0.00175 & 0.00204 & 0.00164 & 0.000853 & 0.00395 & 0.0019 \\
\hline & $(0.00347)$ & $(0.00369)$ & $(0.00391)$ & $(0.00388)$ & $(0.00491)$ & $(0.0046)$ \\
\hline \multirow[t]{2}{*}{1 Year After RML } & -0.000361 & -0.00111 & 0.00344 & 0.00485 & 0.00266 & -0.0027 \\
\hline & $(0.00690)$ & $(0.00659)$ & $(0.00672)$ & $(0.00658)$ & $(0.00830)$ & $(0.0080)$ \\
\hline \multirow[t]{2}{*}{2 Year After RML } & 0.00405 & 0.00267 & 0.00871 & 0.0117 & 0.00789 & 0.0053 \\
\hline & $(0.00810)$ & $(0.00803)$ & $(0.0119)$ & $(0.0122)$ & $(0.0125)$ & $(0.0158)$ \\
\hline \multirow[t]{3}{*}{3 Years+ After RML } & -0.0108 & $-0.0137^{*}$ & $-0.0122^{*}$ & -0.00805 & 0.00380 & -0.0118 \\
\hline & $(0.00742)$ & $(0.00779)$ & $(0.00638)$ & $(0.00602)$ & $(0.0101)$ & $(0.0162)$ \\
\hline & \multicolumn{6}{|c|}{ Panel III: Overall RML Effect, Ages 26 and Older } \\
\hline \multirow[t]{2}{*}{ RML } & $-0.00566^{*}$ & -0.00291 & -0.00330 & -0.00556 & -0.00951 & -0.0075 \\
\hline & $(0.00283)$ & $(0.00345)$ & $(0.00423)$ & $(0.00450)$ & $(0.00780)$ & $(0.0084)$ \\
\hline \multirow[t]{2}{*}{ Pre-Treatment Mean DV } & 0.2216 & 0.2216 & 0.2216 & 0.2216 & 0.2216 & 0.2216 \\
\hline & \multicolumn{6}{|c|}{ Panel IV: Lagged RML Effects, Ages 26 and Older } \\
\hline \multirow[t]{2}{*}{ Year of RML Enactment } & -0.00167 & -0.00154 & -0.00091 & -0.00215 & -0.00413 & -0.0013 \\
\hline & $(0.00199)$ & $(0.00214)$ & $(0.00224)$ & $(0.00256)$ & $(0.00398)$ & $(0.0031)$ \\
\hline \multirow[t]{2}{*}{1 Year After RML } & -0.00404 & -0.00316 & -0.00113 & -0.00174 & -0.00684 & -0.0061 \\
\hline & $(0.00417)$ & $(0.00458)$ & $(0.00459)$ & (0.00473) & $(0.00668)$ & $(0.0065)$ \\
\hline \multirow[t]{2}{*}{2 Year After RML } & $-0.00746^{* *}$ & -0.00666 & -0.00444 & -0.00508 & $-0.0130^{*}$ & -0.0079 \\
\hline & $(0.00327)$ & $(0.00406)$ & $(0.00392)$ & $(0.00491)$ & $(0.00727)$ & $(0.0088)$ \\
\hline \multirow[t]{2}{*}{3 Years+ After RML } & -0.00877 & $-0.0112^{*}$ & $-0.0114^{*}$ & -0.0111 & $-0.0225^{* *}$ & $-0.0197^{*}$ \\
\hline & $(0.00555)$ & $(0.00618)$ & $(0.00611)$ & $(0.00669)$ & $(0.00926)$ & $(0.0089)$ \\
\hline State FE, Year FE \& MML? & Yes & Yes & Yes & Yes & Yes & Yes \\
\hline Socioeconomic controls? & No & Yes & Yes & Yes & Yes & No \\
\hline Tobacco control policies? & No & No & Yes & Yes & Yes & No \\
\hline Social welfare policies? & No & No & No & Yes & Yes & No \\
\hline State Linear Time Trends? & No & No & No & No & Yes & No \\
\hline$N$ & 867 & 867 & 867 & 867 & 867 & 867 \\
\hline
\end{tabular}

***Significant at $1 \%$ level $* *$ Significant at $5 \%$ level $*$ Significant at $10 \%$ level.

Columns (1) to (5) are based on the TWFE estimation and column (6) provides Callaway-Sant'Anna estimates. All estimates are weighted. Demographic controls include gender, age, educational attainment, race/ethnicity; economic controls include unemployment rate, state poverty rate, and log of ACS mean total pre-tax personal income; smoking policy controls include index of indoor vaping restrictions, any e-cig MLSA, total cig taxes, index of indoor smoking restrictions, minimum age for cig sales; other policy controls include: state EITC refundable credit rate, $\log$ of minimum wage, whether the governor is a Democrat, presence of an ACA Medicaid expansion, presence of a must access prescription drug monitoring program, and beer tax per gallon. Standard errors corrected for clustering at the state level are in parentheses. All regressions include state fixed effects and year fixed effects. 
Table 8. Recreational Marijuana Laws and Cigarette Use, Ages 18 and Older, BRFSS, 2000-2019

\begin{tabular}{|c|c|c|c|c|c|c|c|c|c|}
\hline & \multicolumn{3}{|c|}{ Cigarette Use } & \multicolumn{3}{|c|}{ Everyday Cigarette Use } & \multicolumn{3}{|c|}{ Quit } \\
\hline & TWFE & TWFE & CS & TWFE & TWFE & $\mathrm{CS}$ & TWFE & TWFE & $\mathrm{CS}$ \\
\hline & $(1)$ & $(2)$ & (3) & $(4)$ & $(5)$ & $(6)$ & $(7)$ & $(8)$ & $(9)$ \\
\hline & \multicolumn{9}{|c|}{ Panel I: Overall RML Effect } \\
\hline \multirow[t]{2}{*}{ RML } & 0.00281 & 0.000307 & -0.0051 & 0.00293 & -0.00192 & -0.0073 & -0.00426 & 0.00293 & 0.0041 \\
\hline & $(0.00258)$ & $(0.00264)$ & $(0.0057)$ & $(0.00411)$ & $(0.00175)$ & 0.0056 & $(0.00480)$ & $(0.00411)$ & $(0.0112)$ \\
\hline \multirow[t]{2}{*}{ Pre-Treatment Mean DV } & 0.1884 & 0.1884 & 0.1884 & 0.1359 & 0.1359 & 0.1359 & 0.5601 & 0.5601 & 0.5601 \\
\hline & \multicolumn{9}{|c|}{ Panel II: Lagged RML Effects } \\
\hline \multirow[t]{2}{*}{ Year of RML Enactment } & -0.00223 & 0.00115 & -0.0025 & -0.00215 & 0.000796 & -0.0041 & -0.00327 & 0.000371 & 0.0015 \\
\hline & $(0.00309)$ & $(0.00285)$ & $(0.0052)$ & $(0.00279)$ & (0.00223) & $(0.0056)$ & $(0.00443)$ & $(0.00400)$ & $(0.0095)$ \\
\hline \multirow[t]{2}{*}{1 Year After RML } & 0.00117 & 0.00151 & -0.0053 & -0.000784 & 0.000472 & -0.0068 & -0.00531 & 0.000862 & 0.0019 \\
\hline & $(0.00218)$ & $(0.00299)$ & $(0.0076)$ & $(0.00236)$ & $(0.00240)$ & $(0.0051)$ & $(0.00339)$ & $(0.00405)$ & $(0.0106)$ \\
\hline \multirow[t]{2}{*}{2 Year After RML } & $0.00634^{* *}$ & 0.00590 & -0.0032 & 0.00150 & 0.00184 & -0.0079 & $-0.0140^{* * *}$ & -0.00593 & 0.0006 \\
\hline & $(0.00294)$ & $(0.00351)$ & $(0.0025)$ & $(0.00319)$ & $(0.00353)$ & $(0.0033)$ & $(0.00496)$ & $(0.00357)$ & $(0.0085)$ \\
\hline \multirow[t]{2}{*}{3 Years+ After RML } & -0.000676 & -0.00118 & -0.0095 & -0.00186 & -0.00324 & -0.0104 & 0.00255 & $0.0134^{* *}$ & 0.0123 \\
\hline & $(0.00299)$ & $(0.00459)$ & $(0.0071)$ & $(0.00251)$ & $(0.00290)$ & $(0.0109)$ & $(0.00408)$ & $(0.00542)$ & $(0.0141)$ \\
\hline State FE, Year-Month FE \& MML? & Yes & Yes & Yes & Yes & Yes & Yes & Yes & Yes & Yes \\
\hline Individual and State Controls? & Yes & Yes & No & Yes & Yes & No & Yes & Yes & No \\
\hline State Linear Time Trends? & No & Yes & No & No & Yes & No & No & Yes & No \\
\hline$N$ & 7619864 & 7619864 & 7619864 & 7619864 & 7619864 & 7619864 & 3419731 & 3419731 & 3419731 \\
\hline \multicolumn{10}{|c|}{$\begin{array}{l}\text { Columns (1) (2) (4) (5) (7) and (8) are based on the TWFE estimation and columns (3), (6), and (9) present Callaway-Sant'Anna estimates. } \\
\text { All estimates are weighted. Demographic controls include gender, age, educational attainment, race/ethnicity; economic controls include unemployment rate, state } \\
\text { poverty rate, and log of ACS mean total pre-tax personal income; smoking policy controls include index of indoor vaping restrictions, any e-cig MLSA, total cig taxes, } \\
\text { index of indoor smoking restrictions, minimum age for cig sales; other policy controls include: state EITC refundable credit rate, log of minimum wage, whether the } \\
\text { governor is a Democrat, presence of an ACA Medicaid expansion, presence of a must access prescription drug monitoring program, and beer tax per gallon. Standard } \\
\text { errors corrected for clustering at the state level are in parentheses. All regressions include state fixed effects, year-by-month fixed effects, and medical marijuana laws. }\end{array}$} \\
\hline
\end{tabular}


Table 9. Heterogeneity in Effect of RMLs on Smoking, by Age, BRFSS, 2000-2019

\begin{tabular}{|c|c|c|c|c|c|c|c|c|c|}
\hline & \multicolumn{3}{|c|}{ Cigarette Use } & \multicolumn{3}{|c|}{ Everyday Cigarette Use } & \multicolumn{3}{|c|}{ Quit } \\
\hline & TWFE & TWFE & CS & TWFE & TWFE & CS & TWFE & TWFE & CS \\
\hline & $(1)$ & $(2)$ & (3) & $(4)$ & $(5)$ & $(6)$ & $(7)$ & $(8)$ & $(9)$ \\
\hline & \multicolumn{9}{|c|}{ Panel I: Ages 18-to20 } \\
\hline RML & 0.00379 & -0.00500 & -0.0086 & -0.00311 & -0.00795 & 0.0005 & -0.0304 & 0.0159 & 0.0072 \\
\hline & $(0.00446)$ & $(0.0103)$ & $(0.0181)$ & $(0.00379)$ & $(0.00717)$ & $(0.0161)$ & $(0.0287)$ & $(0.0410)$ & $(0.0711)$ \\
\hline$N$ & 155203 & 155203 & 155203 & 155203 & 155203 & 155203 & 34108 & 34108 & 34108 \\
\hline \multirow{2}{*}{ Pre-Treatment Mean DV } & 0.1722 & 0.1722 & 0.1722 & 0.1116 & 0.1116 & 0.1116 & 0.2118 & 0.2118 & 0.2118 \\
\hline & \multicolumn{9}{|c|}{ Panel II: Ages 21 and Older } \\
\hline RML & 0.00268 & 0.000754 & -0.0048 & 0.000780 & -0.00146 & -0.0077 & -0.00376 & 0.00257 & 0.0038 \\
\hline & $(0.00280)$ & $(0.00245)$ & $(0.0051)$ & $(0.00189)$ & $(0.00164)$ & $(0.0079)$ & $(0.00461)$ & $(0.00422)$ & $(0.0061)$ \\
\hline$N$ & 7464661 & 7464661 & 7464661 & 7464661 & 7464661 & 7464661 & 3385623 & 3385623 & 3385623 \\
\hline Pre-Treatment Mean DV & 0.1893 & 0.1893 & 0.1893 & 0.1373 & 0.1373 & 0.1373 & 0.5701 & 0.5701 & 0.5701 \\
\hline State FE, Year-Month FE \& MML? & Yes & Yes & Yes & Yes & Yes & Yes & Yes & Yes & Yes \\
\hline Individual and State Controls? & Yes & Yes & No & Yes & Yes & No & Yes & Yes & No \\
\hline State Linear Time Trends? & No & Yes & No & No & Yes & $\mathrm{No}$ & No & Yes & No \\
\hline
\end{tabular}

State Linear Time Trends?

*** Significant at $1 \%$ level **Significant at $5 \%$ level $*$ Significant at $10 \%$ level.

All estimates are weighted. Demographic controls include gender, age, educational attainment, race/ethnicity; economic controls include unemployment rate, state poverty rate, and log of ACS mean total pre-tax personal income; smoking policy controls include index of indoor vaping restrictions, any e-cig MLSA, total cig taxes, index of indoor smoking restrictions, minimum age for cig sales; other policy controls include: state EITC refundable credit rate, log of minimum wage, whether the governor is a Democrat, presence of an ACA Medicaid expansion, presence of a must access prescription drug monitoring program, and beer tax per gallon. Standard errors corrected for clustering at the state level are in parentheses. All regressions include state fixed effects, year-by-month fixed effects, and medical marijuana laws. 
Table 10. Recreational Marijuana Laws and E-Cigarette Use, TWFE Estimates, BRFSS, 2016-2018

\begin{tabular}{|c|c|c|c|c|c|c|}
\hline & \multicolumn{2}{|c|}{ Ages 18 and Older } & \multicolumn{2}{|c|}{ Ages 18-to-20 } & \multicolumn{2}{|c|}{ Ages 21 and Older } \\
\hline & $(1)$ & $(2)$ & (3) & (4) & $(5)$ & $(6)$ \\
\hline \multicolumn{7}{|c|}{ Panel I: Overall RML Effect } \\
\hline RML & $-0.0265^{* * *}$ & $-0.0450 * * *$ & $-0.107 * * *$ & $-0.132^{* *}$ & $-0.0174 *$ & $-0.0343^{*}$ \\
\hline & $(0.00804)$ & $(0.0130)$ & $(0.0295)$ & $(0.0644)$ & $(0.00933)$ & $(0.0199)$ \\
\hline Pre-Treatment Mean DV & 0.0342 & 0.0342 & 0.1369 & 0.1369 & 0.0319 & 0.0319 \\
\hline \multicolumn{7}{|c|}{ Panel II: Lagged RML Effects } \\
\hline Year of RML Enactment & -0.000489 & 0.00599 & -0.0632 & -0.0733 & 0.00285 & 0.00932 \\
\hline & $(0.0144)$ & $(0.0198)$ & $(0.0933)$ & $(0.143)$ & $(0.0235)$ & $(0.0272)$ \\
\hline 1 Year After RML & $-0.0244^{*}$ & -0.0331 & -0.134 & -0.150 & -0.0154 & -0.0269 \\
\hline & $(0.0136)$ & $(0.0215)$ & $(0.0883)$ & $(0.172)$ & $(0.0197)$ & $(0.0241)$ \\
\hline State FE, Year-Month FE \& MML? & Yes & Yes & Yes & Yes & Yes & Yes \\
\hline Individual and State Controls? & Yes & Yes & Yes & Yes & Yes & Yes \\
\hline State Linear Time Trends? & No & Yes & No & Yes & No & Yes \\
\hline$N$ & 187114 & 187114 & 11018 & 11018 & 176096 & 176096 \\
\hline
\end{tabular}

$* * *$ Significant at $1 \%$ level $* *$ Significant at $5 \%$ level $*$ Significant at $10 \%$ level.

All estimates are weighted. Demographic controls include gender, age, educational attainment, race/ethnicity; economic controls include unemployment rate, state poverty rate, and log of ACS mean total pre-tax personal income; smoking policy controls include index of indoor vaping restrictions, any e-cig MLSA, total cig taxes, index of indoor smoking restrictions, minimum age for cig sales; other policy controls include: state EITC refundable credit rate, log of minimum wage, whether the governor is a Democrat, presence of an ACA Medicaid expansion, presence of a must access prescription drug monitoring program, and beer tax per gallon. Standard errors corrected for clustering at the state level are in parentheses. All regressions include state fixed effects, year-by-month fixed effects, and medical marijuana laws. 
Table 11. Recreational Marijuana Laws and Tobacco Use by Age, CPS-TUS, 2000-2019

Tobacco Use

Cigarette Use

Everyday Cigarette Use

\begin{tabular}{|c|c|c|c|c|c|c|c|c|c|}
\hline & TWFE & TWFE & CS & TWFE & TWFE & CS & TWFE & TWFE & CS \\
\hline & $(1)$ & (2) & (3) & $(4)$ & $(5)$ & (6) & $(7)$ & $(8)$ & (9) \\
\hline & \multicolumn{9}{|c|}{ Panel I: Ages 18 and Older } \\
\hline$N$ & 1129233 & 1129233 & 1129233 & 1133845 & 1133845 & 1133845 & 1133845 & 1133845 & 1133845 \\
\hline Pre-Treatment Mean DV & 0.2020 & 0.2020 & 0.2020 & 0.1805 & 0.1805 & 0.1805 & 0.1455 & 0.1455 & 0.1455 \\
\hline
\end{tabular}

Panel II: Ages 18-to20

\begin{tabular}{lccccccccc}
\hline RML & -0.03208 & -0.03820 & 0.0264 & $-0.0316^{* *}$ & -0.03125 & 0.0145 & $-0.0297^{* *}$ & $-0.0337^{*}$ & -0.0062 \\
& $(0.02046)$ & $(0.02767)$ & $(0.0184)$ & $(0.01180)$ & $(0.02345)$ & $(0.0234)$ & $(0.01396)$ & $(0.01708)$ & $(0.0195)$ \\
\hline$N$ & 33539 & 33539 & 33539 & 33588 & 33588 & 33588 & 33588 & 33588 & 33588 \\
\hline Pre-Treatment Mean DV & 0.1863 & 0.1863 & 0.1863 & 0.1612 & 0.1612 & 0.1612 & 0.1247 & 0.1247 & 0.1247 \\
\hline
\end{tabular}

\begin{tabular}{lccccccccc}
\multicolumn{10}{c}{ Panel III: Ages 21 and Older } \\
\hline RML & -0.00179 & 0.00419 & 0.003 & 0.00151 & 0.00564 & 0.006 & -0.00205 & 0.00391 & -0.0033 \\
& $(0.00511)$ & $(0.00561)$ & $(0.0034)$ & $(0.00434)$ & $(0.00550)$ & $(0.0082)$ & $(0.00370)$ & $(0.00605)$ & $(0.007)$ \\
\hline$N$ & 1095694 & 1095694 & 1095694 & 1100257 & 1100257 & 1100257 & 1100257 & 1100257 & 1100257 \\
\hline Pre-Treatment Mean DV & 0.2029 & 0.2029 & 0.2029 & 0.1816 & 0.1816 & 0.1816 & 0.1467 & 0.1467 & 0.1467 \\
\hline State FE, Year-Month FE \& MML? & Yes & Yes & Yes & Yes & Yes & Yes & Yes & Yes & Yes \\
Individual and State Controls? & Yes & Yes & No & Yes & Yes & No & Yes & Yes & No \\
State Linear Time Trends? & No & Yes & No & No & Yes & No & No & Yes & No \\
\hline$N$ & 1129233 & 1129233 & 1129233 & 1133845 & 1133845 & 1133845 & 1133845 & 1133845 & 1133845 \\
\hline
\end{tabular}

***Significant at $1 \%$ level **Significant at $5 \%$ level *Significant at $10 \%$ level.

Columns (1) (2) (4) (5) (7) and (8) are based on the TWFE estimation and columns (3), (6), and (9) present Callaway-Sant'Anna estimates.

All estimates are weighted by the CPS-TUS sampling weights. Sociodemographic controls include indicators for age, gender, race (black, race other than black or white), Hispanic ethnicity, and educational attainment (high school, some college, college or above); tobacco policy controls include index of indoor vaping restrictions, any e-cig MLSA, total cig taxes, index of indoor smoking restrictions, minimum age for cig sales; other economic and policy controls include: unemployment rate, state poverty rate, log of ACS mean total pre-tax personal income, state EITC refundable credit rate, $\log$ of minimum wage, whether the governor is a Democrat, presence of an ACA Medicaid expansion, presence of a must access prescription drug monitoring program, and beer tax per gallon. Standard errors corrected for clustering at the state level are in parentheses. All specifications include state fixed effects and year-by-month fixed effects. The x-axis in the Callaway Sant'Anna event study graphs denotes CPS-TUS waves. 
Table 12. Recreational Marijuana Laws and Marijuana Use by Age, PATH

\begin{tabular}{|c|c|c|c|c|c|c|}
\hline & $\begin{array}{l}\text { Past 12- } \\
\text { month } \\
\text { Marijuana } \\
\text { Use }\end{array}$ & $\begin{array}{c}\text { Past 30-day } \\
\text { Marijuana } \\
\text { Use }\end{array}$ & $\begin{array}{l}\text { Past 30-day } \\
\text { Blunt Use }\end{array}$ & $\begin{array}{l}\text { Number of } \\
\text { days of Blunt } \\
\text { Use in Past } \\
30 \text { days }\end{array}$ & $\begin{array}{l}\text { Past 2-day } \\
\text { Vaped } \\
\text { Marijuana } \\
\text { Use }\end{array}$ & $\begin{array}{c}\text { Ever Vaped } \\
\text { Marijuana } \\
\text { Use }\end{array}$ \\
\hline & $(1)$ & $(2)$ & (3) & (4) & (5) & (6) \\
\hline \multicolumn{7}{|c|}{ Panel I: Ages 18 and Older } \\
\hline RML & $\begin{array}{c}0.020^{* * *} \\
(0.005)\end{array}$ & $\begin{array}{c}0.019 * * * \\
(0.004)\end{array}$ & $\begin{array}{c}0.001 \\
(0.002) \\
\end{array}$ & $\begin{array}{c}0.031 \\
(0.048) \\
\end{array}$ & $\begin{array}{c}0.008^{* * *} \\
(0.003)\end{array}$ & $\begin{array}{c}0.019^{* * *} \\
(0.005)\end{array}$ \\
\hline$N$ & 156,804 & 156,671 & 101,489 & 83,414 & 87,457 & 87,754 \\
\hline Pre-Treatment Mean DV & 0.253 & 0.183 & 0.062 & 0.716 & 0.038 & 0.170 \\
\hline \multicolumn{7}{|c|}{ Panel II: Ages 21 and Older } \\
\hline RML & $\begin{array}{c}0.020^{* * *} \\
(0.005)\end{array}$ & $\begin{array}{c}0.018^{* * *} \\
(0.005)\end{array}$ & $\begin{array}{c}0.002 \\
(0.002) \\
\end{array}$ & $\begin{array}{c}0.041 \\
(0.053) \\
\end{array}$ & $\begin{array}{c}0.008^{* * *} \\
(0.003)\end{array}$ & $\begin{array}{c}0.017 * * * \\
(0.005) \\
\end{array}$ \\
\hline$N$ & 132,002 & 131,898 & 85,106 & 68,697 & 71,226 & 71,464 \\
\hline Pre-Treatment Mean DV & 0.234 & 0.172 & 0.053 & 0.654 & 0.036 & 0.165 \\
\hline Years & 2013-2019 & $2013-2019$ & 2014-2019 & $2015-2019$ & $2015-2019$ & $2015-2019$ \\
\hline
\end{tabular}

***Significant at $1 \%$ level **Significant at $5 \%$ level *Significant at $10 \%$ level.

All estimates are weighted. All regressions include individual fixed effects, state fixed effects, year-by-month fixed effects, wave fixed effects, and medical marijuana laws. Demographic controls include gender, age, educational attainment, race/ethnicity; economic controls include unemployment rate, state poverty rate, and log of ACS mean total pre-tax personal income; smoking policy controls include index of indoor vaping restrictions, total e-cigarette taxes, any e-cigarette MLSA, total cigarette taxes, index of indoor smoking restrictions, minimum age for cigarette sales; other policy controls include: state EITC refundable credit rate, log of minimum wage, whether the governor is a Democrat, presence of an ACA Medicaid expansion, presence of a must access prescription drug monitoring program, and beer tax per gallon. Standard errors, in parentheses, are clustered within 156 primary sampling units that are nested within states (except in one instance). 
Table 13A. Recreational Marijuana Laws and Tobacco Use by Age, PATH

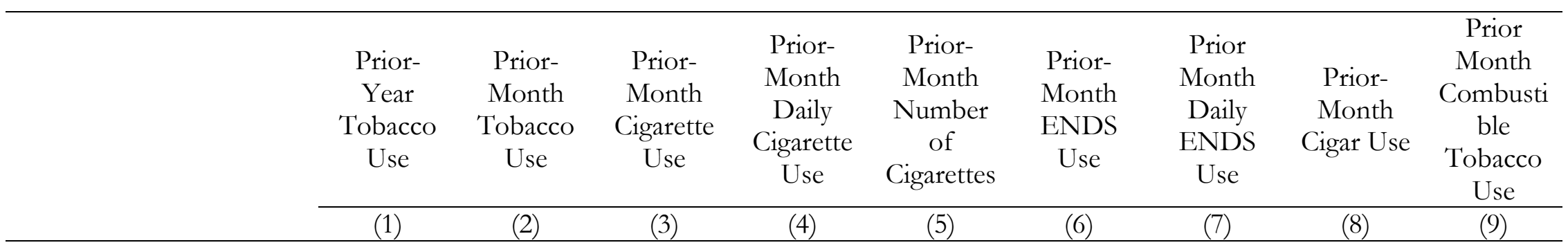

\begin{tabular}{lcccccccccc}
\multicolumn{10}{c}{ Panel I: Ages 18 and Older } \\
\hline RML & -0.003 & 0.003 & 0.005 & 0.000 & 9.186 & -0.006 & -0.001 & -0.004 & 0.001 \\
& $(0.008)$ & $(0.006)$ & $(0.005)$ & $(0.003)$ & $(10.029)$ & $(0.004)$ & $(0.003)$ & $(0.004)$ & $(0.007)$ \\
\hline N & 156,888 & 156,898 & 156,866 & 156,898 & 156,434 & 156,732 & 156,898 & 156,765 & 156,898 \\
\hline Pre-Treatment Mean DV & 0.562 & 0.496 & 0.377 & 0.252 & 136.753 & 0.134 & 0.033 & 0.130 & 0.439 \\
\hline
\end{tabular}

\begin{tabular}{|c|c|c|c|c|c|c|c|c|c|}
\hline \multirow{3}{*}{ RML } & \multicolumn{9}{|c|}{ Panel II: Ages 21 and Older } \\
\hline & -0.001 & 0.004 & 0.006 & -0.000 & 9.988 & -0.006 & -0.001 & -0.003 & 0.002 \\
\hline & $(0.008)$ & $(0.007)$ & $(0.006)$ & $(0.003)$ & $(10.631)$ & $(0.004)$ & $(0.003)$ & $(0.004)$ & $(0.007)$ \\
\hline$N$ & 132,070 & 132,077 & 132,047 & 132,077 & 131,651 & 131,930 & 132,077 & 131,954 & 132,077 \\
\hline Pre-Treatment Mean DV & 0.575 & 0.514 & 0.406 & 0.283 & 154.400 & 0.123 & 0.032 & 0.125 & 0.461 \\
\hline Years & $\begin{array}{l}2013- \\
2019\end{array}$ & $\begin{array}{l}2013- \\
2019\end{array}$ & $\begin{array}{l}2013- \\
2019\end{array}$ & $\begin{array}{l}2013- \\
2019\end{array}$ & $\begin{array}{c}2013- \\
2019\end{array}$ & $\begin{array}{c}2013- \\
2019\end{array}$ & $\begin{array}{c}2013- \\
2019\end{array}$ & $\begin{array}{c}2013- \\
2019\end{array}$ & $\begin{array}{l}2013- \\
2019\end{array}$ \\
\hline
\end{tabular}

*** Significant at $1 \%$ level **Significant at $5 \%$ level * Significant at $10 \%$ level.

All estimates are weighted. All regressions include individual fixed effects, state fixed effects, year-by-month fixed effects, wave fixed effects, and medical marijuana laws. Demographic controls include gender, age, educational attainment, race/ethnicity; economic controls include unemployment rate, state poverty rate, and log of ACS mean total pre-tax personal income; smoking policy controls include index of indoor vaping restrictions, total e-cigarette taxes, any e-cigarette MLSA, total cigarette taxes, index of indoor smoking restrictions, minimum age for cigarette sales; other policy controls include: state EITC refundable credit rate, log of minimum wage, whether the governor is a Democrat, presence of an ACA Medicaid expansion, presence of a must access prescription drug monitoring program, and beer tax per gallon. Standard errors, in parentheses, are clustered within 156 primary sampling units that are nested within states (except in one instance). 
Table 13B. Lagged Effects of Recreational Marijuana Laws on Marijuana and Tobacco Use by Age, PATH

\begin{tabular}{|c|c|c|c|c|c|}
\hline & $\begin{array}{l}\text { Prior-Month } \\
\text { Marijuana Use }\end{array}$ & $\begin{array}{l}\text { Prior-Month } \\
\text { Cigarette Use }\end{array}$ & $\begin{array}{l}\text { Prior-Month } \\
\text { ENDS Use }\end{array}$ & $\begin{array}{l}\text { Prior-Month } \\
\text { Cigar Use }\end{array}$ & $\begin{array}{l}\text { Prior-Month } \\
\text { Combustible } \\
\text { Tobacco Use }\end{array}$ \\
\hline & $(1)$ & $(2)$ & (3) & (4) & $(5)$ \\
\hline & \multicolumn{5}{|c|}{ Panel I: Ages 18 and Older } \\
\hline Year of RML Enactment & $\begin{array}{c}0.016^{* * *} \\
(0.004)\end{array}$ & $\begin{array}{c}0.004 \\
(0.005)\end{array}$ & $\begin{array}{l}-0.005 \\
(0.004)\end{array}$ & $\begin{array}{l}-0.005 \\
(0.004)\end{array}$ & $\begin{array}{l}-0.001 \\
(0.007)\end{array}$ \\
\hline 1 Year After RML & $\begin{array}{c}0.011 \\
(0.008)\end{array}$ & $\begin{array}{c}0.010 \\
(0.008)\end{array}$ & $\begin{array}{c}-0.013^{* *} \\
(0.006)\end{array}$ & $\begin{array}{c}0.003 \\
(0.008)\end{array}$ & $\begin{array}{c}0.006 \\
(0.011)\end{array}$ \\
\hline 2 Year After RML & $\begin{array}{c}0.028^{* * * *} \\
(0.006)\end{array}$ & $\begin{array}{c}0.009 \\
(0.007)\end{array}$ & $\begin{array}{c}-0.015^{* *} \\
(0.006)\end{array}$ & $\begin{array}{c}0.005 \\
(0.006)\end{array}$ & $\begin{array}{c}0.003 \\
(0.009)\end{array}$ \\
\hline 3 Years+ After RML & $\begin{array}{c}0.015 \\
(0.009)\end{array}$ & $\begin{array}{c}0.004 \\
(0.008)\end{array}$ & $\begin{array}{c}-0.016^{* *} \\
(0.007)\end{array}$ & $\begin{array}{c}0.009 \\
(0.008)\end{array}$ & $\begin{array}{c}0.002 \\
(0.010)\end{array}$ \\
\hline$N$ & 156,671 & 156,866 & 156,732 & 156,765 & 156,898 \\
\hline \multirow[t]{2}{*}{ Pre-Treatment Mean DV } & 0.183 & 0.377 & 0.134 & 0.130 & 0.439 \\
\hline & \multicolumn{5}{|c|}{ Panel II: Ages 21 and Older } \\
\hline Year of RML Enactment & $\begin{array}{c}0.015^{* * *} \\
(0.005)\end{array}$ & $\begin{array}{c}0.005 \\
(0.006)\end{array}$ & $\begin{array}{l}-0.005 \\
(0.004)\end{array}$ & $\begin{array}{l}-0.004 \\
(0.004)\end{array}$ & $\begin{array}{c}0.000 \\
(0.007)\end{array}$ \\
\hline 1 Year After RML & $\begin{array}{c}0.008 \\
(0.009)\end{array}$ & $\begin{array}{c}0.012 \\
(0.008)\end{array}$ & $\begin{array}{l}-0.012^{*} \\
(0.006)\end{array}$ & $\begin{array}{c}0.002 \\
(0.009)\end{array}$ & $\begin{array}{c}0.007 \\
(0.012)\end{array}$ \\
\hline 2 Year After RML & $\begin{array}{c}0.026^{* * *} \\
(0.007)\end{array}$ & $\begin{array}{c}0.010 \\
(0.008)\end{array}$ & $\begin{array}{c}-0.015^{* *} \\
(0.006)\end{array}$ & $\begin{array}{c}0.004 \\
(0.007)\end{array}$ & $\begin{array}{c}0.003 \\
(0.010)\end{array}$ \\
\hline 3 Years+ After RML & $\begin{array}{c}0.011 \\
(0.010)\end{array}$ & $\begin{array}{c}0.005 \\
(0.008)\end{array}$ & $\begin{array}{c}-0.016^{* *} \\
(0.007)\end{array}$ & $\begin{array}{c}0.007 \\
(0.008)\end{array}$ & $\begin{array}{c}0.002 \\
(0.011)\end{array}$ \\
\hline$N$ & 131,898 & 132,047 & 131,930 & 131,954 & 132,077 \\
\hline Pre-Treatment Mean DV & 0.172 & 0.406 & 0.123 & 0.125 & 0.461 \\
\hline
\end{tabular}

***Significant at $1 \%$ level $* *$ Significant at $5 \%$ level $*$ Significant at $10 \%$ level.

All estimates are weighted. All regressions include individual fixed effects, state fixed effects, year-by-month fixed effects, wave fixed effects, and medical marijuana laws. Demographic controls include gender, age, educational attainment, race/ethnicity; economic controls include unemployment rate, state poverty rate, and log of ACS mean total pre-tax personal income; smoking policy controls include index of indoor vaping restrictions, total e-cigarette taxes, any e-cigarette MLSA, total cigarette taxes, index of indoor smoking restrictions, minimum age for cigarette sales; other policy controls include: state EITC refundable credit rate, log of minimum wage, whether the governor is a Democrat, presence of an ACA Medicaid expansion, presence of a must access prescription drug monitoring program, and beer tax per gallon. Standard errors, in parentheses, are clustered within 156 primary sampling units that are nested within states (except in one instance). 
Table 14. Exploring Dynamics: Initiation and Cessation by Age, PATH

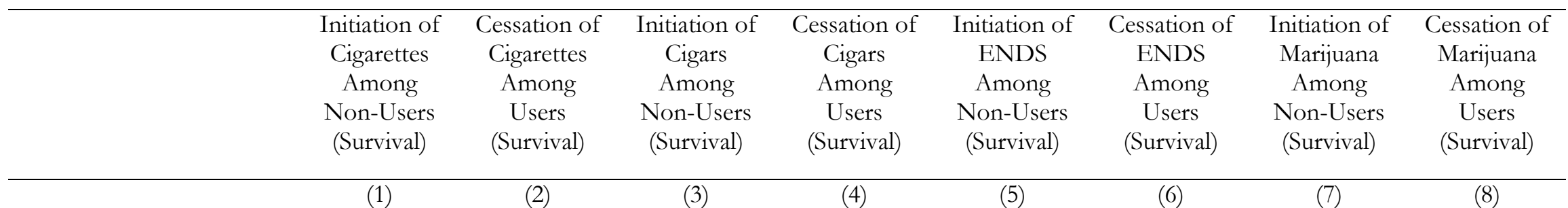

\begin{tabular}{|c|c|c|c|c|c|c|c|c|}
\hline \multicolumn{9}{|c|}{ Panel I: Ages 18 and Older } \\
\hline RML & 0.002 & -0.008 & -0.002 & 0.057 & -0.002 & 0.007 & $0.013 * * *$ & -0.019 \\
\hline & $(0.005)$ & $(0.012)$ & $(0.002)$ & $(0.041)$ & $(0.003)$ & $(0.049)$ & $(0.004)$ & $(0.020)$ \\
\hline$N$ & 82,455 & 53,162 & 118,258 & 14,661 & 118,174 & 13,399 & 116,108 & 18,214 \\
\hline Pre-Treatment Mean DV & 0.038 & 0.081 & 0.039 & 0.263 & 0.048 & 0.300 & 0.049 & 0.153 \\
\hline \multicolumn{9}{|c|}{ Panel II: Ages 21 and Older } \\
\hline RML & 0.004 & -0.011 & -0.002 & 0.040 & -0.002 & 0.012 & $0.013^{* * *}$ & -0.025 \\
\hline & $(0.005)$ & $(0.013)$ & $(0.002)$ & $(0.045)$ & $(0.003)$ & $(0.053)$ & $(0.004)$ & $(0.021)$ \\
\hline$N$ & 65,747 & 48,980 & 100,682 & 11,832 & 100,452 & 10,676 & 99,467 & 14,411 \\
\hline Pre-Treatment Mean DV & 0.032 & 0.076 & 0.036 & 0.254 & 0.042 & 0.306 & 0.043 & 0.146 \\
\hline Years & $2013-2019$ & $2013-2019$ & $2013-2019$ & $2013-2019$ & $2013-2019$ & $2013-2019$ & $2013-2019$ & $2013-2019$ \\
\hline
\end{tabular}

$* * *$ Significant at $1 \%$ level **Significant at $5 \%$ level *Significant at $10 \%$ level.

All estimates are weighted. All regressions include individual fixed effects, state fixed effects, year-by-month fixed effects, wave fixed effects, and medical marijuana laws. Demographic controls include gender, age, educational attainment, race/ethnicity; economic controls include unemployment rate, state poverty rate, and log of ACS mean total pre-tax personal income; smoking policy controls include index of indoor vaping restrictions, total e-cigarette taxes, any e-cigarette MLSA, total cigarette taxes, index of indoor smoking restrictions, minimum age for cigarette sales; other policy controls include: state EITC refundable credit rate, log of minimum wage, whether the governor is a Democrat, presence of an ACA Medicaid expansion, presence of a must access prescription drug monitoring program, and beer tax per gallon. Standard errors, in parentheses, are clustered within 156 primary sampling units that are nested within states (except in one instance). 
Table 15. Exploring Dynamics: Dual Use by Age, PATH

\begin{tabular}{|c|c|c|c|c|}
\hline & $\begin{array}{c}\text { Dual Marijuana and } \\
\text { Tobacco Use }\end{array}$ & $\begin{array}{c}\text { Initiation of Marijuana } \\
\text { among Baseline Tobacco } \\
\text { Users }\end{array}$ & $\begin{array}{c}\text { Initiation of } \\
\text { Tobacco and } \\
\text { Marijuana among } \\
\text { Baseline Non-users }\end{array}$ & $\begin{array}{c}\text { Dual Marijuana and } \\
\text { ENDS Use }\end{array}$ \\
\hline & $(1)$ & $(2)$ & (3) & (4) \\
\hline & \multicolumn{4}{|c|}{ Panel I: Ages 18 and Older } \\
\hline RML & $\begin{array}{c}0.013^{* * *} \\
(0.003)\end{array}$ & $\begin{array}{c}0.032^{* * *} \\
(0.012)\end{array}$ & $\begin{array}{c}0.002 \\
(0.002)\end{array}$ & $\begin{array}{c}0.003 \\
(0.002)\end{array}$ \\
\hline$N$ & 156,707 & 52,427 & 64,787 & 156,805 \\
\hline Pre-Treatment Mean DV & 0.141 & 0.067 & 0.018 & 0.048 \\
\hline & \multicolumn{4}{|c|}{ Panel II: Ages 21 and Older } \\
\hline RML & $\begin{array}{c}0.012^{* * *} \\
(0.004)\end{array}$ & $\begin{array}{l}0.030 * * \\
(0.012)\end{array}$ & $\begin{array}{c}0.002 \\
(0.002)\end{array}$ & $\begin{array}{c}0.003 \\
(0.002)\end{array}$ \\
\hline$N$ & 131,927 & 47,993 & 51,672 & 132,009 \\
\hline Pre-Treatment Mean DV & 0.133 & 0.061 & 0.013 & 0.040 \\
\hline Years & 2013-2019 & $2013-2019$ & 2013-2019 & 2013-2019 \\
\hline
\end{tabular}

***Significant at $1 \%$ level **Significant at $5 \%$ level *Significant at $10 \%$ level.

All estimates are weighted. All regressions include individual fixed effects, state fixed effects, year-by-month fixed effects, wave fixed effects, and medical marijuana laws. Demographic controls include gender, age, educational attainment, race/ethnicity; economic controls include unemployment rate, state poverty rate, and log of ACS mean total pre-tax personal income; smoking policy controls include index of indoor vaping restrictions, total e-cigarette taxes, any e-cigarette MLSA, total cigarette taxes, index of indoor smoking restrictions, minimum age for cigarette sales; other policy controls include: state EITC refundable credit rate, log of minimum wage, whether the governor is a Democrat, presence of an ACA Medicaid expansion, presence of a must access prescription drug monitoring program, and beer tax per gallon. Standard errors, in parentheses, are clustered within 156 primary sampling units that are nested within states (except in one instance). 
Appendix Figure 1. Trends in Marijuana, Tobacco, and Cigarette Use, by Age Group, NSDUH, 2002-2019

Panel (a): Marijuana Use

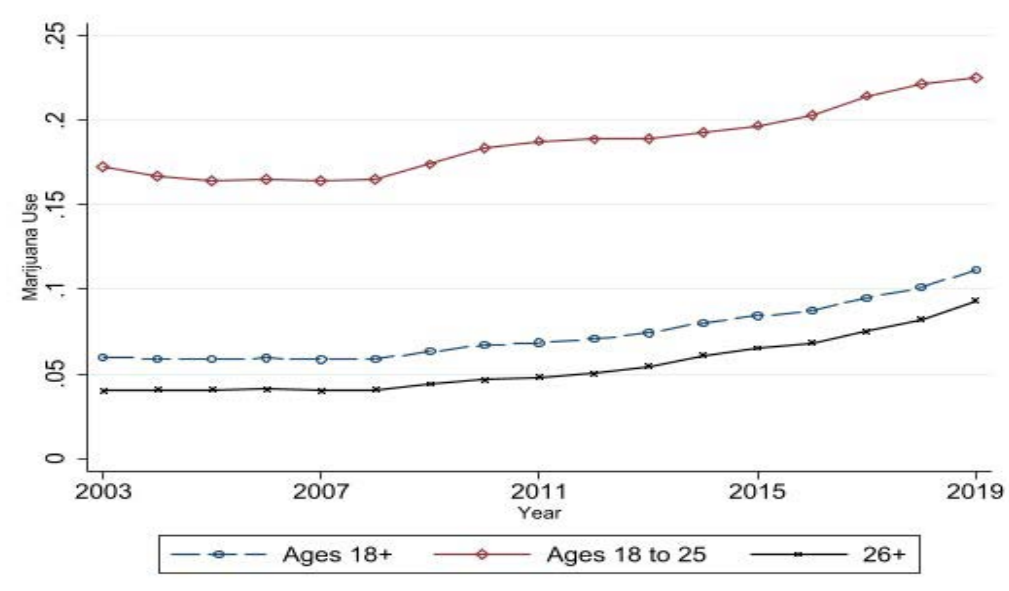

Panel (b): Tobacco Use

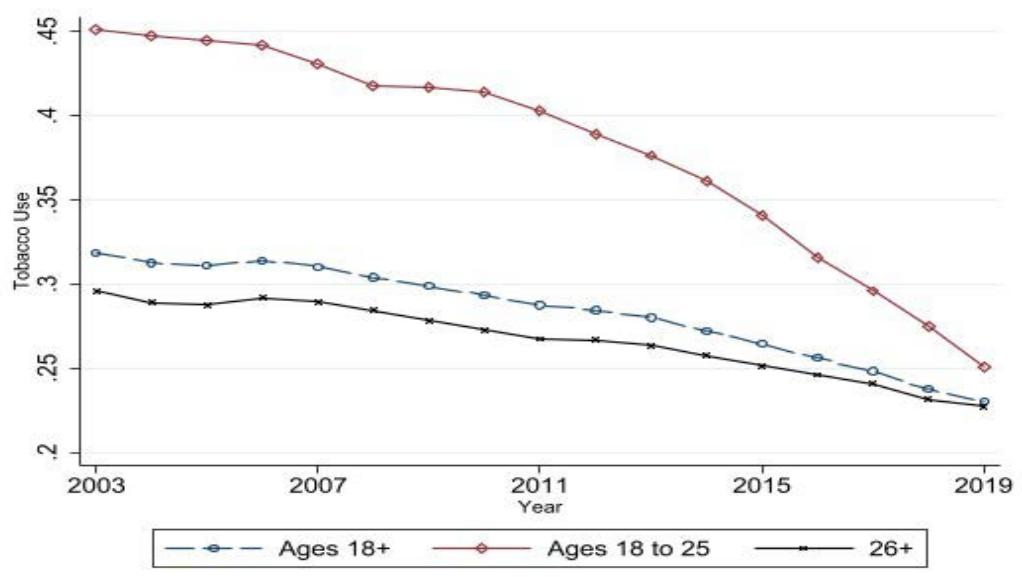

Panel (c): Cigarette Use

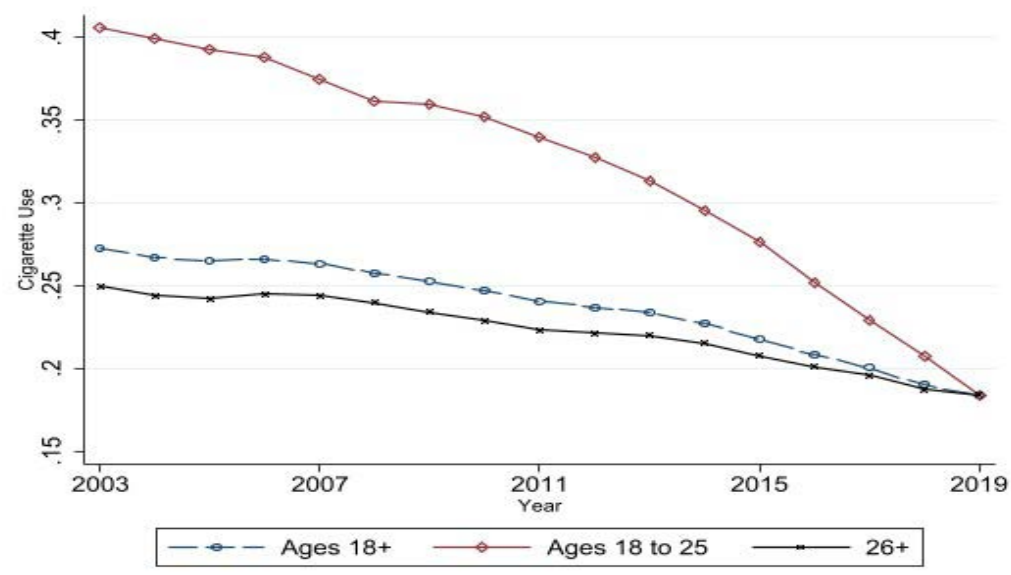


Appendix Figure 2. Trends in Smoking, by Age Group, BRFSS, 2000-2019

Panel (a): Cigarette Use

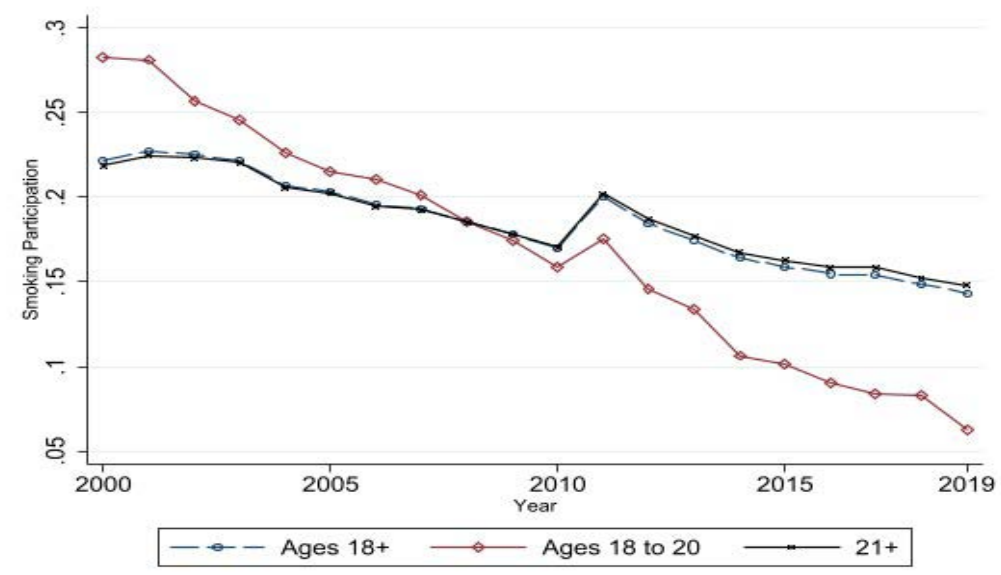

Panel (b): Everyday Smoking

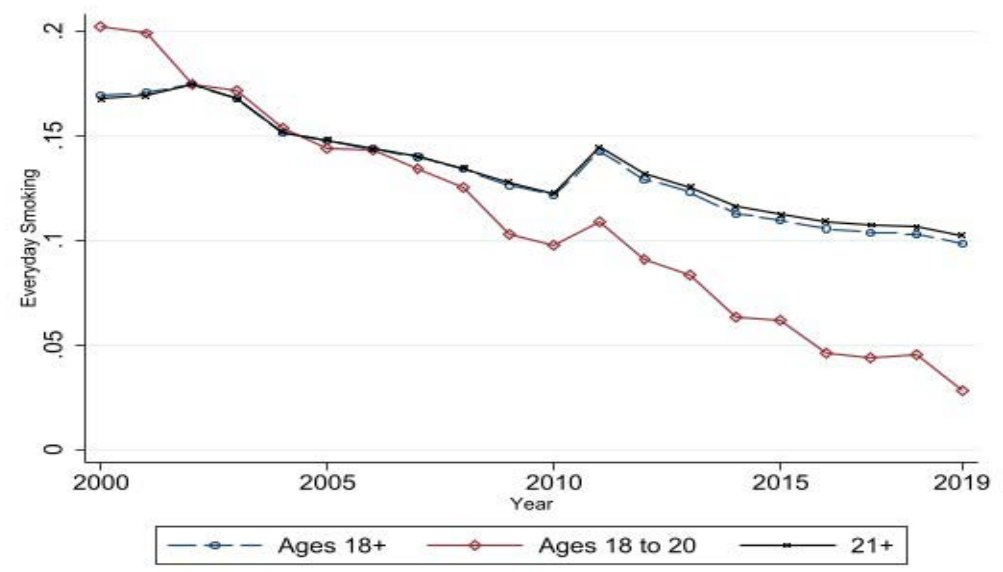

Panel (c): Quit

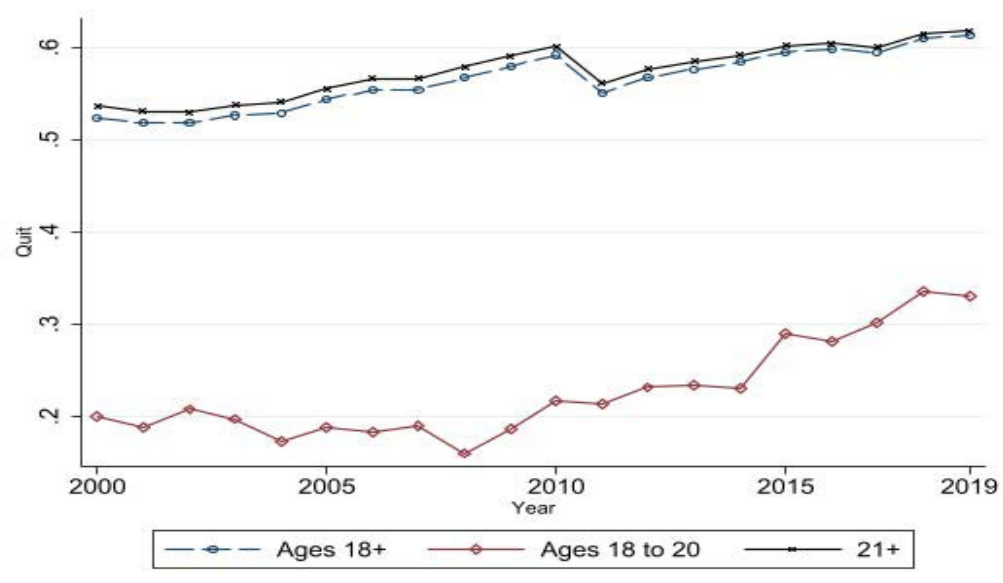


Appendix Figure 3. Trends in Smoking, by Age Group, CPS-TUS, 2000-2019

Panel (a): Cigarette Use

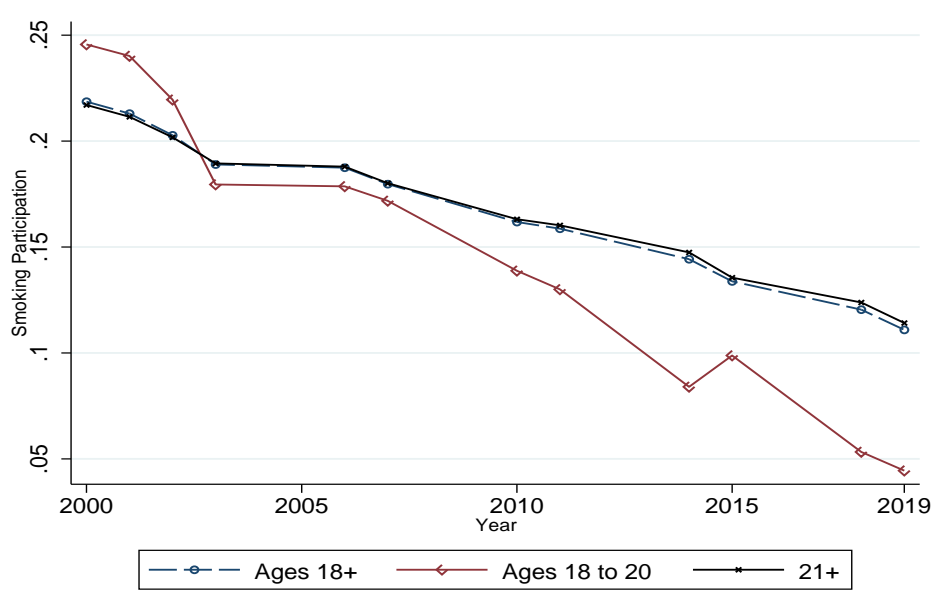

Panel (b): Everyday Smoking

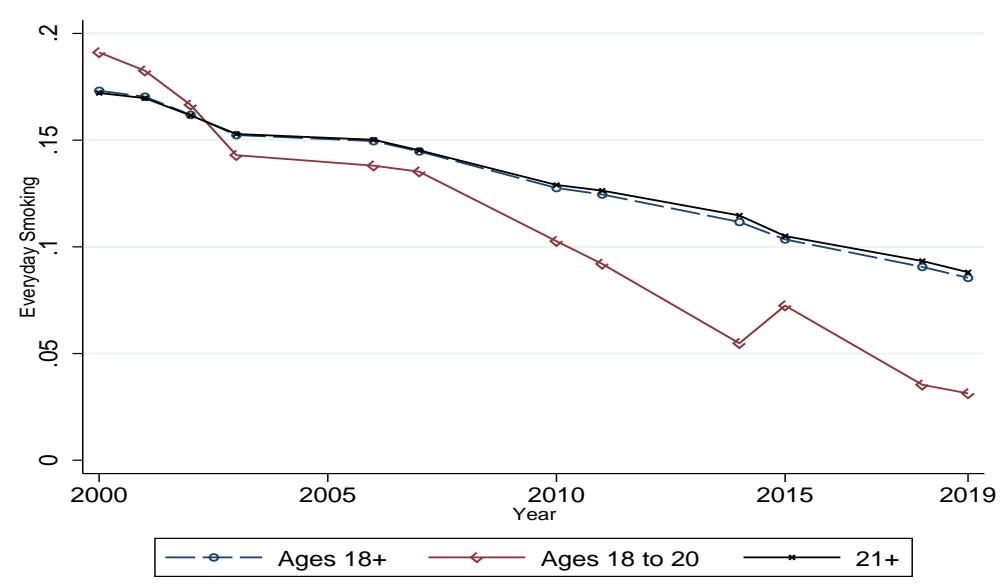

Panel (c): Quit

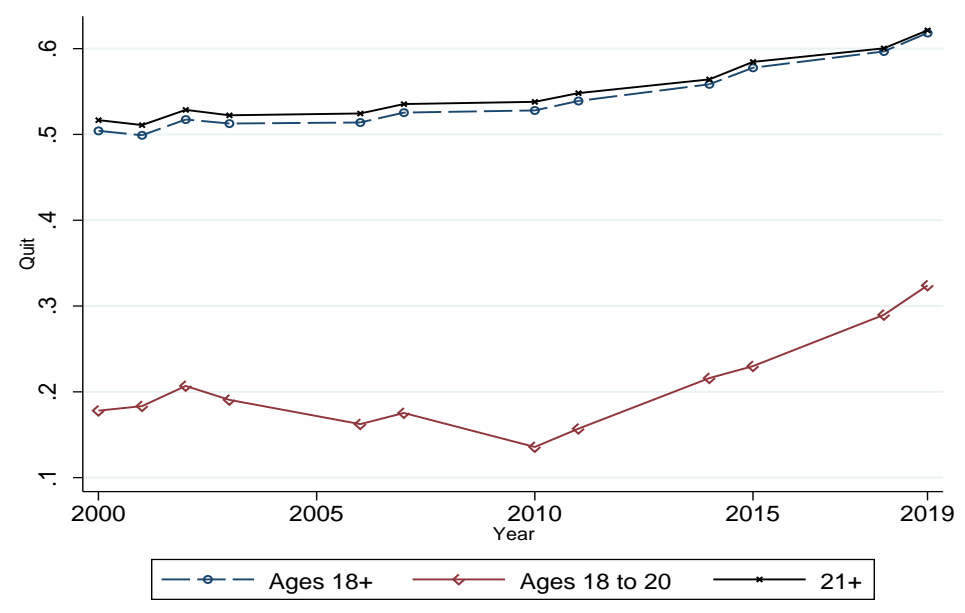


Appendix Figure 4. Event-Study Analyses for RMLs and Marijuana Use for Adults Ages 18 and Older, NSDUH, 2002-2019

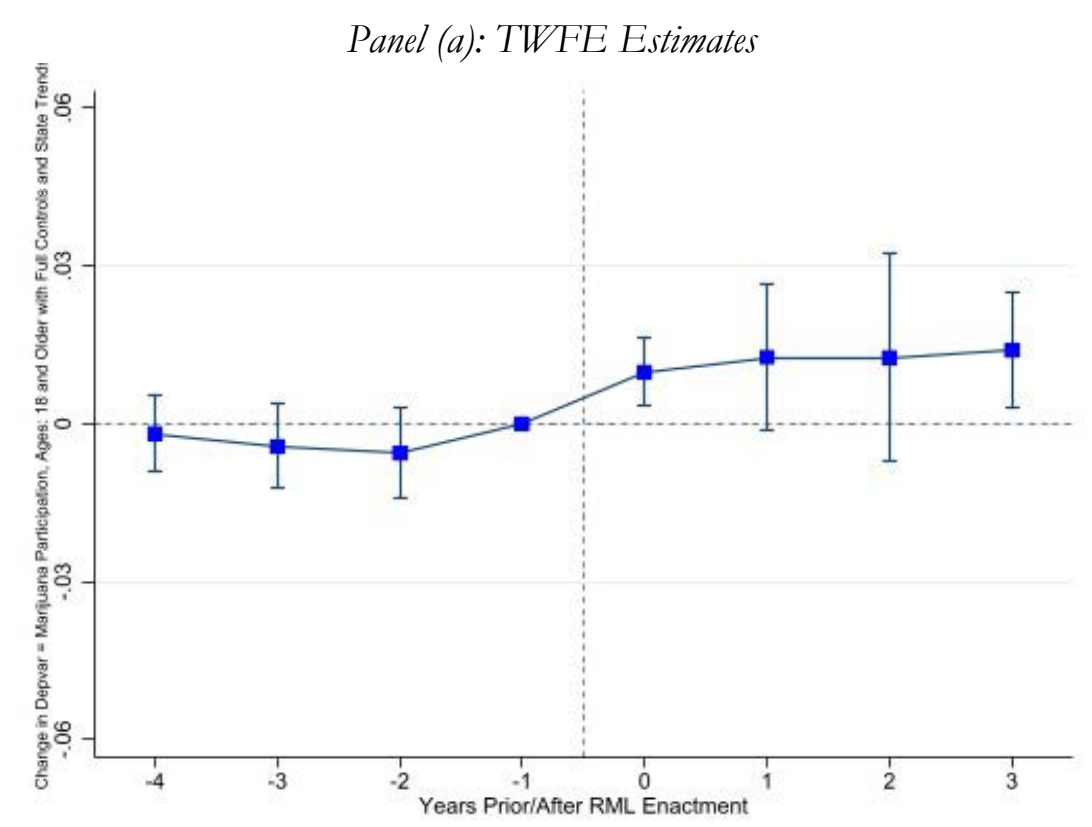

Panel (b): Callaway and Sant'Anna Estimates

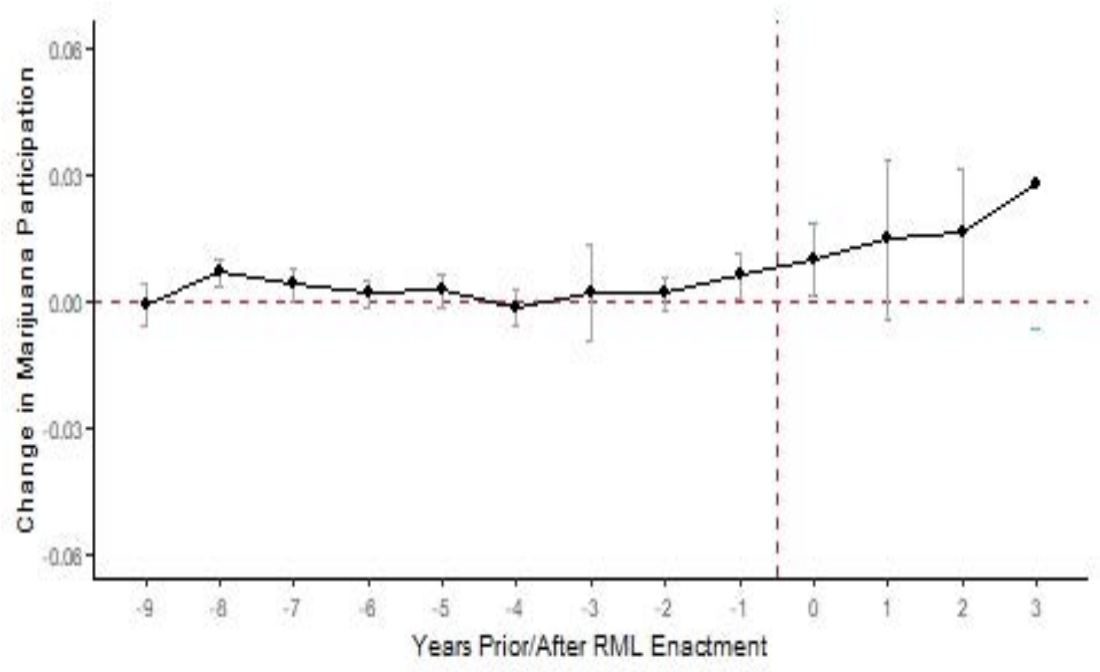

Notes: TWFE and Callaway-Sant'Anna (2021) estimates (and their 95\% CIs) are shown above. 
Appendix Figure 5. Synthetic Control Estimates for Washington

Panel (a): Marijuana Use

RML Effect $=0.032($ p-value $=0.192)$

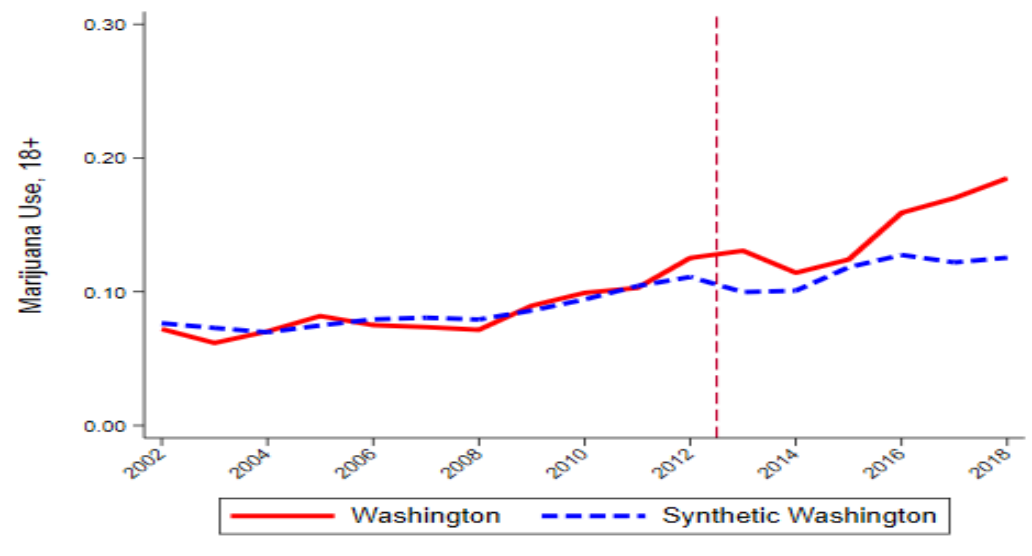

Panel (b): Tobacco Use

RML Effect $=-0.004($ p-value $=0.231)$

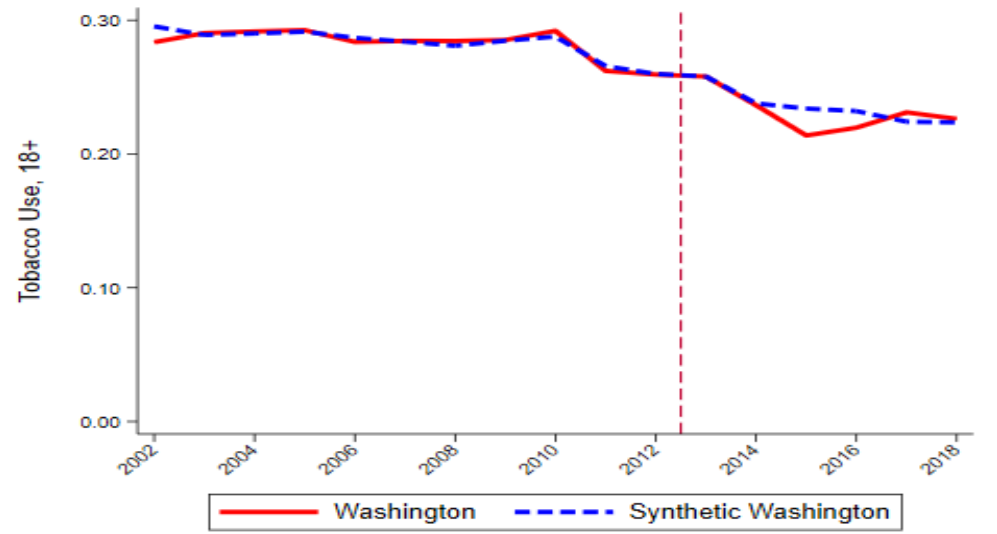

Panel (c): Cigarette Use

$R M L$ Effect $=-0.000($-value $=0.038)$

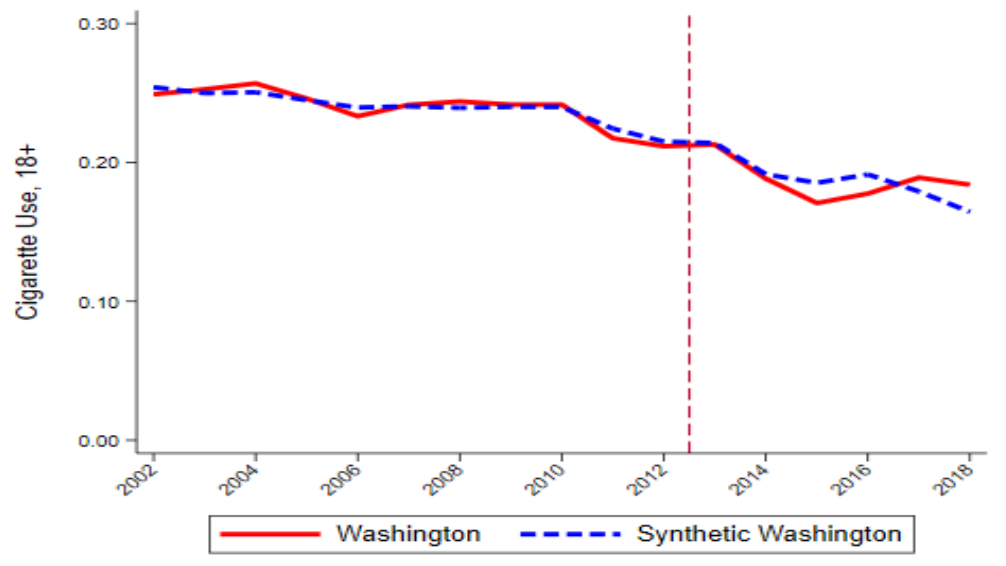




\section{Appendix Figure 6. Synthetic Control Estimates for Colorado}
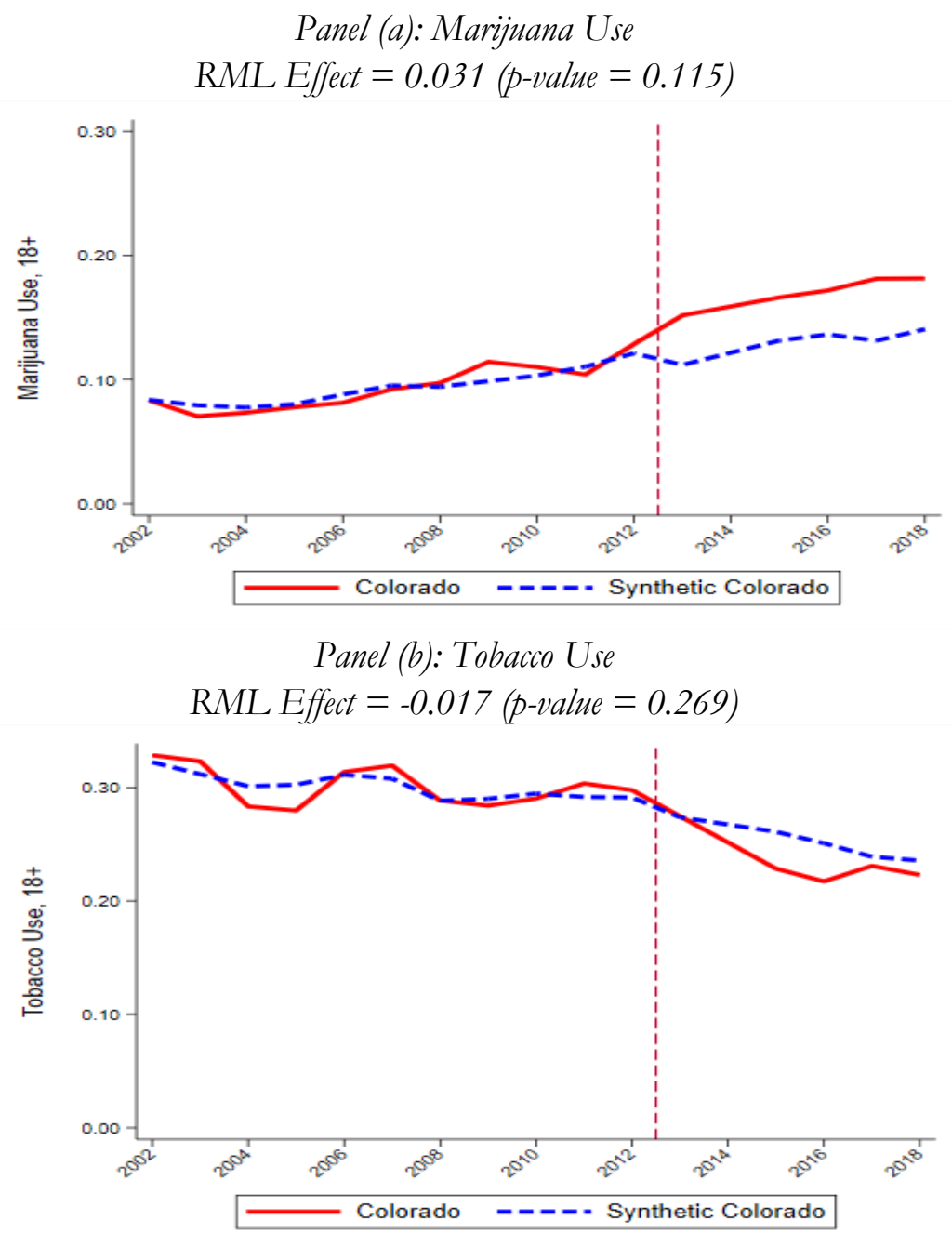

Panel (c): Cigarette Use

RML Effect $=-0.009($-value $=0.269)$

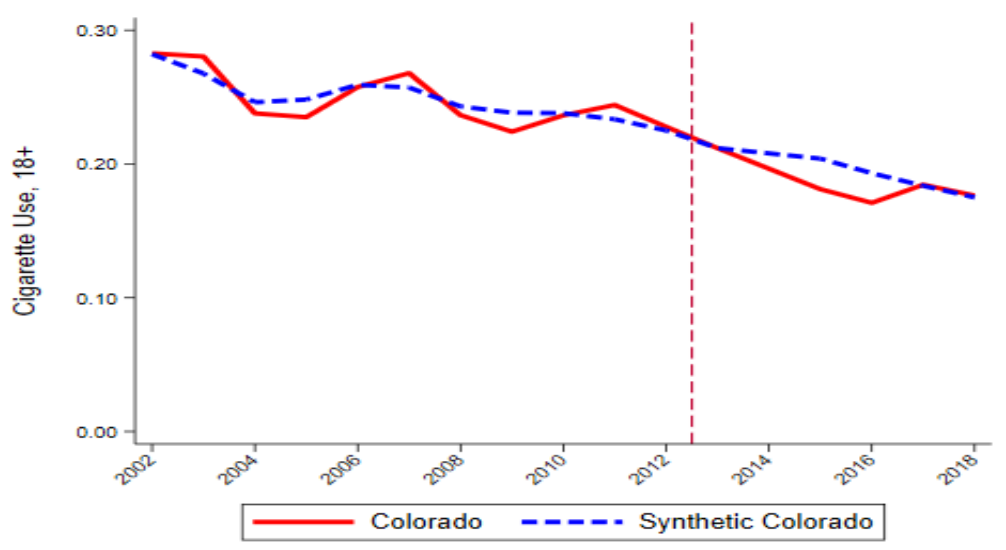




\section{Appendix Figure 7. Synthetic Control Estimates for Alaska}

Panel (a): Marijuana Use

RML Effect $=0.018($ p-value $=0.407)$

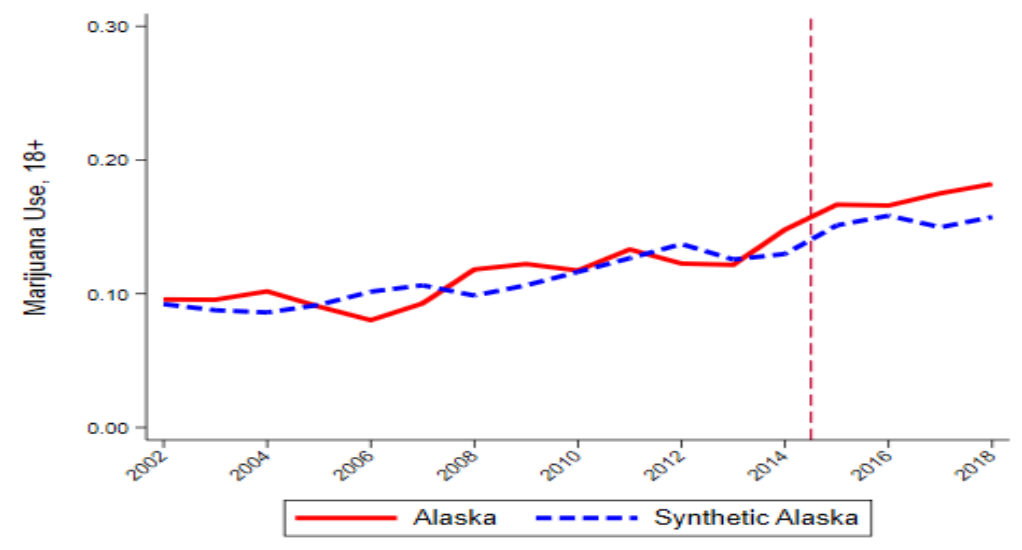

Panel (b): Tobacco Use

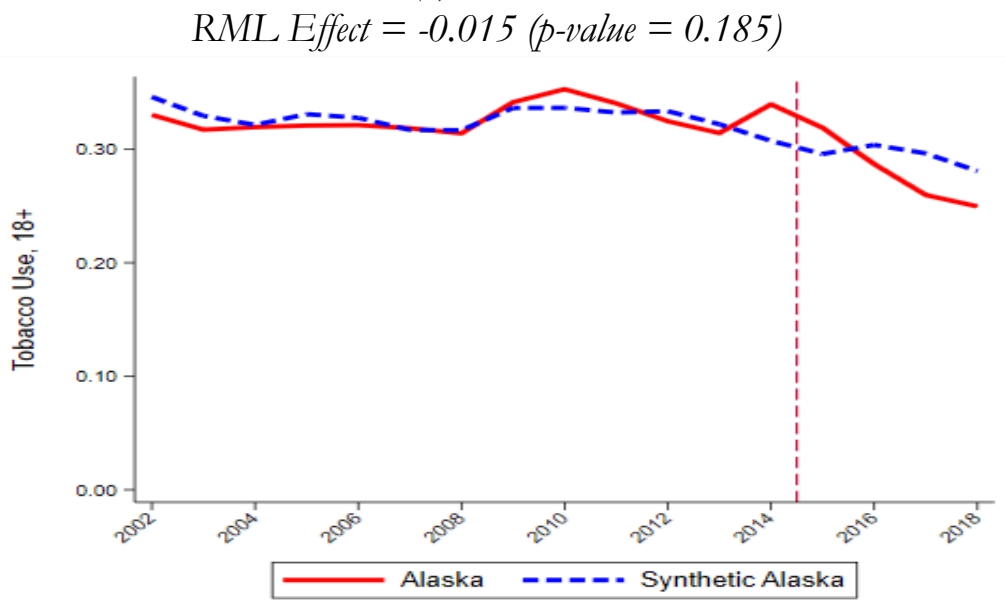

Panel (c): Cigarette Use

RML Effect $=-0.013($ p-value $=0.148)$

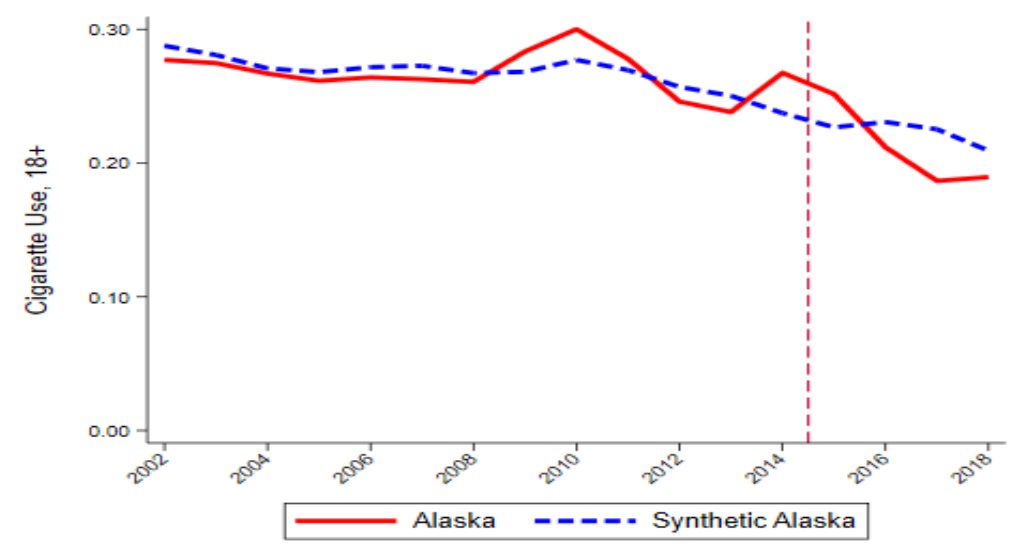




\section{Appendix Figure 8. Synthetic Control Estimates for California}

Panel (a): Marijuana Use

RML Effect $=0.001$ (p-value $=0.118)$

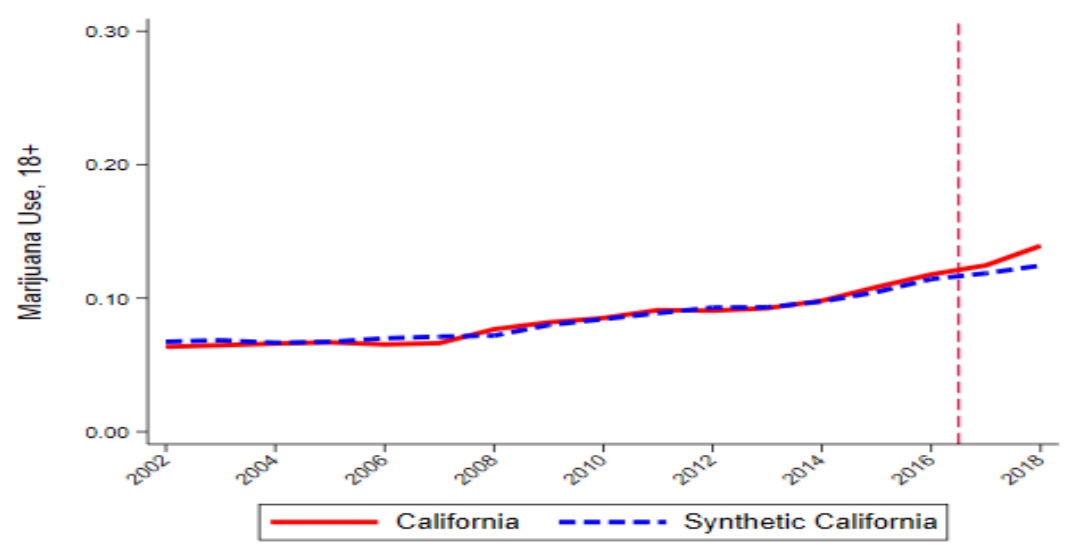

Panel (b): Tobacco Use

RML Effect $=-0.016($-value $=0.265)$

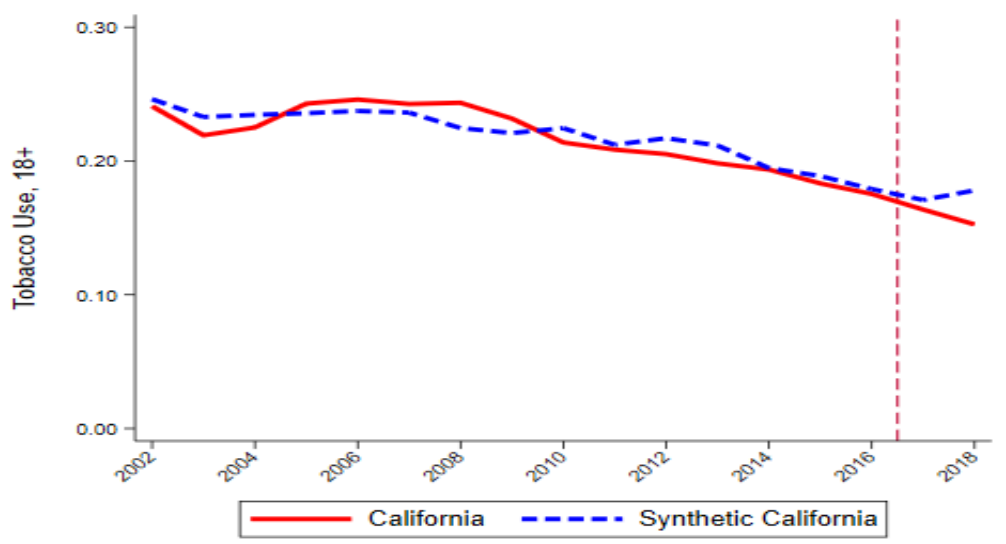

Panel (c): Cigarette Use

RML Effect $=-0.012($-value $=0.235)$

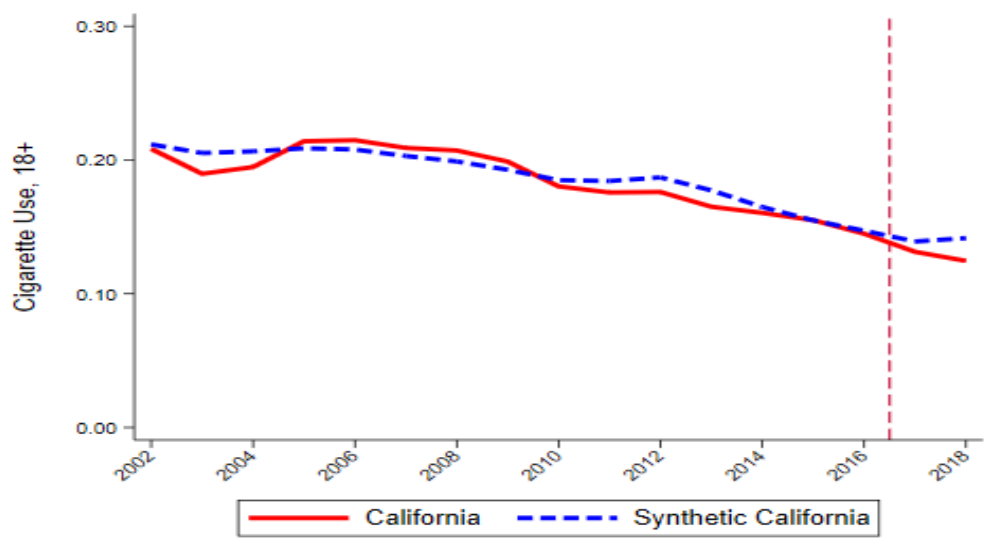




\section{Appendix Figure 9. Synthetic Control Estimates for Oregon}
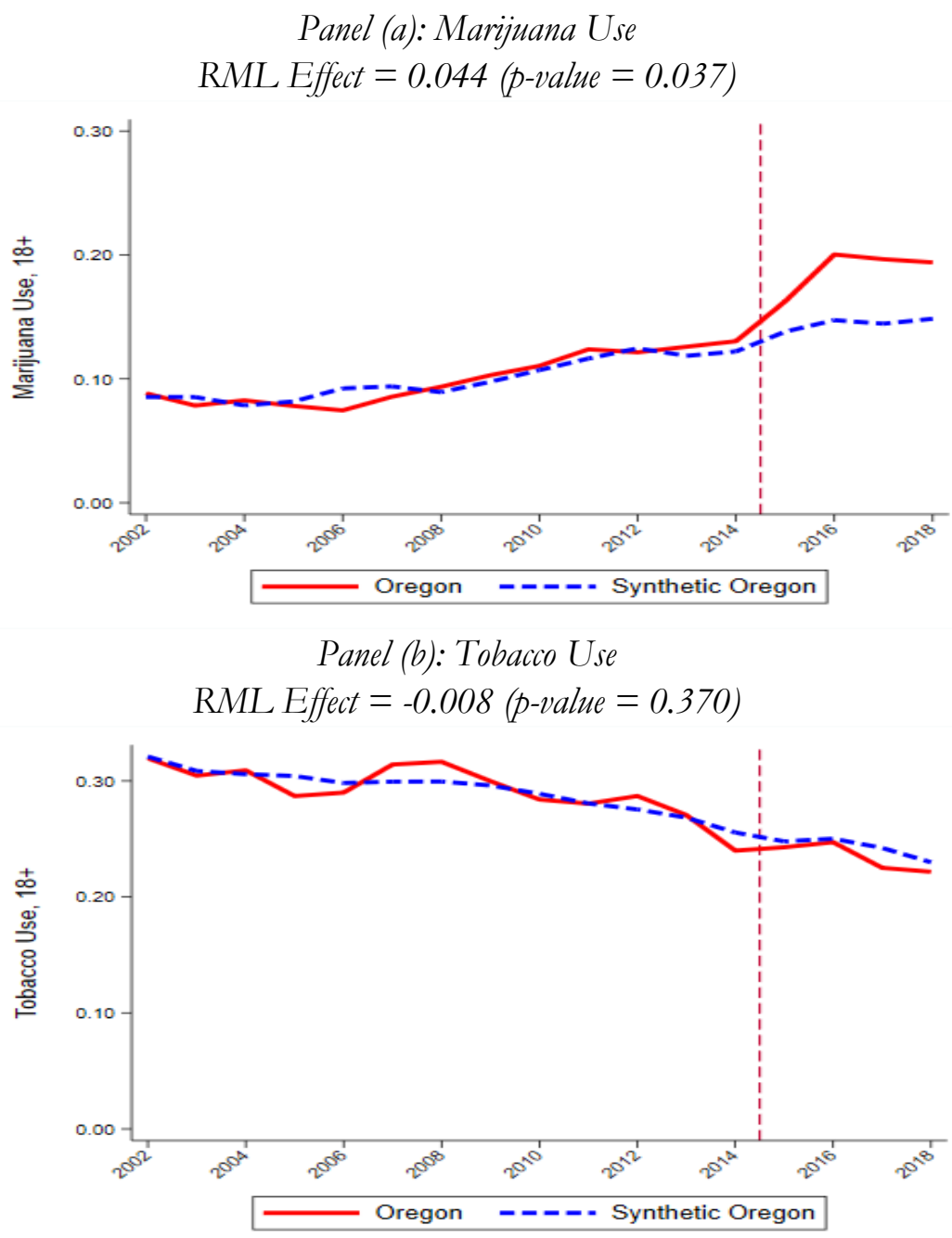

Panel (c): Cigarette Use

RML Effect $=-0.006($-value $=0.333)$

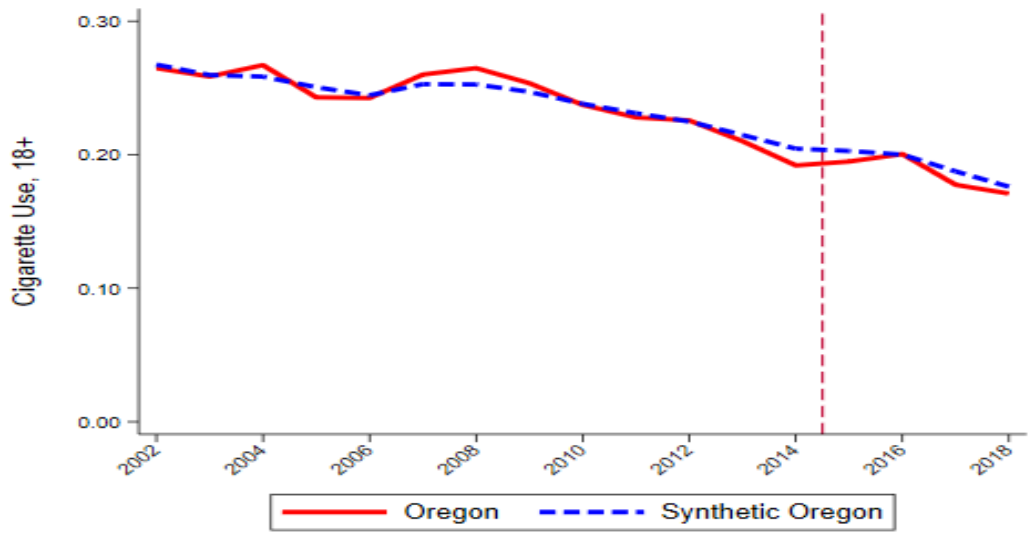




\section{Appendix Figure 10. Synthetic Control Estimates for Massachusetts}

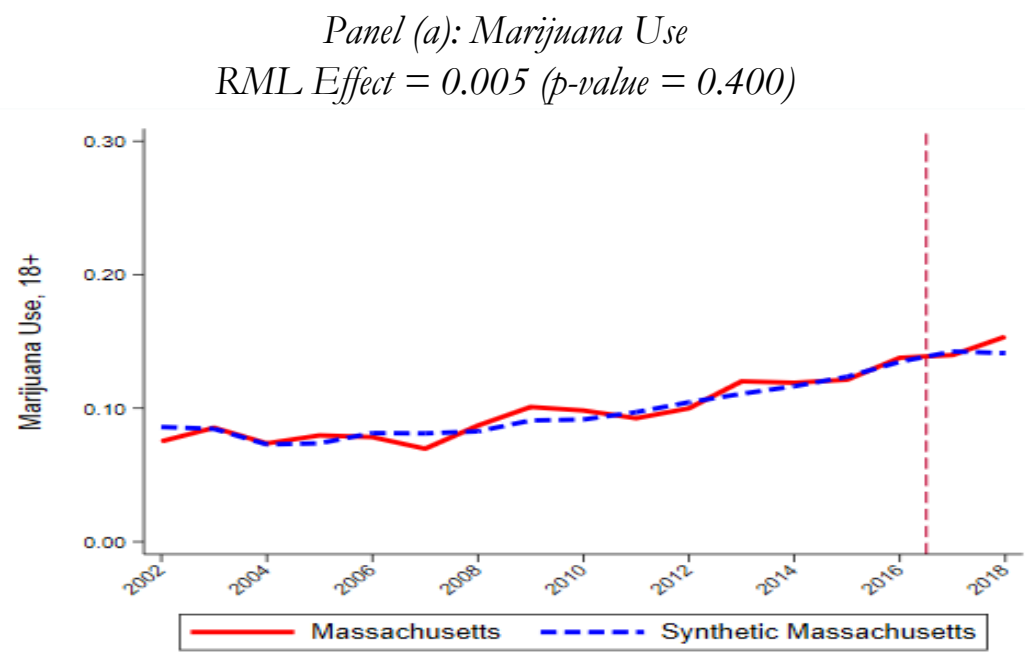

Panel (b): Tobacco Use

RML Effect $=-0.004$ (p-value $=0.286)$

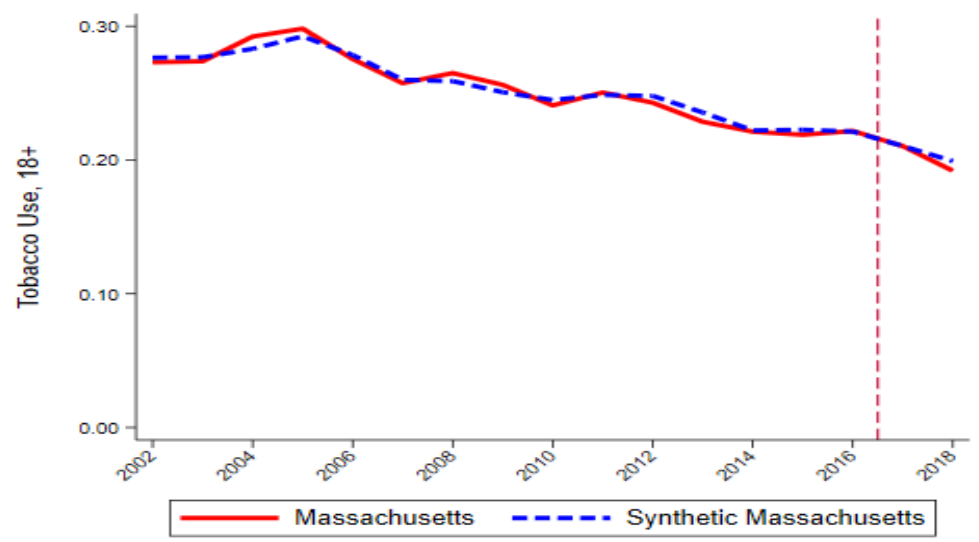

Panel (c): Cigarette Use

RML Effect $=-0.004($-value $=0.314)$

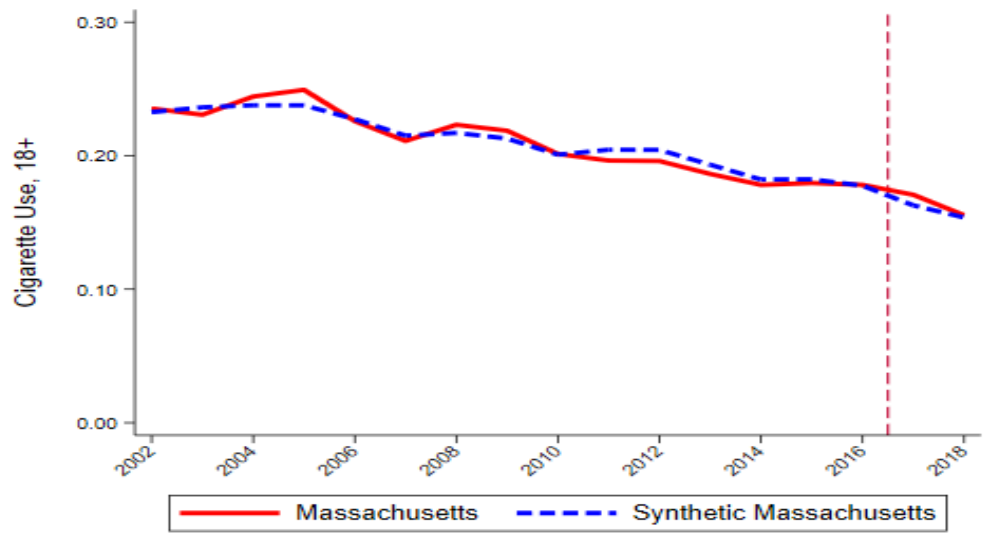


Appendix Table 1. Recreational Marijuana Law Effective Dates and Dates Recreational Sales of Marijuana Permitted, 2000-2020

\begin{tabular}{ccc}
\hline & $\begin{array}{c}\text { RML } \\
\text { enactment dates }\end{array}$ & $\begin{array}{c}\text { Dates recreational } \\
\text { sales of marijuana } \\
\text { allowed }\end{array}$ \\
\hline Alaska & $2 / 24 / 2015$ & $10 / 29 / 2016$ \\
Arizona & $11 / 30 / 2020$ & $1 / 1 / 2018$ \\
California & $11 / 9 / 2016$ & $1 / 1 / 2014$ \\
Colorado & $12 / 10 / 2012$ & $2 / 26 / 2015$ \\
D.C. & $2 / 26 / 2015$ & $1 / 1 / 2020$ \\
Illinois & $1 / 1 / 2020$ & \\
Maine & $1 / 31 / 2017$ & $11 / 20 / 2018$ \\
Massachusetts & $12 / 15 / 2016$ & $12 / 1 / 2019$ \\
Michigan & $12 / 6 / 2018$ & $7 / 1 / 2017$ \\
Montana & $1 / 1 / 2021$ & $10 / 1 / 2015$ \\
Nevada & $1 / 1 / 2017$ & \\
Oregon & $7 / 1 / 2015$ & $7 / 8 / 2014$ \\
Vermont & $7 / 1 / 2018$ & \\
Washington & $12 / 6 / 2012$ &
\end{tabular}

Source: Anderson and Rees (2021) 
Appendix Table 3. Heterogeneity in Effect of RMLs on Smoking, by Age, BRFSS 2000-2019

\begin{tabular}{|c|c|c|c|c|c|c|}
\hline & \multicolumn{2}{|c|}{ Cigarette Use } & \multicolumn{2}{|c|}{ Everyday Smoking } & \multicolumn{2}{|c|}{ Quit } \\
\hline & $(1)$ & $(2)$ & (3) & (4) & (5) & $(6)$ \\
\hline & TWFE & CS & TWFE & CS & TWFE & CS \\
\hline & \multicolumn{6}{|c|}{ Panel I: Ages 18-25 } \\
\hline RML & $\begin{array}{c}-0.00381 \\
(0.00880) \\
\end{array}$ & $\begin{array}{c}-0.0035 \\
(0.0149) \\
\end{array}$ & $\begin{array}{l}-0.00526 \\
(0.00640) \\
\end{array}$ & $\begin{array}{l}-0.0007 \\
(0.0066) \\
\end{array}$ & $\begin{array}{r}-0.00804 \\
(0.0128) \\
\end{array}$ & $\begin{array}{c}-0.0233 \\
(0.047) \\
\end{array}$ \\
\hline \multirow[t]{2}{*}{ Observations } & 707823 & 707823 & 707823 & 707823 & 139506 & 139506 \\
\hline & \multicolumn{6}{|c|}{ Panel II: Ages 26 and Older } \\
\hline RML & $\begin{array}{c}0.00101 \\
(0.00277) \\
\end{array}$ & $\begin{array}{l}-0.0061 \\
(0.0051) \\
\end{array}$ & $\begin{array}{c}-0.000661 \\
(0.00225) \\
\end{array}$ & $\begin{array}{c}-0.0086^{*} \\
(0.003) \\
\end{array}$ & $\begin{array}{c}0.00354 \\
(0.00409)\end{array}$ & $\begin{array}{c}0.0055 \\
(0.0047) \\
\end{array}$ \\
\hline Observations & 6802394 & 6802394 & 6802394 & 6802394 & 3278058 & 3278058 \\
\hline State FE, Year-Month FE \& MML? & Yes & Yes & Yes & Yes & Yes & Yes \\
\hline Individual and State Controls? & Yes & No & Yes & No & Yes & No \\
\hline State Linear Time Trends? & Yes & No & Yes & No & Yes & No \\
\hline $\begin{array}{l}\text { lll estimates are weighted. Demographic } \\
\text { overty rate, and ACS mean total pre-tax } \\
\text { f indoor smoking restrictions, minimum } \\
\text { Democrat, percent of quarter with ACA } \\
\text { tate level are in parentheses. All regressio } \\
\text { t } 10 \% \text { level. }\end{array}$ & icy controls & $\begin{array}{l}\text { ttainment, } r a \\
\text { include inde } \\
\text { ude: state El } \\
\text { a pdmp_ma } \\
\text { nonth fixed }\end{array}$ & $\begin{array}{l}\text { inicity; econor } \\
\text { door vaping } r \\
\text { fundable credi } \\
\text { tax per gallon } \\
* * * \text { Significan }\end{array}$ & $\begin{array}{l}\text { trols include } \\
\text { ns, any e-cig } \\
\text { hinimum wa } \\
\text { ard errors co } \\
\text { level }{ }^{* *} \text { Sign }\end{array}$ & $\begin{array}{l}\text { mployment } \\
\text { SA, total cig } \\
\text { whether the g } \\
\text { ted for cluste }\end{array}$ & $\begin{array}{l}\text {, state } \\
\text { es, index } \\
\text { rnor is a } \\
g \text { at the } \\
\text { Significant }\end{array}$ \\
\hline
\end{tabular}


Appendix Table 4. Recreational Marijuana Laws and E-cigarette Use, Ages 18 and Older, CPS-TUS

\begin{tabular}{|c|c|c|c|c|c|c|}
\hline & \multicolumn{2}{|c|}{ Ages 18 and Older } & \multicolumn{2}{|c|}{ Ages 18-20 } & \multicolumn{2}{|c|}{ Ages 21 and Older } \\
\hline & $(1)$ & $(2)$ & (3) & (4) & (5) & (6) \\
\hline & \multicolumn{6}{|c|}{ Panel I: Overall RML Effect } \\
\hline \multirow[t]{2}{*}{ RML } & -0.00070 & 0.00482 & 0.01398 & 0.02276 & -0.00162 & 0.00356 \\
\hline & $(0.00190)$ & $(0.00349)$ & $(0.02500)$ & $(0.03641)$ & $(0.00218)$ & $(0.00297)$ \\
\hline \multirow[t]{2}{*}{ Pre-Treatment Mean DV } & 0.0248 & 0.0248 & 0.0461 & 0.0461 & 0.0237 & 0.0237 \\
\hline & \multicolumn{6}{|c|}{ Panel II: Lagged RML Effects } \\
\hline \multirow[t]{2}{*}{ Year of RML Enactment } & -0.00308 & 0.00502 & -0.05256 & -0.03270 & -0.00101 & $0.00667 *$ \\
\hline & $(0.00568)$ & $(0.00576)$ & $(0.03595)$ & $(0.08516)$ & $(0.00461)$ & $(0.00397)$ \\
\hline \multirow[t]{2}{*}{1 Year After RML } & -0.00019 & 0.01246 & -0.01116 & 0.00634 & -0.00011 & $0.01228^{* *}$ \\
\hline & $(0.00395)$ & $(0.00750)$ & $(0.03687)$ & $(0.10262)$ & $(0.00321)$ & $(0.00606)$ \\
\hline \multirow[t]{2}{*}{2 Year After RML } & -0.00524 & -0.00047 & -0.02557 & -0.02091 & -0.00473 & 0.00009 \\
\hline & $(0.00373)$ & $(0.00975)$ & $(0.04404)$ & $(0.14911)$ & $(0.00451)$ & $(0.00872)$ \\
\hline \multirow[t]{2}{*}{3 Years+ After RML } & -0.00602 & -0.00276 & 0.01035 & 0.00670 & $-0.00746^{*}$ & -0.00366 \\
\hline & $(0.00374)$ & $(0.01087)$ & $(0.04759)$ & $(0.16874)$ & $(0.00425)$ & $(0.00881)$ \\
\hline State FE, Year-Month FE \& MML? & Yes & Yes & Yes & Yes & Yes & Yes \\
\hline Individual and State Controls? & Yes & Yes & Yes & Yes & Yes & Yes \\
\hline State Linear Time Trends? & No & Yes & No & Yes & No & Yes \\
\hline$N$ & 297258 & 297258 & 5831 & 5831 & 291427 & 291427 \\
\hline
\end{tabular}

All estimates are based on the TWFE estimation and are weighted by the CPS-TUS sampling weights. Sociodemographic controls include indicators for age, gender, race (black, race other than black or white), Hispanic ethnicity, and educational attainment (high school, some college, college or above); tobacco policy controls include index of indoor vaping restrictions, any e-cig MLSA, total cig taxes, index of indoor smoking restrictions, minimum age for cig sales; other economic and policy controls include: unemployment rate, state poverty rate, $\log$ of ACS mean total pre-tax personal income, state EITC refundable credit rate, log of minimum wage, whether the governor is a Democrat, presence of an ACA Medicaid expansion, presence of a must access prescription drug monitoring program, and beer tax per gallon. Standard errors corrected for clustering at the state level are in parentheses. All specifications include state fixed effects and year-by-month fixed effects. 
Appendix Table 5. Recreational Marijuana Laws and Marijuana Use, Lagged Effects, Additional Age Groups, PATH

\begin{tabular}{|c|c|c|c|c|c|}
\hline & $\begin{array}{l}\text { Past } 30 \text { day } \\
\text { Marijuana Use }\end{array}$ & $\begin{array}{l}\text { Prior-Month } \\
\text { Cigarette Use }\end{array}$ & $\begin{array}{l}\text { Prior-Month } \\
\text { ENDS Use }\end{array}$ & $\begin{array}{l}\text { Prior-Month } \\
\text { Cigar Use }\end{array}$ & $\begin{array}{l}\text { Prior Month } \\
\text { Combustible } \\
\text { Tobacco Use }\end{array}$ \\
\hline & $(1)$ & $(2)$ & (3) & (4) & $(5)$ \\
\hline \multicolumn{6}{|c|}{ Panel I: Ages 18 to 20} \\
\hline \multirow[t]{2}{*}{ Year of RML Enactment } & 0.004 & -0.018 & 0.034 & -0.029 & -0.020 \\
\hline & $(0.033)$ & $(0.018)$ & $(0.022)$ & $(0.031)$ & $(0.027)$ \\
\hline \multirow[t]{2}{*}{1 Year After RML } & 0.047 & -0.059 & 0.020 & 0.021 & 0.024 \\
\hline & $(0.067)$ & $(0.037)$ & $(0.052)$ & $(0.047)$ & $(0.056)$ \\
\hline \multirow[t]{2}{*}{2 Year After RML } & 0.024 & -0.035 & 0.026 & -0.008 & -0.004 \\
\hline & $(0.053)$ & $(0.035)$ & $(0.053)$ & $(0.043)$ & $(0.048)$ \\
\hline \multirow[t]{2}{*}{3 Years+ After RML } & 0.041 & -0.033 & -0.001 & -0.027 & -0.015 \\
\hline & $(0.074)$ & $(0.048)$ & $(0.079)$ & $(0.044)$ & $(0.066)$ \\
\hline$N$ & 24,773 & 24,819 & 24,802 & 24,811 & 24,821 \\
\hline \multirow[t]{2}{*}{ Pre-Treatment Mean DV } & 0.244 & 0.223 & 0.194 & 0.155 & 0.321 \\
\hline & \multicolumn{5}{|c|}{ Panel II: Ages 18 to 25} \\
\hline \multirow[t]{2}{*}{ Year of RML Enactment } & $0.041 * * *$ & -0.009 & -0.009 & -0.009 & -0.016 \\
\hline & $(0.012)$ & $(0.012)$ & $(0.013)$ & $(0.011)$ & $(0.014)$ \\
\hline \multirow[t]{2}{*}{1 Year After RML } & 0.043 & 0.014 & -0.015 & -0.010 & 0.001 \\
\hline & $(0.027)$ & $(0.023)$ & $(0.021)$ & $(0.023)$ & $(0.026)$ \\
\hline \multirow[t]{2}{*}{2 Year After RML } & $0.044^{*}$ & 0.002 & -0.021 & 0.001 & -0.000 \\
\hline & $(0.023)$ & $(0.020)$ & $(0.022)$ & $(0.019)$ & $(0.021)$ \\
\hline \multirow[t]{2}{*}{3 Years+ After RML } & 0.050 & 0.003 & -0.030 & -0.005 & -0.023 \\
\hline & $(0.034)$ & $(0.022)$ & $(0.029)$ & $(0.022)$ & $(0.028)$ \\
\hline$N$ & 53,661 & 53,746 & 53,706 & 53,737 & 53,754 \\
\hline \multirow[t]{2}{*}{ Pre-Treatment Mean DV } & 0.256 & 0.293 & 0.182 & 0.166 & 0.388 \\
\hline & \multicolumn{5}{|c|}{ Panel III: Ages 26 and Older } \\
\hline Year of RML Enactment & $\begin{array}{l}0.012^{* *} \\
(0.005)\end{array}$ & $\begin{array}{c}0.006 \\
(0.006)\end{array}$ & $\begin{array}{l}-0.004 \\
(0.004)\end{array}$ & $\begin{array}{l}-0.003 \\
(0.005)\end{array}$ & $\begin{array}{c}0.002 \\
(0.007)\end{array}$ \\
\hline
\end{tabular}




\begin{tabular}{|c|c|c|c|c|c|}
\hline 1 Year After RML & $\begin{array}{c}0.010 \\
(0.010)\end{array}$ & $\begin{array}{c}0.010 \\
(0.008)\end{array}$ & $\begin{array}{c}-0.012 * * \\
(0.006)\end{array}$ & $\begin{array}{c}0.005 \\
(0.008)\end{array}$ & $\begin{array}{c}0.008 \\
(0.012)\end{array}$ \\
\hline \multirow[t]{2}{*}{2 Year After RML } & $0.026^{* * *}$ & 0.009 & $-0.012 * *$ & 0.006 & 0.003 \\
\hline & $(0.007)$ & $(0.008)$ & $(0.006)$ & $(0.006)$ & $(0.010)$ \\
\hline \multirow[t]{2}{*}{3 Years+ After RML } & 0.012 & 0.007 & -0.011 & 0.011 & 0.007 \\
\hline & $(0.010)$ & $(0.008)$ & $(0.007)$ & $(0.008)$ & $(0.011)$ \\
\hline$N$ & 103,010 & 103,120 & 103,026 & 103,028 & 103,144 \\
\hline Pre-Treatment Mean DV & 0.146 & 0.421 & 0.109 & 0.111 & 0.465 \\
\hline Years & 2013-2019 & 2013-2019 & 2013-2019 & 2013-2019 & 2013-2019 \\
\hline
\end{tabular}

***Significant at $1 \%$ level **Significant at $5 \%$ level *Significant at $10 \%$ level.

All estimates are weighted. All regressions include individual fixed effects, state fixed effects, year-by-month fixed effects, wave fixed effects, and medical marijuana laws. Demographic controls include gender, age, educational attainment, race/ethnicity; economic controls include unemployment rate, state poverty rate, and log of ACS mean total pre-tax personal income; smoking policy controls include index of indoor vaping restrictions, total e-cigarette taxes, any e-cigarette MLSA, total cigarette taxes, index of indoor smoking restrictions, minimum age for cigarette sales; other policy controls include: state EITC refundable credit rate, log of minimum wage, whether the governor is a Democrat, presence of an ACA Medicaid expansion, presence of a must access prescription drug monitoring program, and beer tax per gallon. Standard errors, in parentheses, are clustered within 156 primary sampling units that are nested within states (except in one instance). 
Appendix Table 6. Recreational Marijuana Laws and Marijuana Use, Additional Age Groups, PATH

\begin{tabular}{|c|c|c|c|c|c|c|}
\hline & $\begin{array}{l}\text { Past } 12 \\
\text { month } \\
\text { Marijuana } \\
\text { Use } \\
\end{array}$ & $\begin{array}{c}\text { Past } 30 \text { day } \\
\text { Marijuana } \\
\text { Use }\end{array}$ & $\begin{array}{l}\text { Past } 30 \text { day } \\
\text { Blunt Use }\end{array}$ & $\begin{array}{c}\text { Number of } \\
\text { days of Blunt } \\
\text { Use in Past } \\
30 \text { days }\end{array}$ & $\begin{array}{l}\text { Past } 2 \text { day } \\
\text { Vaped } \\
\text { Marijuana } \\
\text { Use } \\
\end{array}$ & $\begin{array}{c}\text { Ever Vaped } \\
\text { Marijuana } \\
\text { Use }\end{array}$ \\
\hline & & $(2)$ & (3) & (4) & (5) & (6) \\
\hline & \multicolumn{6}{|c|}{ Panel I: Ages 18 to 20} \\
\hline RML & $\begin{array}{c}0.021 \\
(0.031)\end{array}$ & $\begin{array}{c}0.004 \\
(0.033)\end{array}$ & $\begin{array}{l}-0.006 \\
(0.023)\end{array}$ & $\begin{array}{c}-0.168 \\
(0.455)\end{array}$ & $\begin{array}{l}-0.027 \\
(0.019)\end{array}$ & $\begin{array}{c}0.033 \\
(0.029) \\
\end{array}$ \\
\hline$N$ & 24,802 & 24,773 & 16,383 & 14,717 & 16,231 & 16,290 \\
\hline \multirow[t]{2}{*}{ Pre-Treatment Mean DV } & 0.355 & 0.244 & 0.106 & 1.002 & 0.047 & 0.191 \\
\hline & \multicolumn{6}{|c|}{ Panel II: Ages 18 to 25} \\
\hline RML & $\begin{array}{c}0.033^{* * *} \\
(0.011)\end{array}$ & $\begin{array}{c}0.045^{* * *} \\
(0.013)\end{array}$ & $\begin{array}{l}-0.001 \\
(0.012) \\
\end{array}$ & $\begin{array}{l}-0.039 \\
(0.183)\end{array}$ & $\begin{array}{c}0.007 \\
(0.011) \\
\end{array}$ & $\begin{array}{c}0.043^{* *} \\
(0.018)\end{array}$ \\
\hline$N$ & 53,716 & 53,661 & 33,970 & 29,607 & 32,030 & 32,153 \\
\hline \multirow{2}{*}{ Pre-Treatment Mean DV } & 0.363 & 0.256 & 0.115 & 1.160 & 0.052 & 0.224 \\
\hline & \multicolumn{6}{|c|}{ Panel III: Ages 26 and Older } \\
\hline \multirow[t]{2}{*}{ RML } & $0.018^{* * *}$ & $0.015^{* * *}$ & 0.002 & 0.031 & $0.009 * * *$ & $0.015^{* * *}$ \\
\hline & $(0.006)$ & $(0.005)$ & $(0.002)$ & $(0.047)$ & $(0.003)$ & $(0.004)$ \\
\hline$N$ & 103,088 & 103,010 & 67,519 & 53,807 & 55,427 & 55,601 \\
\hline Pre-Treatment Mean DV & 0.196 & 0.146 & 0.035 & 0.471 & 0.030 & 0.139 \\
\hline Years & $2013-2019$ & $2013-2019$ & 2014-2019 & $2015-2019$ & $2015-2019$ & $2015-2019$ \\
\hline \multicolumn{7}{|c|}{$\begin{array}{l}\text { ***Significant at } 1 \% \text { level } * * \text { Significant at } 5 \% \text { level } * \text { Significant at } 10 \% \text { level. } \\
\text { All estimates are weighted. All regressions include individual fixed effects, state fixed effects, year-by-month fixed effects, wave fixed effects, and medical marijuana } \\
\text { laws. Demographic controls include gender, age, educational attainment, race/ethnicity; economic controls include unemployment rate, state poverty rate, and log of } \\
\text { ACS mean total pre-tax personal income; smoking policy controls include index of indoor vaping restrictions, total e-cigarette taxes, any e-cigarette MLSA, total } \\
\text { cigarette taxes, index of indoor smoking restrictions, minimum age for cigarette sales; other policy controls include: state EITC refundable credit rate, log of minimum } \\
\text { wage, whether the governor is a Democrat, presence of an ACA Medicaid expansion, presence of a must access prescription drug monitoring program, and beer tax } \\
\text { per gallon. Standard errors, in parentheses, are clustered within } 156 \text { primary sampling units that are nested within states (except in one instance). }\end{array}$} \\
\hline
\end{tabular}


Appendix Table 7. Recreational Marijuana Laws and Tobacco Use, Additional Age Groups, PATH, 2013-2019

\begin{tabular}{|c|c|c|c|c|c|c|c|c|c|}
\hline & $\begin{array}{l}\text { Prior- } \\
\text { Year } \\
\text { Tobacco } \\
\text { Use }\end{array}$ & $\begin{array}{l}\text { Prior- } \\
\text { Month } \\
\text { Tobacco } \\
\text { Use }\end{array}$ & $\begin{array}{l}\text { Prior- } \\
\text { Month } \\
\text { Cigarette } \\
\text { Use }\end{array}$ & $\begin{array}{l}\text { Prior- } \\
\text { Month } \\
\text { Daily } \\
\text { Cigarette } \\
\text { Use }\end{array}$ & $\begin{array}{c}\text { Prior- } \\
\text { Month } \\
\text { Number } \\
\text { of } \\
\text { Cigarettes }\end{array}$ & $\begin{array}{l}\text { Prior- } \\
\text { Month } \\
\text { ENDS } \\
\text { Use }\end{array}$ & $\begin{array}{l}\text { Prior } \\
\text { Month } \\
\text { Daily } \\
\text { ENDS } \\
\text { Use } \\
\end{array}$ & $\begin{array}{c}\text { Prior- } \\
\text { Month } \\
\text { Cigar Use }\end{array}$ & $\begin{array}{c}\text { Prior Month } \\
\text { Combustible } \\
\text { Tobacco } \\
\text { Use }\end{array}$ \\
\hline & $(1)$ & (2) & (3) & (4) & $(5)$ & (6) & $(7)$ & (8) & (9) \\
\hline \multicolumn{10}{|c|}{ Panel I: Ages 18 to 20} \\
\hline RML & $\begin{array}{c}0.011 \\
(0.027)\end{array}$ & $\begin{array}{c}0.001 \\
(0.026)\end{array}$ & $\begin{array}{l}-0.017 \\
(0.019)\end{array}$ & $\begin{array}{c}0.011 \\
(0.010)\end{array}$ & $\begin{array}{c}8.821 \\
(6.699) \\
\end{array}$ & $\begin{array}{c}0.041 \\
(0.025)\end{array}$ & $\begin{array}{c}0.007 \\
(0.015)\end{array}$ & $\begin{array}{l}-0.024 \\
(0.033)\end{array}$ & $\begin{array}{l}-0.017 \\
(0.027)\end{array}$ \\
\hline$N$ & 24,818 & 24,821 & 24,819 & 24,821 & 24,783 & 24,802 & 24,821 & 24,811 & 24,821 \\
\hline Pre-Treatment Mean DV & 0.496 & 0.401 & 0.223 & 0.084 & 43.012 & 0.194 & 0.039 & 0.155 & 0.321 \\
\hline \multicolumn{10}{|c|}{ Panel II: Ages 18 to 25} \\
\hline RML & $\begin{array}{l}-0.020 \\
(0.019)\end{array}$ & $\begin{array}{l}-0.004 \\
(0.015)\end{array}$ & $\begin{array}{l}-0.006 \\
(0.012)\end{array}$ & $\begin{array}{c}0.002 \\
(0.007)\end{array}$ & $\begin{array}{l}-32.869 \\
(33.560)\end{array}$ & $\begin{array}{l}-0.007 \\
(0.014)\end{array}$ & $\begin{array}{l}-0.002 \\
(0.006)\end{array}$ & $\begin{array}{l}-0.011 \\
(0.012)\end{array}$ & $\begin{array}{l}-0.011 \\
(0.015)\end{array}$ \\
\hline$N$ & 53,749 & 53,754 & 53,746 & 53,754 & 53,648 & 53,706 & 53,754 & 53,737 & 53,754 \\
\hline Pre-Treatment Mean DV & 0.551 & 0.455 & 0.293 & 0.136 & 65.037 & 0.182 & 0.037 & 0.166 & 0.388 \\
\hline
\end{tabular}

\section{Panel III: Ages 26 and Older}

\begin{tabular}{|c|c|c|c|c|c|c|c|c|c|}
\hline RML & 0.000 & 0.004 & 0.007 & -0.000 & 15.005 & -0.005 & -0.001 & -0.002 & 0.003 \\
\hline & $(0.008)$ & $(0.007)$ & $(0.006)$ & $(0.004)$ & $(11.379)$ & $(0.004)$ & $(0.003)$ & $(0.005)$ & $(0.007)$ \\
\hline$N$ & 103,139 & 103,144 & 103,120 & 103,144 & 102,786 & 103,026 & 103,144 & 103,028 & 103,144 \\
\hline Pre-Treatment Mean DV & 0.568 & 0.517 & 0.421 & 0.312 & 174.184 & 0.109 & 0.031 & 0.111 & 0.465 \\
\hline
\end{tabular}

*** Significant at $1 \%$ level **Significant at $5 \%$ level * Significant at $10 \%$ level.

All estimates are weighted. All regressions include individual fixed effects, state fixed effects, year-by-month fixed effects, wave fixed effects, and medical marijuana laws. Demographic controls include gender, age, educational attainment, race/ethnicity; economic controls include unemployment rate, state poverty rate, and log of ACS mean total pre-tax personal income; smoking policy controls include index of indoor vaping restrictions, total e-cigarette taxes, any e-cigarette MLSA, total cigarette taxes, index of indoor smoking restrictions, minimum age for cigarette sales; other policy controls include: state EITC refundable credit rate, log of minimum wage, whether the governor is a Democrat, presence of an ACA Medicaid expansion, presence of a must access prescription drug monitoring program, and beer tax per gallon. Standard errors, in parentheses, are clustered within 156 primary sampling units that are nested within states (except in one instance). Data are drawn from the 2013-2019 PATH. 